\title{
Article \\ Sonic Artefacts of Teotihuacan, Mexico (Horns, Trumpets and Pipes)
}

\author{
Arnd Adje Both
}

check for updates

Citation: Both, A.A. Sonic Artefacts of Teotihuacan, Mexico (Horns, Trumpets and Pipes). Acoustics 2021, 3,507-544. https://doi.org/ $10.3390 /$ acoustics 3030034

Academic Editor: Francesco Aletta

Received: 16 June 2021

Accepted: 14 July 2021

Published: 3 August 2021

Publisher's Note: MDPI stays neutral with regard to jurisdictional claims in published maps and institutional affiliations.

Copyright: (C) 2021 by the author. Licensee MDPI, Basel, Switzerland. This article is an open access article distributed under the terms and conditions of the Creative Commons Attribution (CC BY) license (https:// creativecommons.org/licenses/by/ $4.0 /)$.
School of Arts and Humanities, University of Huddersfield, Queensgate, Huddersfield HD1 3DH, UK; A.Both@hud.ac.uk

\begin{abstract}
This paper presents the acoustic study of a sample of sonic artefacts, in particular a selection of wind instruments (horns, trumpets and pipes), from the UNESCO World Heritage Centre of Teotihuacan, Mexico, based on a thorough examination of the accessible and playable archaeological finds and the construction and subsequent test of a series of experimental models. Combined with the archaeological and iconographical information, the study helps to deduce information with regard to the urban settings in which these instruments might have been used. It also reveals some basic acoustic components of the music once performed in Teotihuacan.
\end{abstract}

Keywords: Teotihuacan; musical instruments; sonic artefacts; aerophones; horns; trumpets; flutes; organology; acoustics; pre-Columbian; Mesoamerica

\section{Introduction}

The UNESCO World Heritage Centre of Teotihuacan, which is situated in the Central Mexican Highlands at an altitude of 2280 masl, was a civic-religious centre established in the Late Preclassic period (around $150 \mathrm{BCE}$ ) and represents one of the most powerful cultures during the Classic period of Mesoamerica (between 200-650 CE), maintaining relations with the sites of contemporary cultures of Oaxaca, the Gulf Coast and the Maya area, among others. This is also reflected in the array of sonic artefacts employed at the site, suggesting mutual cultural interactions in terms of the organological development throughout time. With reference to the aerophones, some instruments were certainly imported (such as shell horns that are obtained from both the Pacific and the Atlantic coasts). Other aerophones show particular forms only found in Teotihuacan and are not comparable to other cultures, some of which were also exported (such as quadruple flutes and whistling vessel types [1,2]). Other instruments, particularly a range of idiophones, were already widely employed in the Middle Preclassic period and are subsequently known in all later cultures, including Teotihuacan. Among such finds are ceramic rattles and clappers, gourd rattles, conch rattles, bone and deer antler rasps or turtle shell clappers, which will be discussed in a forthcoming paper [3]. Membranophones, such as wooden or ceramic drums, are absent in the archaeological record or finds have not been correctly identified yet. Similar to a series of aerophones and most of the idiophones (with the exception of gourd rattles), there is little iconographic evidence of Teotihuacan drums. All artefacts discussed here could have been used in the context of musical performances and, therefore, are considered musical instruments, although some of them may primarily have been used for signaling. As the detailed context of sound production in Teotihuacan and the musical concepts developed in the Central Mexican Highlands during the Classic period are unknown, the instruments are generally described as sound producing instruments and the archaeological finds as sonic artefacts.

Although the site has been the subject of intense research since the first archaeological investigations carried out in the end of the 19th century, the sonic artefacts of Teotihuacan have been the subject of only a very small selection of dedicated studies to date [4-7]. This stands in contrast to the importance of the city during the Classic period of Mesoamerica 
and the higher level of music-archaeological research on other contemporary cultures situated in Oaxaca and the Maya area. The present study is the result of an ongoing research project on the sonic environment of Teotihuacan in which the sound producing instruments of the site are studied within the acoustic ecology of the city. ${ }^{1}$ One part of the project consists of a survey of the archaeological finds preserved in various institutions ${ }^{2}$ in terms of their organology (the morphology and size of the acoustically relevant parts) and inherent acoustic parameters, if the condition of the original objects allows for experimental playing.

As the full array of instruments reported for Teotihuacan is not preserved and not all finds could be tested because of their fragmented or fragile condition, another part of the project consists of the reconstruction of an array of Teotihuacan instruments in the form of experimental models. The models are produced accurately according to the morphology and the general measurements of the archaeological finds documented for the project. In the production of a series of models per instrument type carried out by the author and instrument maker Osvaldo Padrón, we aimed to better understand the organology involved in the construction of each instrument type, particularly in relation to the manner sound is generated and the question of which particular sonic characteristics are produced with the application of different playing techniques. This experimental process was very fruitful since a large amount of specific data was compiled regarding the construction, sonic function and acoustic properties of the documented artefacts. In addition, other factors, such as Teotihuacan music iconography and the archaeological contexts of the finds, if known, are being revised to support the interpretation of the playing postures and cultural contexts in which the instruments were sounded. By taking all available information into account, the playing techniques and acoustic possibilities can be narrowed down.

As we are examining the remains of instrumental sound production of a past culture, only certain sonic parameters can be reconstructed and analyzed. A number of instruments known from iconography, such as the different types of gourd rattles, were made from perishable natural materials and did not survive and most of the sonic artefacts are in a fragmented state. Furthermore, iconographic evidence showing playing postures and performance contexts only covers a selection of the instruments employed in the city and textual evidence is absent. However, the experimental playing of the sonic artefacts and the reconstructions carried out for the project allows for better analysis of the particular Teotihuacan acoustic ecologies. One still observable parameter is frequency range, defined by the lowest and highest frequencies of the fundamental notes (for the Teotihuacan wind instruments generated with different blowing pressure levels), which is provided in $\mathrm{Hz}$ for the physical property, and translated into pitches (precisely, musical notes with cents deviations) for the perceptual property [8]. ${ }^{3}$ Further observable factors include the sound pressure levels (SPL, provided in $\mathrm{dBA}$ ) and the spectral contents including frequency components, such as the individual harmonics and other factors contributing to the particular timbre of the discussed instruments (visualized by sound spectra and spectrograms) [9-13]. ${ }^{4}$

The acoustic data codifies the principal parameters of which the music of Teotihuacan was composed. Other factors, such as the melodic or rhythmic structures, can only be studied in exceptional cases where the body of the instrument permits limited playing techniques with a reduced tonal range (instruments belonging to this group are the duct flutes without fingerholes, such as the piston whistles, and vessel flutes without fingerholes, such as the whistling vessels). Most other documented instruments can be sounded according to a range of different playing possibilities, especially the duct flutes equipped with fingerholes. Any music played on these instruments must be considered contemporary and interpretative, particularly when subjected to simultaneous playing (although such playing can still provide an idea of the musical possibilities inherent in the sonic artefacts). In turn, the obtained set of acoustic data provides quantifiable and measurable information related to the music once performed in Teotihuacan.

A third part of the project consists of testing a sample of the reconstructions and experimental models at the archaeological site, within its partly preserved and reconstructed 
architectural setting. This research corresponds to the sound mapping approach of the project and has not been completed yet. It will help verify which type of sound producing instrument could have been played and heard in which parts of the city. The analyzed power levels of the instruments discussed here are contributing factors towards this step. Then, also the sound pressure levels, the architectural acoustics and the natural soundscape will be taken into account.

\section{Materials and Methods}

In the following a selection of the wind instruments employed in Teotihuacan is reviewed, especially in terms of their organology and acoustics. The two largest groups of Teotihuacan aerophones are the lip reed instruments, which consist of four instrument types (shell horns; ceramic horns; ceramic trumpets; bone trumpets), and the duct flutes, which consist of two types (tubular flutes or pipes; globular/ovoid flutes or vessel flutes). The vessel flutes, which represent a diverse group with various subtypes, will be discussed in a complementary paper [14]. The obtained data are useful for comparison and provides the basis for further interpretations, particularly with regard to the employment of the sound producing instruments within the urban environment of the site. This might help to understand the sonic interactions of the people that once inhabited Teotihuacan.

For the present study, conventional archaeo-organological approaches in the description and analysis of sound artefacts are applied. Experimental music-archaeological approaches are applied in playing the sound artefacts or, if their condition did not allow for sounding, in their accurate reconstruction according to the documented organological data [15].

\subsection{Lip Reed Instruments}

For Teotihuacan, four types of lip reed instruments are documented: shell horns made from marine mollusks (composed of several subtypes according to species), ceramic horns simulating the form of shell horns (or skeuomorphs), ceramic trumpets and bone trumpets made from human femur simulating the form of ceramic trumpets [16]. ${ }^{5}$ The question of whether one of the types (shell horns) was also converted in a single reed instrument is under examination (see below). For the present study, the acoustic characteristics of the Teotihuacan shell horns, ceramic horns and ceramic trumpets has been analyzed.

\subsubsection{Shell Horns}

Documented archaeological contexts of Teotihuacan marine shell horns are located at predominant places, such as burials of high-ranking persons in the Pyramid of the Moon or elaborate offerings with 20 or more instruments such as in the tunnel beneath the Temple of the Feathered Serpent $[4,17] .{ }^{6}$ The horns from these contexts are all made from Triplofusus gigantea shells obtained from the coasts of the Caribbean Sea, some of which show engravings related to iconographic conventions of the Maya area and Oaxaca. At least three horns without documented archaeological contexts are made from Triplofusus princeps obtained from the Pacific coast, which are stuccoed and painted according to Teotihuacan iconography (Figure 1). ${ }^{7}$ Single finds are made from Caribbean species other than Triplofusus gigantea, such as one Turbinella angulata specimen from the central burial of the Temple of the Feathered Serpent $[18,19]^{8}$ and two horns made from Aliger gigas (one excavated by Linné in Tlamimilolpan, Figure 2) and the other from an offering of the Temple of the Feathered Serpent) [20]. ${ }^{9}$ The latter two finds are produced from young gastropods and are, therefore, quite small $(6.0 \mathrm{~cm}$ and $10.1 \mathrm{~cm}$ in length, respectively), although they can still be sounded. All other finds are made from full-grown gastropods ranging, in terms of length, between 35.0 and $45.0 \mathrm{~cm}$ for the Triplofusus gigantea and Triplofusus princeps horns. The mouth holes, which are produced by the removal of the apex and knocking off the remaining tip of the columella, resemble the form of a cup-shaped mouthpiece with irregular borders, presenting $2.5-2.7 \mathrm{~cm}$ of outer diameter at the rim, $1.8-2.0 \mathrm{~cm}$ of cup diameter and a depth of $1.7-1.9 \mathrm{~cm}$. For the small horns made from Aliger 
gigas, the cup diameter and the depth are smaller $(1.1-1.3 \mathrm{~cm}$ for the cup diameter and $1.2 \mathrm{~cm}$ for the depth). Due to the natural form of the shell, the throat is more oval than circular and its position is not located in the very centre of the cup.

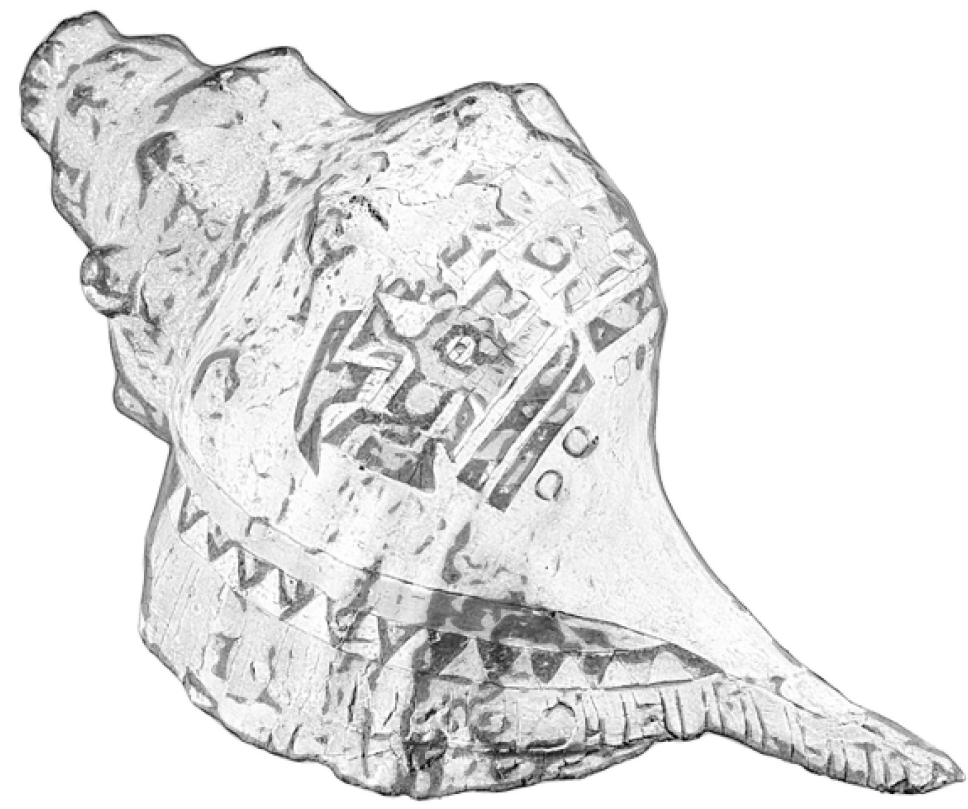

Figure 1. Stuccoed and painted shell horn made from Triplofusus princeps, Teotihuacan (MNA, Inv. 10-223548); length: $35.8 \mathrm{~cm}$. All drawings of the sonic artefacts are created by the author and based on the photographic documentation made for the project.

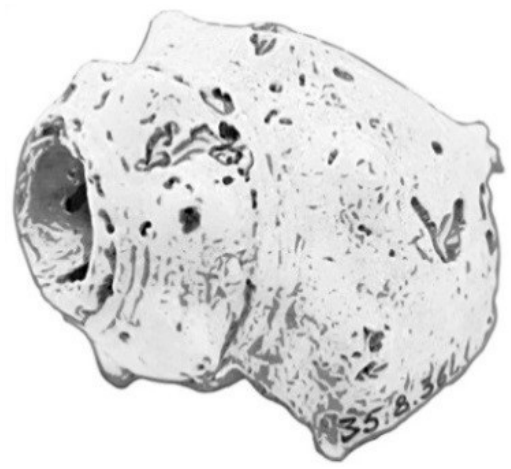

Figure 2. Shell horn made from Aliger gigas, Teotihuacan (EmS, Inv. 35.08.0361); length: $6.1 \mathrm{~cm}$.

A particularity of the Teotihuacan shell horns is the adornment of a feather decoration in the form of a headdress with plumes of the quetzal bird (species of the genus Pharomachrus and Euptilotis) and the employment of mouthpieces, as shown in a series of mural depictions and reliefs [4] (pp. 183-187, Figures 1-10) [21] (pp. 262-263, 272-273, Figures 5-9). For the tassel headdress of the instruments, it may be the case that this iconographic element possessed mere symbolic function without reflection in the physical world, with the exception of being painted on the body of the shell in the stuccoed specimens. ${ }^{10}$ With regard to the nature of the mouthpieces, for a long period of time, only suggestions could have been made as to their nature [4] (p. 187), [21] (p. 262). Recently, a single archaeological find of a shell horn with an associated ceramic mouthpiece has been documented among the tunnel finds beneath the Temple of the Feathered Serpent [17] (p. 248). Currently, unpublished comparable finds from the TMP and several specimen excavated by Linné might also represent shell horn mouthpieces (Figure 3). ${ }^{11}$ However, the possibility that mouthpieces made in the shape of the mouthpieces of the ceramic trumpets have been 
employed (see below) cannot be excluded. It is possible that the mouthpieces were usually removed before the instruments were deposited.

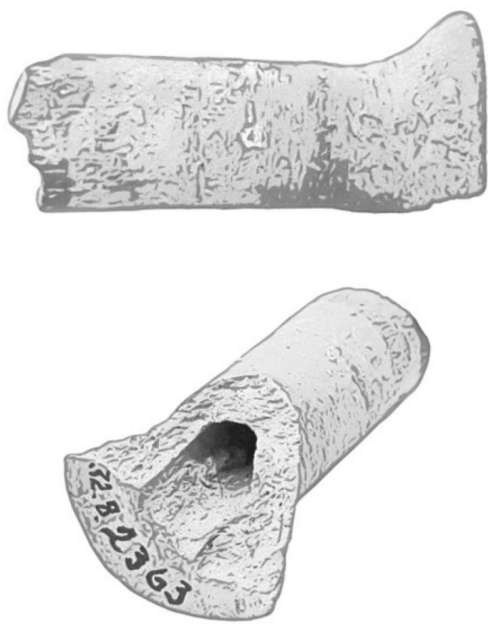

(a)

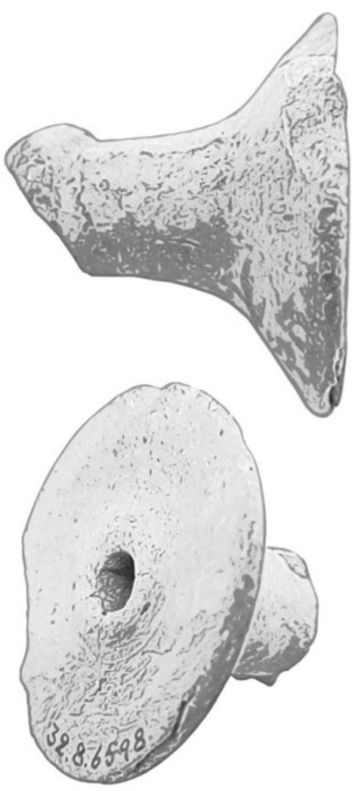

(b)

Figure 3. Possible discoidal shell horn mouthpieces from ceramics excavated by Sigvald Linné in Teotihuacan: (a) EmS (Inv. 32.08.2363), fragment, possibly Mayan, length: $4.4 \mathrm{~cm}$; (b) EmS (Inv. 32.08.6598), fragment, length: $3.6 \mathrm{~cm}$.

The basic parameters influencing the acoustics of the instruments are the size and the structure of the double helicoid chamber of the shells, which differs considerably from one species to another and therefore results in different standing waves with some frequencies accentuated and others that are not [21] (pp. 267, 277, Figures 18-21) [22] (pp. 155-161). From the organological point of view, the Teotihacan shell horns can therefore be grouped according to at least three subtypes (Triplofusus gigantea and Triplofusus princeps; Turbinella angulata; Aliger gigas). In general terms, the greater the size of the instruments, the larger the resonators, the lower the generated frequencies and the greater the sound pressure levels. The question of the employment of mouthpieces is interesting in terms of the enhancement of the playing techniques, particularly allowing for a better attack, as less physical strength is needed and the lip-vibration can be controlled better. This also has an effect on the sound produced.

One of the above mentioned stuccoed sonic artefacts made from Triplofusus princeps (Figure 1) has been recorded for the project. The instrument measures $35.8 \mathrm{~cm}$ in length, $20.4 \mathrm{~cm}$ in width and $15.8 \mathrm{~cm}$ in height. Due to the irregular shaped and partly porous rim and the remaining part of the columella, which has not been fully removed, it appeared to sound the horn with difficulty until a comfortable playing position was found. The fundamental frequencies obtained are spread over a very narrow range between 263 and $265 \mathrm{~Hz}$ (equivalent to $\mathrm{C}_{4}{ }^{+9 /+22}$ ) and it was impossible to overblow the instrument. The spectrogram and corresponding spectrum show a dominant fundamental with five very strong lower harmonics and a series of less strong upper harmonics that slowly decrease in amplitude as the order of harmonics increases; this contributes to the particular drone sound of the instrument, which is not as bright in comparison to the other horns described below (Figure 4, Table 1 and Sample S1). 


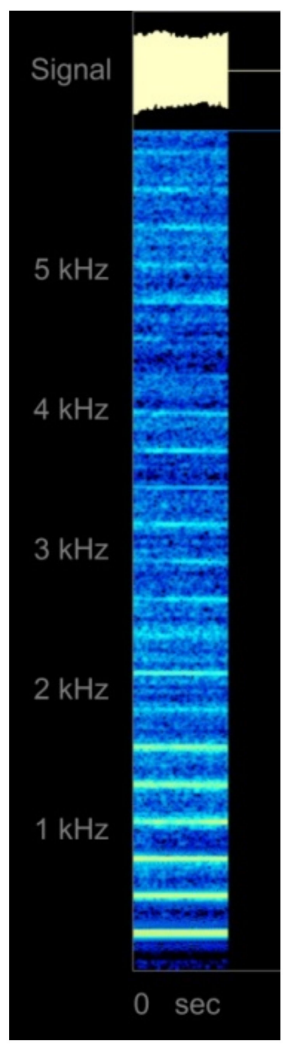

(a)

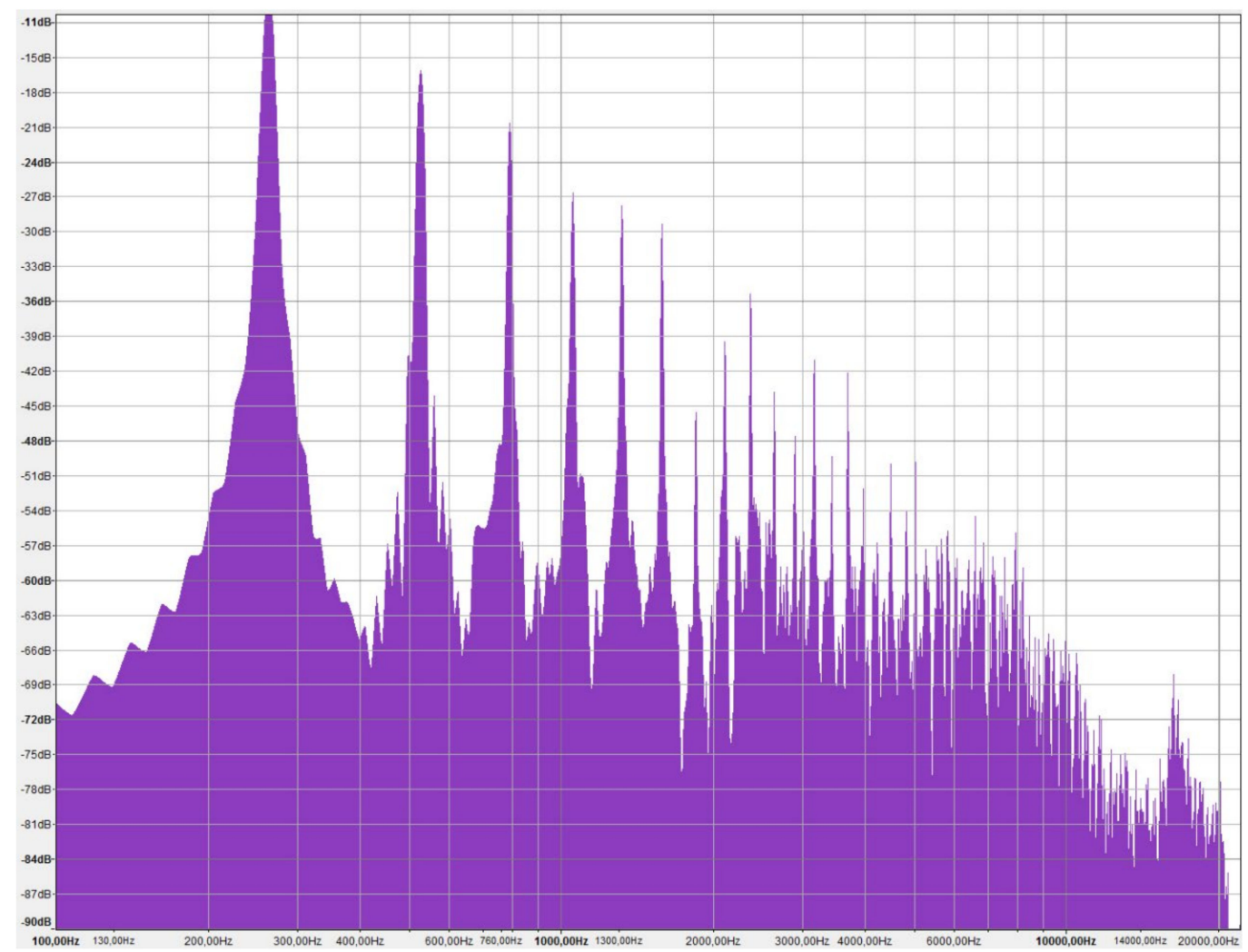

(b)

Figure 4. Spectral components of the stuccoed shell horn made from Triplofusus princeps, Teotihuacan (MNA, Inv. 10-223548), low blowing pressure: (a) spectrogram; (b) spectrum (Sample S1).

Table 1. Acoustic data sheet of the analyzed shell horns.

\begin{tabular}{|c|c|c|c|c|}
\hline $\begin{array}{l}\text { Sound Producing } \\
\text { Instrument }\end{array}$ & Playing Technique & $\begin{array}{c}\text { Frequency Rates } \\
\text { (Fundamental Tones) }\end{array}$ & Tonal Deviation & $\begin{array}{l}\text { Sound Pressure } \\
\text { Level at } 1 \mathrm{~m} \\
\text { (Max. Values) }\end{array}$ \\
\hline \multirow{2}{*}{$\begin{array}{c}\text { Shell horn, large } \\
\text { Triplofusus princeps (MNA, } \\
\text { Inv. } 10-223548,35.8 \mathrm{~cm})\end{array}$} & $\begin{array}{l}\text { lip-vibration, low } \\
\text { blowing pressure }\end{array}$ & $263-265 \mathrm{~Hz}$ & $\mathrm{C}_{4}+9 /+22$ & \multirow[b]{2}{*}{ Not measured } \\
\hline & $\begin{array}{l}\text { lip-vibration, low } \\
\text { blowing pressure, } \\
\text { hand-insertion technique }\end{array}$ & Not measured & & \\
\hline \multirow{5}{*}{$\begin{array}{l}\text { Shell horn, large Triplofusus } \\
\text { princeps (experimental } \\
\text { model, } 35.5 \mathrm{~cm} \text { ) }\end{array}$} & $\begin{array}{l}\text { lip-vibration, low } \\
\text { blowing pressure }\end{array}$ & $324-327 \mathrm{~Hz}$ & $\mathrm{E}_{4}^{-30 /-14}$ & 108.6-111.5 dBA \\
\hline & $\begin{array}{l}\text { lip-vibration, low } \\
\text { blowing pressure, } \\
\text { hand-insertion technique }\end{array}$ & $265-270 \mathrm{~Hz}$ & $\mathrm{C}_{4}{ }^{+22}$ to $\mathrm{C \#}_{4}^{-45}$ & 95.6-97.8 dBA \\
\hline & $\begin{array}{l}\text { Flat mouthpiece, } \\
\text { lip-vibration, overblown } \\
\text { (one regime) }\end{array}$ & $1057 \mathrm{~Hz}$ & $\mathrm{C}_{6}+17$ & $109.6-110.3 \mathrm{dBA}$ \\
\hline & $\begin{array}{l}\text { Ceramic cup-shaped } \\
\text { mouthpiece, } \\
\text { lip-vibration, low } \\
\text { blowing pressure }\end{array}$ & $324-329 \mathrm{~Hz}$ & $\mathrm{E}_{4}-30 /-3$ & 106.5-108.8 dBA \\
\hline & $\begin{array}{l}\text { Ceramic cup-shaped } \\
\text { mouthpiece, } \\
\text { lip-vibration, overblown } \\
\text { (six regimes) }\end{array}$ & $\begin{array}{l}539 \mathrm{~Hz} ; 587 \mathrm{~Hz} ; 635 \mathrm{~Hz} ; \\
698 \mathrm{~Hz} ; 741 \mathrm{~Hz} ; 789 \mathrm{~Hz}\end{array}$ & $\begin{array}{l}\mathrm{C \#}_{5}^{-49} \text { (lowest); } \\
\mathrm{G}_{5}{ }^{+11} \text { (highest) }\end{array}$ & 103.1-106.5 dBA \\
\hline
\end{tabular}


Table 1. Cont.

\begin{tabular}{|c|c|c|c|c|}
\hline $\begin{array}{l}\text { Sound Producing } \\
\text { Instrument }\end{array}$ & Playing Technique & $\begin{array}{c}\text { Frequency Rates } \\
\text { (Fundamental Tones) }\end{array}$ & Tonal Deviation & $\begin{array}{l}\text { Sound Pressure } \\
\text { Level at } 1 \mathrm{~m} \\
\text { (Max. Values) }\end{array}$ \\
\hline \multirow{2}{*}{$\begin{array}{l}\text { Shell horn, small } \\
\text { Aliger gigas (experimental } \\
\text { model, } 9.5 \mathrm{~cm})\end{array}$} & $\begin{array}{l}\text { lip-vibration, low } \\
\text { blowing pressure }\end{array}$ & $598-615 \mathrm{~Hz}$ & $\mathrm{D}_{5}{ }^{+31}$ to $\mathrm{D \#}_{5}{ }^{-20}$ & 98.5-101.1 dBA \\
\hline & $\begin{array}{l}\text { lip-vibration, low } \\
\text { blowing pressure, } \\
\text { hand-insertion technique }\end{array}$ & $505-522 \mathrm{~Hz}$ & $\mathrm{~B}_{4}{ }^{+39}$ to $\mathrm{C}_{5}{ }^{-4}$ & 95.5-97.2 dBA \\
\hline
\end{tabular}

Further experiments were carried out with a horn made from a contemporary Triplofusus princeps specimen, with and without the employment of different ceramic mouthpieces (Figure 5). The model measures $35.5 \mathrm{~cm}$ in length, $17.5 \mathrm{~cm}$ in width and $15.0 \mathrm{~cm}$ in height and is, thus, slightly smaller than the above described sound artefact. The opening of the shell forming the mouth hole was produced with a cup diameter of $1.8-2.2 \mathrm{~cm}$ and a depth of $1.9 \mathrm{~cm}$. The fundamental frequencies obtained are between $324-327 \mathrm{~Hz}$ (equivalent to $\mathrm{E}_{4}{ }^{-30 /-14}$ ) and, as expected, are higher than the frequencies of the sonic artefact previously described. In comparison, only three strong lower harmonics of the harmonic series are present and the upper harmonics are less strong (Figure 6, Table 1 and Sample S2). This suggests an increasing number of strong harmonics concomitant with the increasing size of the shells.

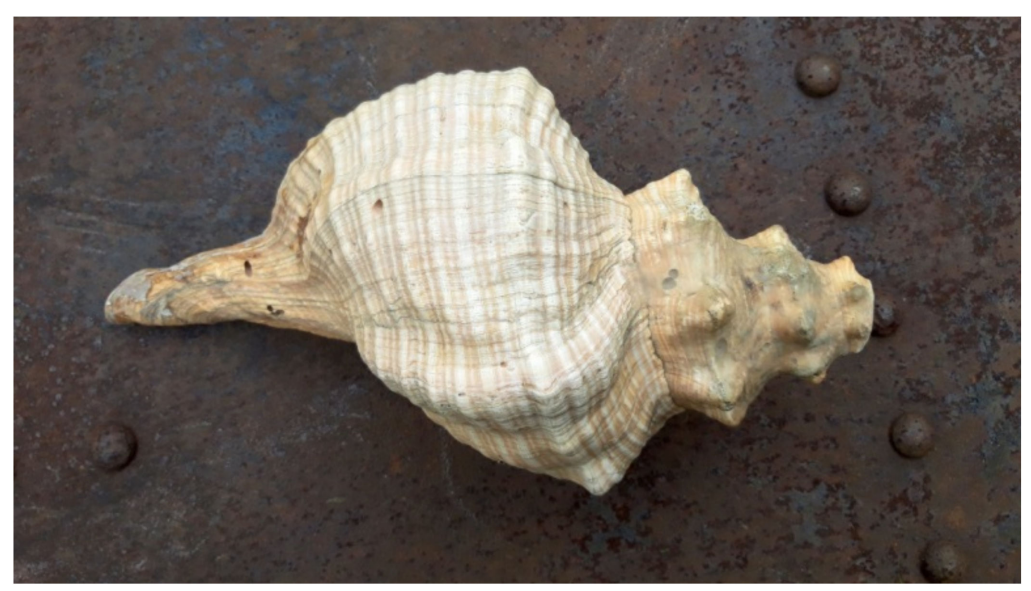

Figure 5. Shell horn made from Triplofusus princeps. Experimental model by the author (2021), length: $35.5 \mathrm{~cm}$.

The experimental model was used for further acoustic tests. By inserting the hand into the bell, much lower frequencies between 265 and $270 \mathrm{~Hz}$ (equivalent to $\mathrm{C}_{4}{ }^{+22}$ to $\mathrm{C}_{4}{ }^{-45}$ ) are obtained. Thus, by gradually opening the bell, virtually all frequencies between 265 and $327 \mathrm{~Hz}$ can be produced (in terms of the tonal range, located within four semitones). It is possible but not clear, however, whether this technique had been employed. The maximum sound pressure level measured of the instrument is $111.5 \mathrm{dBA}$ at $1 \mathrm{~m}$. Depending on the weather conditions, the sound of the shell horns is, therefore, loud enough to propagate at least 1.0-2.0 km (according to [13]; for field experiments in Peru providing tested grounding, see [23]). When inserting the hand into the bell and reducing the size of the opening, not only lower frequencies were achieved. With 95.6-97.8 dBA at $1 \mathrm{~m}$, the level of sound is also reduced, indicating that such techniques are only appropriate for communication within a smaller radius (0.5-0.7 km, according to [13]). 


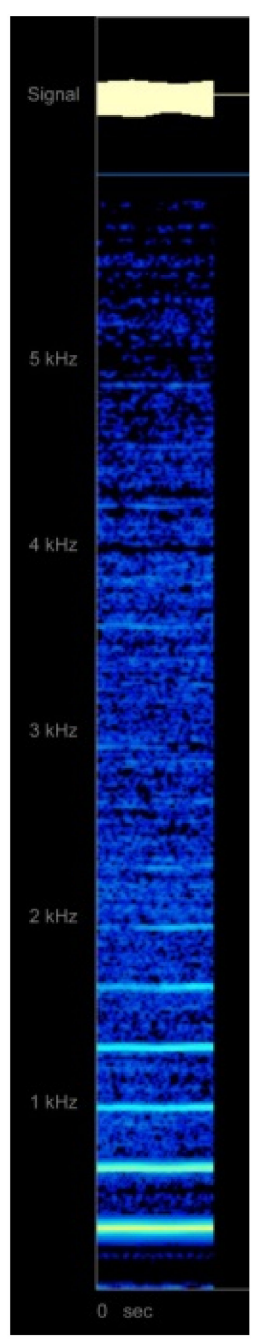

(a)

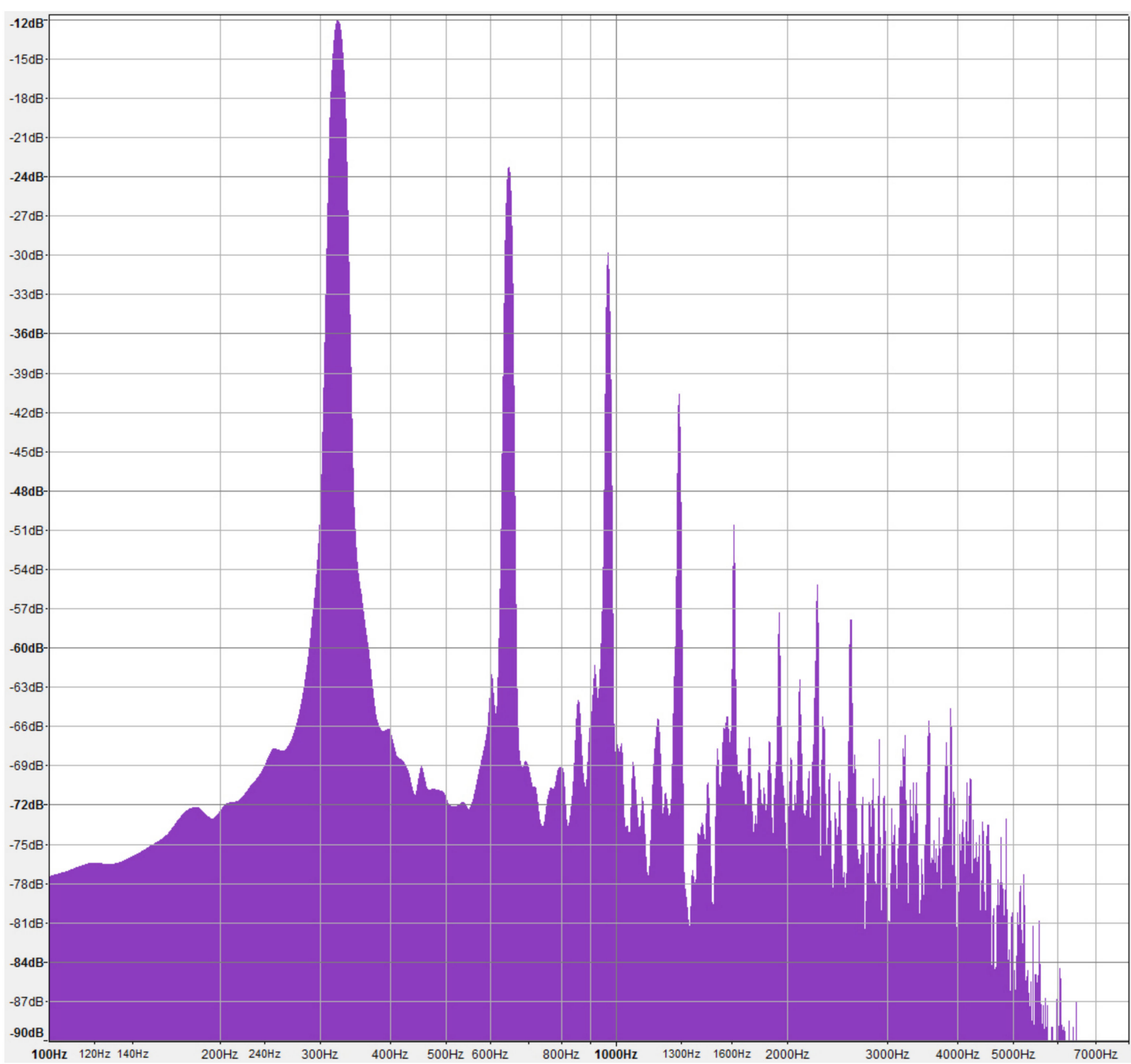

(b)

Figure 6. Spectral components of shell horn made from Triplofusus princeps. Experimental model, low blowing pressure: (a) spectrogram; (b) spectrum (Sample S2).

One of the ceramic discoidal mouthpiece models employed for acoustic tests was produced according to the characteristic form and the dimensions of the abovementioned ceramic shell horn mouthpieces excavated by Linné (Figure 7). The piece is characterized by a disc with a circular perforation of $4.3 \mathrm{~cm}$ in diameter, joined with a tube of $5.5 \mathrm{~cm}$ in length $(6.4 \mathrm{~cm}$ with beeswax used to ensure an airtight seal), an outer diameter of $4.5 \mathrm{~cm}$ and a backbore of $0.7 \mathrm{~cm}$ in diameter. As foreseen, such mouthpiece hardly allows the horn to be played as a lip reed instrument as the player cannot fully set their vibrating lips. In this case, it was only possible to produce short blasts with high pressure and the horn overblows $(1057 \mathrm{~Hz})$, but it is still very potent in terms of sound pressure level (109.6-110.3 dbA). Ongoing research includes the verification of the hypothesis that a single reed was inserted into the mouthpiece and the horns thus converted into reed wind instruments [24]. As the use of this particular mouthpiece form has not been further explored yet, extended acoustic tests and analyses are still outstanding. 


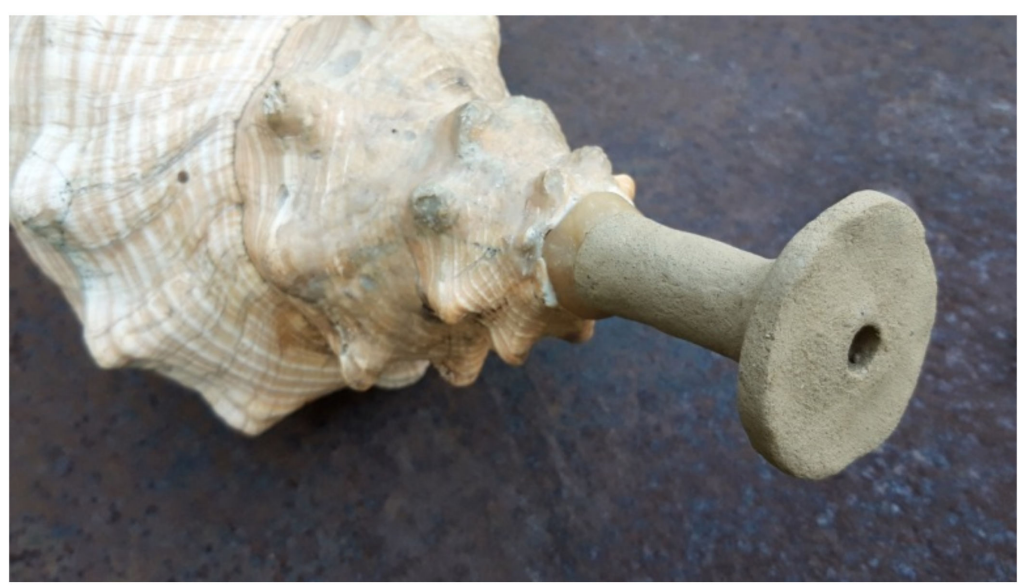

Figure 7. Shell horn made from Triplofusus princeps. Experimental model with ceramic discoidal mouthpiece created by the author (2021).

Alternatively, a ceramic cup-shaped mouthpiece conventionally used for the ceramic trumpets was employed (Figure 8). The piece was taken from a broken experimental model that was produced close to the original finds (see below). It measures $5.9 \mathrm{~cm}$ in length ( $6.8 \mathrm{~cm}$ with beeswax used to ensure an airtight seal). The part of the tube that is converted into the shank of the mouthpiece presents an outer diameter of $1.8 \mathrm{~cm}$ with a backbore of $1.2 \mathrm{~cm}$ in diameter. The mouthpiece shows an outer diameter of $1.4 \mathrm{~cm}$ at the rim, $1.1 \mathrm{~cm}$ for the diameter of the cup and a throat of $0.6 \mathrm{~cm}$ in diameter. Apart from the enhanced possibilities for the trumpeter, the reduced diameter and depth of the cup, the throat and the cylindrical backbore of the mouthpiece are the organological parameters resulting in a very different acoustic characteristics of the horns. The fundamental frequencies obtained, however, are between 324 and $329 \mathrm{~Hz}$ (equivalent to $\mathrm{E}_{4}{ }^{-30 /-3}$ ) and, therefore, virtually identical to when the horn is played without the mouthpiece. The major difference is that only the second harmonics are very strong and the third harmonics are weak, while the upper harmonics are stronger, especially above the frequency range of $2.0 \mathrm{kHz}$ (Figure 9, Table 1 and Sample S3). The mouthpiece also adds a range of harmonics to either side of the fundamental, creating a subtle effect that is also visualized in the spectra of the Teotihuacan ceramic horn and ceramic trumpets that are described further below. It thus adds harmonic and timbral content to the horn, rendering its sound richer [25]. ${ }^{12}$ With 106.5-108.8 dBA at $1 \mathrm{~m}$, the maximum sound pressure level is slightly reduced but still remains very high.

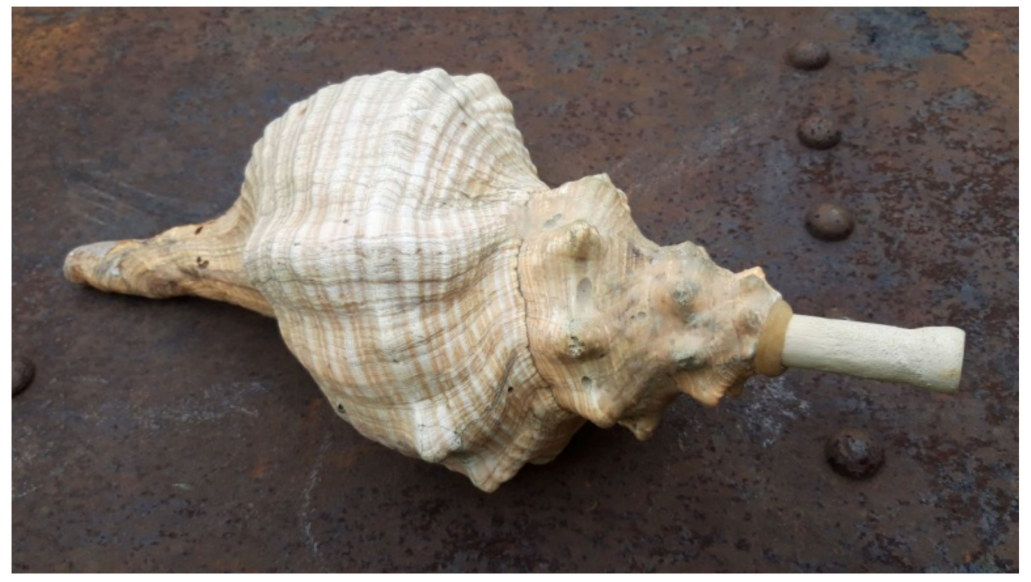

Figure 8. Shell horn made from Triplofusus princeps. Experimental model equipped with a ceramic cup-shaped mouthpiece. 


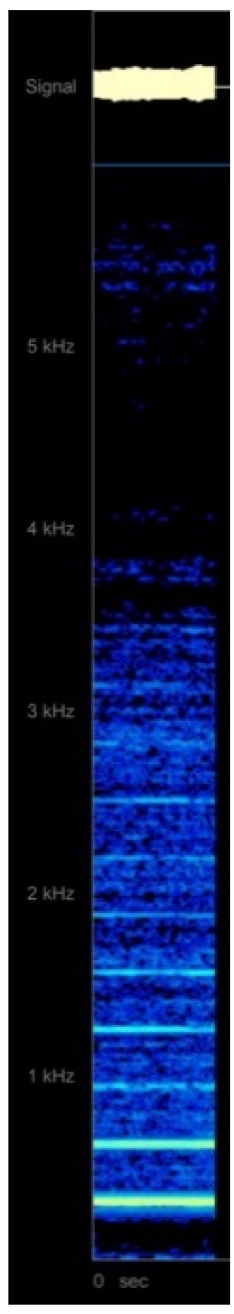

(a)

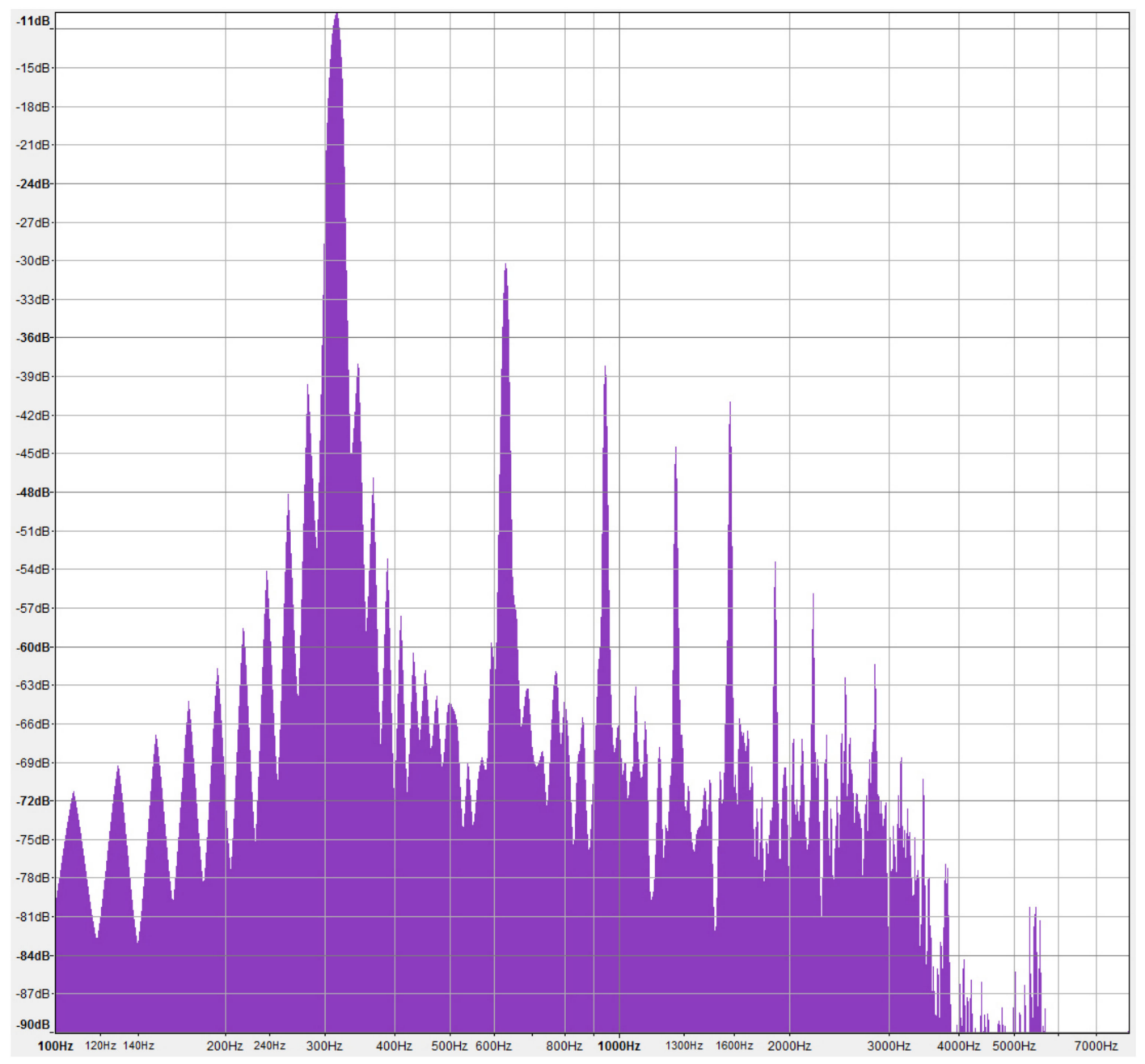

(b)

Figure 9. Spectral components of shell horn made from Triplofusus princeps. Experimental model with ceramic mouthpiece and low blowing pressure: (a) spectrogram; (b) spectrum (Sample S3).

Furthermore, the employment of cup-shaped mouthpieces increases the possibility that the horns can be overblown. The highest frequency thus obtained on the model is $789 \mathrm{~Hz}$ (equivalent to $\mathrm{G}_{5}{ }^{+11}$ ) and, therefore, was located more than an octave higher than the fundamental. As can be observed in the spectrogram and the corresponding spectrum the first three lower harmonics are much stronger than the other harmonics, which contributes to a brighter sound (Figure 10, Table 1 and Sample S4).

In order to test the acoustics of the small horns produced from young Aliger gigas shells, an experimental model has been made (Figure 11), revealing that the finds actually represent sonic artefacts and not diminutive objects. The model measures $9.5 \mathrm{~cm}$ in length and is, thus, only slightly smaller in terms of size compared to the find from the Temple of the Feathered Serpent mentioned above, while the mouth hole has been produced with identical dimensions (1.1-1.3 cm, for the cup diameter). The instrument produces a very clear and loud sound that is located in a frequency range between 598 and $615 \mathrm{~Hz}$ (corresponding to $\mathrm{D}_{5}{ }^{+31}$ to $\mathrm{DH}_{5}{ }^{-20}$ ) and becomes considerably lower with the application of hand-insertion techniques (505-522 Hz, corresponding to $\mathrm{B}_{4}{ }^{+39}$ to $\mathrm{C}_{5}{ }^{-4}$ ). As for the larger shell horn specimens, the tonal range of four semitones is covered. In contrast to the aforementioned large Triplofusus princeps horns, the first three lower harmonics are closer to the fundamental in terms of the amplitude and each harmonic is clearly present, including a greater amount of strong upper harmonics (Figure 12, Table 1, Sample S5). This condition 
contributes to a brighter and richer sound of the instrument. For the maximum sound pressure levels, $101.1 \mathrm{dBA}$ at $1 \mathrm{~m}$ has been measured (97.2 dBA at $1 \mathrm{~m}$ with the application of hand-insertion techniques). Although the horn is considerably smaller in size than the large gastropods, its sound level is still very high and the instrument is quite powerful, especially when the bell is not partially stopped.

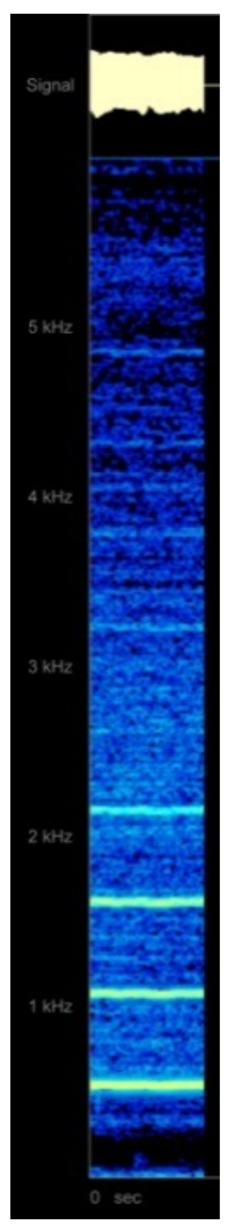

(a)

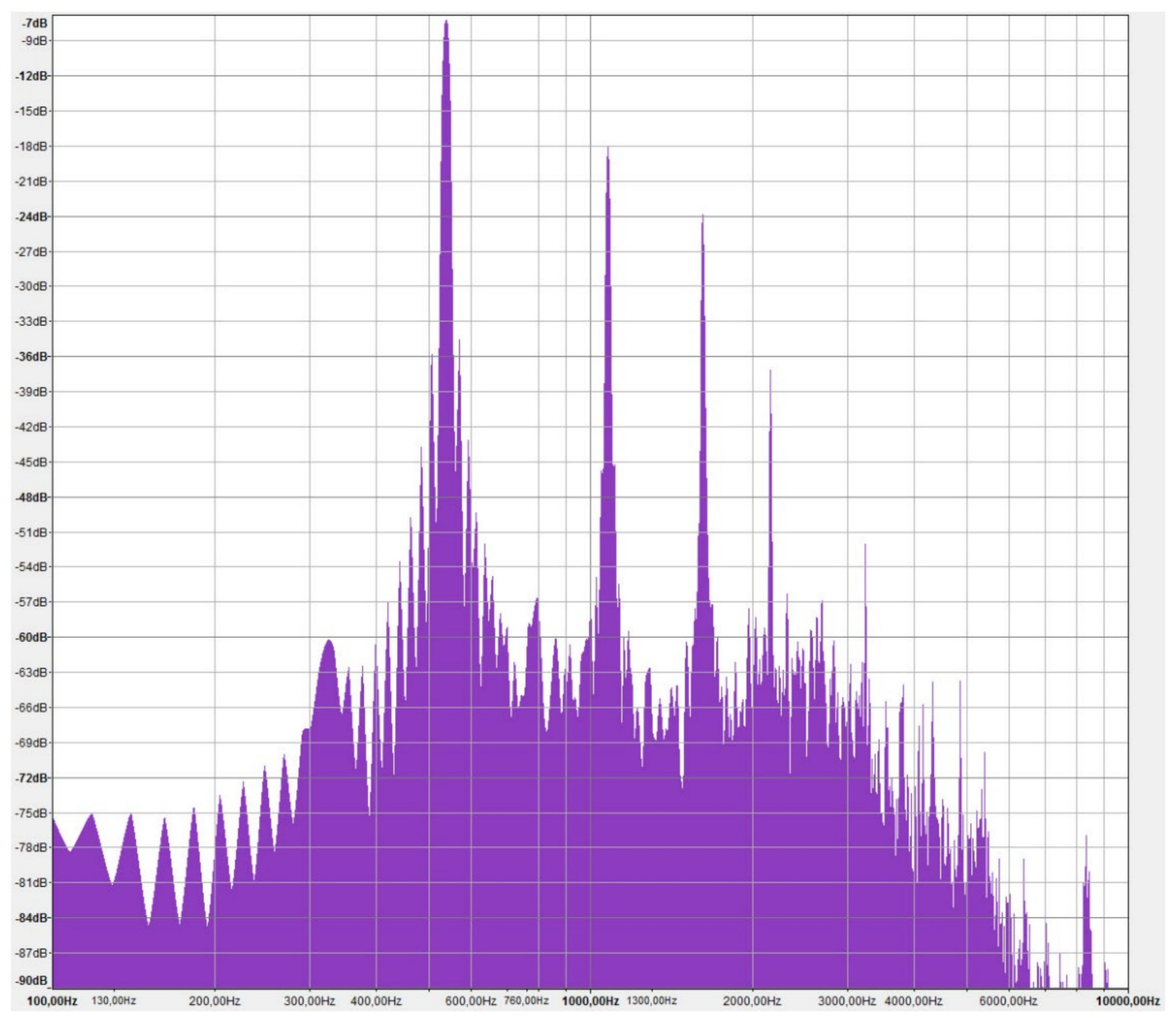

(b)

Figure 10. Spectral components of the shell horn made from Triplofusus princeps. Experimental model with ceramic mouthpiece, overblowing: (a) spectrogram; (b) spectrum (Sample S4).

According to the obtained sound pressure levels located in the range between 99 and $112 \mathrm{dBA}$ at $1 \mathrm{~m}$, shell horns represent by far the loudest and farthest reaching sound producing instruments employed in Teotihuacan. According to optimal environmental conditions, the sound of the horns would propagate over a field within a radius of at least $1.5-2.0 \mathrm{~km}$ and still be well perceived. For the playing postures, it is suggested that the large horns, which are quite heavy (1.5-2.0 kg, for the largest instruments), were supported with one or two hands and sounded in a standing position. However, although the Teotihuacan iconography of the shell horn is particularly rich, the extant murals and relief depictions are not really significant with regard to the playing postures and techniques, as the horns are either shown in a floating position or carried under the arms by priests and depicted to sound on their own. ${ }^{13}$ A succession of murals of the Patio of the Jaguars shows the horns played by jaguars, supposedly representing persons of priestly rank or other members of the elite impersonified as jaguars. The latter depictions show the jaguars in a walking position and supporting their horns in one of the forepaws, indicating that the instruments might have been sounded in processions. Among other possible uses, the Teotihuacan shell 
horns were likely performed from the temples erected on top of the pyramidal platforms. According to the archaeological contexts, the finds of single horns or groups of many horns are suggestive of both solo and massive simultaneous playing taking place in the site.

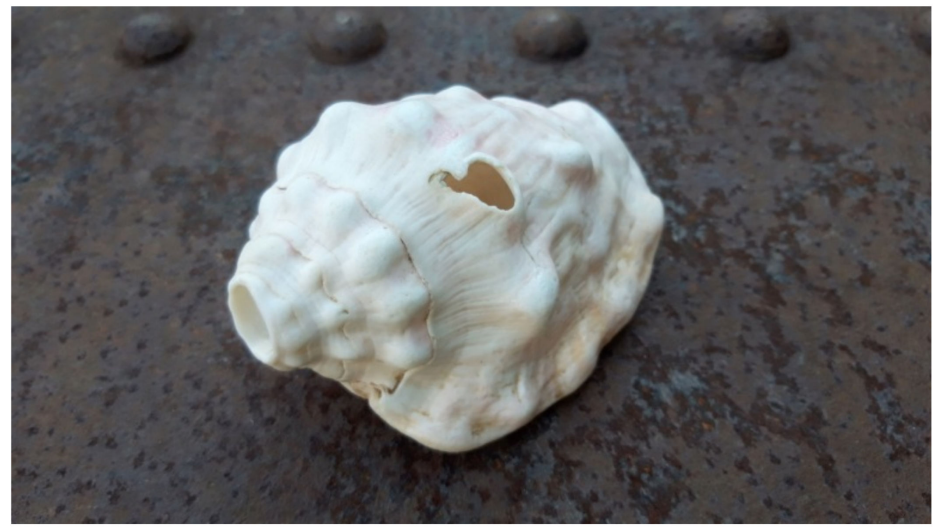

Figure 11. Shell horn made from Aliger gigas. Experimental model by the author (2021), length: $9.5 \mathrm{~cm}$. For experimental playing, the irregular damage on the body whorl had been sealed.

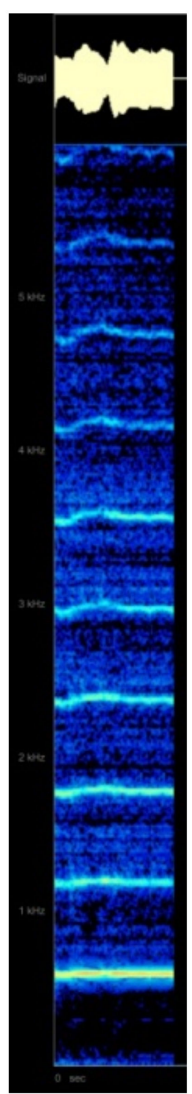

(a)

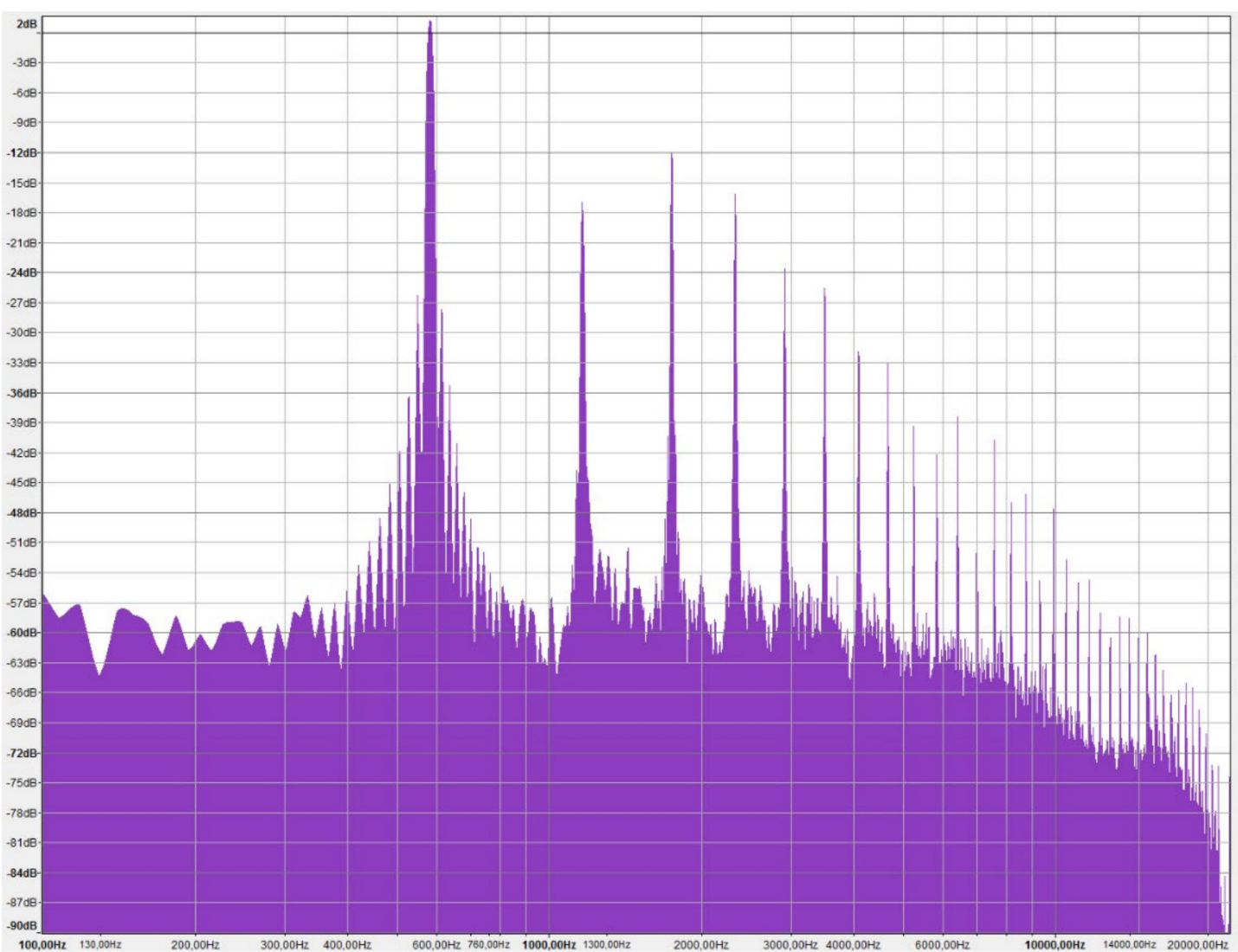

(b)

Figure 12. Spectral components of shell horn made from Aliger gigas. Experimental model, low blowing pressure: (a) spectrogram; (b) spectrum (Sample S5).

\subsubsection{Ceramic Horns}

Ceramic horns simulating the form of seashells are rare finds in Teotihuacan. Only one specimen, which formed part of Burial 32 of Tetitla, is preserved intact (Figure 13) [26,27]. ${ }^{14}$ 
The instruments resemble a somewhat abstract form of the Triplofusus gastropods, without showing a representation of the characteristic knobs of the shells. By contrast, the outer wall presents an adornment in the form of a series of vertical groove-like depressions. The length of the intact find is $28.3 \mathrm{~cm}$, the width $13.9 \mathrm{~cm}$ and the height $12.2 \mathrm{~cm}$, representing the shell of a medium-sized marine snail. The mouthpiece does not only represent the removed tip of the shell but also represents the attachment of a wall forming a cup mouthpiece with an outer diameter of $2.7 \mathrm{~cm}$ at the rim, $1.7 \mathrm{~cm}$ of cup diameter and $1.8 \mathrm{~cm}$ of depth. The position of the relatively large throat (of $0.8 \mathrm{~cm}$ in diameter, approximately) is shifted about $0.4 \mathrm{~cm}$ from the centre of the cup (comparable to the shift observed in the natural antetype).

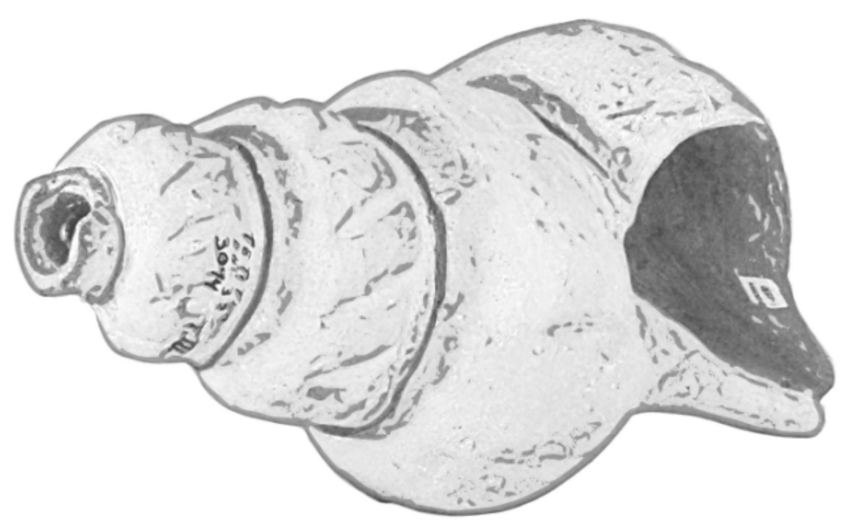

Figure 13. Ceramic horn at Burial 32, Tetitla, Teotihuacan (MNA, Inv. 10-223554), length: $28.3 \mathrm{~cm}$.

For the absence of radiographies or computed tomographies, the inner structure of the resonator is unknown. It can be supposed that it does not perfectly resemble the double helicoid chamber of the natural antetype, which would be extremely difficult to produce in ceramics; compare the radiographies of shell horns and ceramic horns in [28] (pp. 276-278, Figures 107-112). That the chamber must differ is also demonstrated when comparing the acoustic parameters (Tables 1 and 2). As the ceramic horn is smaller than the documented shell horns made from Triplofusus princeps, it would be expected that the instrument produces sounds at a higher frequency range (compared to when played without hand-insertion technique). This, however, was not the case. In testing the sonic artefact, frequencies between 273 and $280 \mathrm{~Hz}$ were obtained (equivalent to $\mathrm{CH}_{4}{ }^{-26 /+18}$ ). The fundamental frequencies are thus very close to one another, indicating that the chamber of the ceramic horn differs from the natural antetype in terms of its structure and volume (for comparable results, see [29,30]). The difference is also made visible in the spectrogram and corresponding spectrum (Figure 14, Table 2 and Sample S6). The horn has less high frequency content, the fundamental presents superimposed harmonics (comparable to the shell horn played with a ceramic cup mouthpiece, see above) and the third harmonic is stronger than the first one, being almost as loud as the fundamental. In terms of frequency spectrum, this Teotihuacan horn is documented with the brightest spectrum.

Table 2. Acoustic data sheet of the ceramic horn (MNA, Inv. 10-223554).

\begin{tabular}{clccc}
\hline $\begin{array}{c}\text { Teotihuacan Sound } \\
\text { Producing Instrument }\end{array}$ & \multicolumn{1}{c}{ Playing Technique } & $\begin{array}{c}\text { Frequency Rates } \\
\text { (Fundamental Tones) }\end{array}$ & Tonal Deviation & Sound Pressure Level \\
\hline $\begin{array}{c}\text { Ceramic horn (MNA, } \\
\text { Inv. 10-223554, } 28.3 \mathrm{~cm})\end{array}$ & $\begin{array}{l}\text { lip-vition, low } \\
\text { pressure, hand- } \\
\text { insertion technique }\end{array}$ & $243-280 \mathrm{~Hz}$ & $\mathrm{CH}_{4}-26 /+18$ & Not measured \\
\hline
\end{tabular}




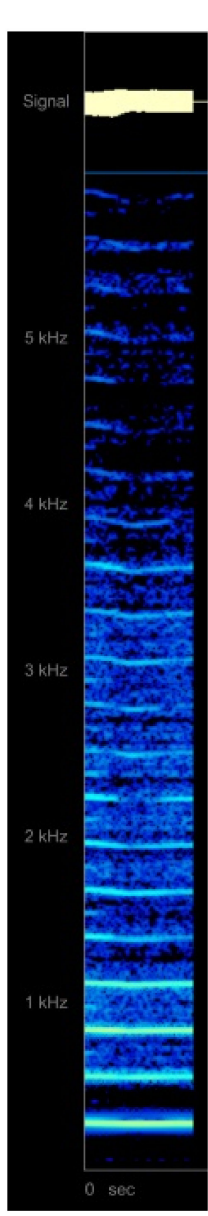

(a)

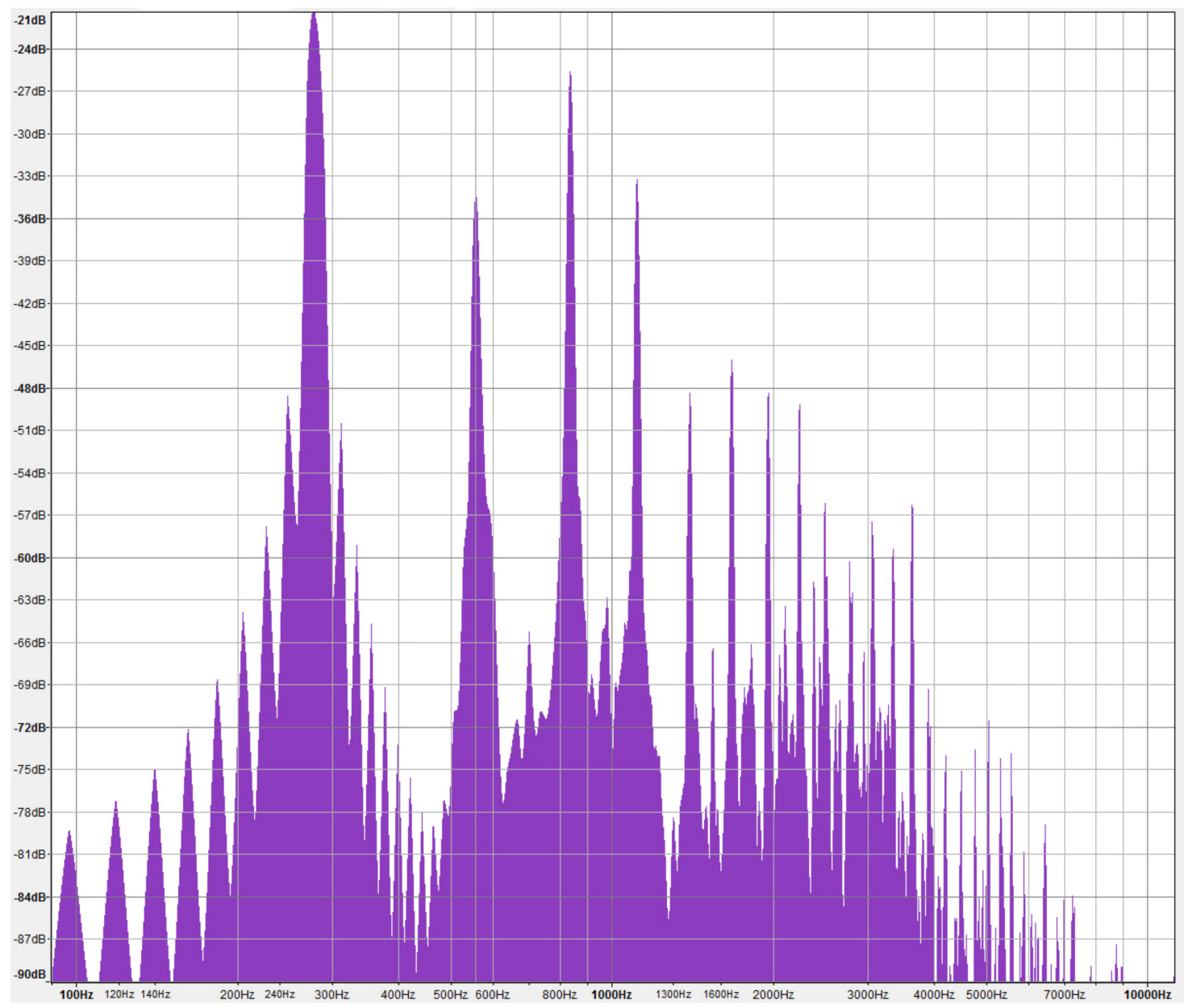

(b)

Figure 14. Spectral components of ceramic horn at Burial 32, Tetitla, Teotihuacan (MNA, Inv. 10-223554), low pressure: (a), spectrogram (b) spectrum (Sample S6).

By inserting the hand into the bell, much lower frequencies between 246 and $248 \mathrm{~Hz}$ (equivalent to $\mathrm{B}_{3}{ }^{-7 /+7}$ ) were obtained. Thus, by gradually opening the bell virtually all frequencies between 246 and $280 \mathrm{~Hz}$ can be obtained (located in the range of three semitones). However, such as for the abovementioned Teotihuacan shell horns, the playing position and techniques applied are unknown.

\subsubsection{Ceramic Trumpets}

A high number of fragmented ceramic trumpets, in particular fragments of tubes and mouthpieces, has been excavated all over the site of Teotihuacan. ${ }^{15}$ The trumpets were composed of a cup mouthpiece, a tube with a cylindrical bore and a bell yard, which opens outward in a flare while turning and, towards the bell exit diameter, into a cup-shaped form with vertical side walls [30]. ${ }^{16}$ The tubes sometimes present figurative enforcements in the form of ringlike or chalice-shaped attachments, the former resembling the nodes of the stem and the latter the junction of the blade and the sheath of a reed. ${ }^{17}$ Only two finds are preserved intact; one specimen without documented archaeological context preserved in the Met (Figure 15) and the second specimen excavated in Burial 17 of a temple structure of the White Patio, Tetitla (Northeast Temple) (Figure 16). ${ }^{18}$ The slightly larger instrument from the Met measures $29.5 \mathrm{~cm}$ in length and $5.2 \mathrm{~cm}$ for the bells' outer diameter and the trumpet from Tetitla measures $28.0 \mathrm{~cm}$ in length and $4.6 \mathrm{~cm}$ for the bell. The cup mouthpiece of the latter specimen presents the diameter of $2.1-2.3 \mathrm{~cm}$ at the rim, $1.5-1.7 \mathrm{~cm}$ for the cup diameter and a depth of $1.4 \mathrm{~cm}$. The throat is slightly oval $(\mathrm{of} 0.55-0.75 \mathrm{~cm}$ in 
diameter). The tube shows the outer diameter of $1.2-1.4 \mathrm{~cm}$ and a bore of approximately $0.6-0.8 \mathrm{~cm}$. The many documented fragments of tubes and mouthpieces show comparable dimensions (the mouthpieces generally range between 1.9 and $2.9 \mathrm{~cm}$ in diameter at the rim, 1.3-2.3 cm for the cup diameter, $0.6-1.6 \mathrm{~cm}$ of depth and between 0.4 and $0.8 \mathrm{~cm}$ for the diameter of the throat; the tube fragments range between 1.2 and $1.6 \mathrm{~cm}$ of outer diameter with bores between 0.4 and $0.9 \mathrm{~cm}$ ). The documented measurements point to a standardized production of ceramic trumpets in Teotihuacan. Although the total length is only known for two specimens, it can be supposed that the instruments usually measured between $26.0-31.5 \mathrm{~cm}$ in length (given $2.0 \mathrm{~cm}$ of deviation from the two intact finds), with bells ranging between $4.5-5.5 \mathrm{~cm}$ in diameter.

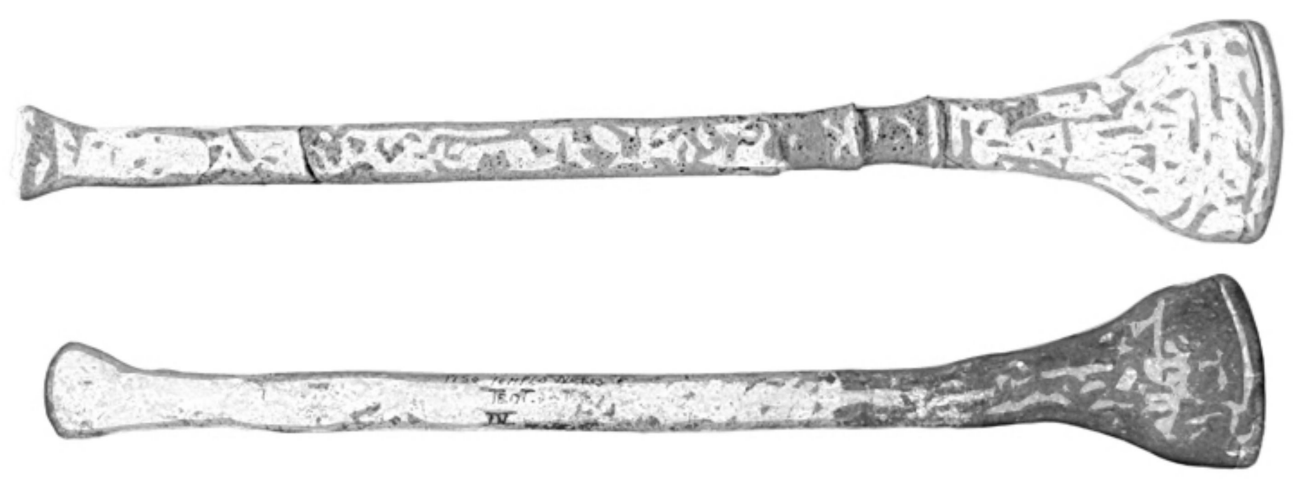

Figure 15. Teotihuacan ceramic trumpets: (a) (Met, Inv. 2002.186), length: $29.5 \mathrm{~cm}$; (b) (MNA, Inv. 10-222559), length: $28.0 \mathrm{~cm}$.

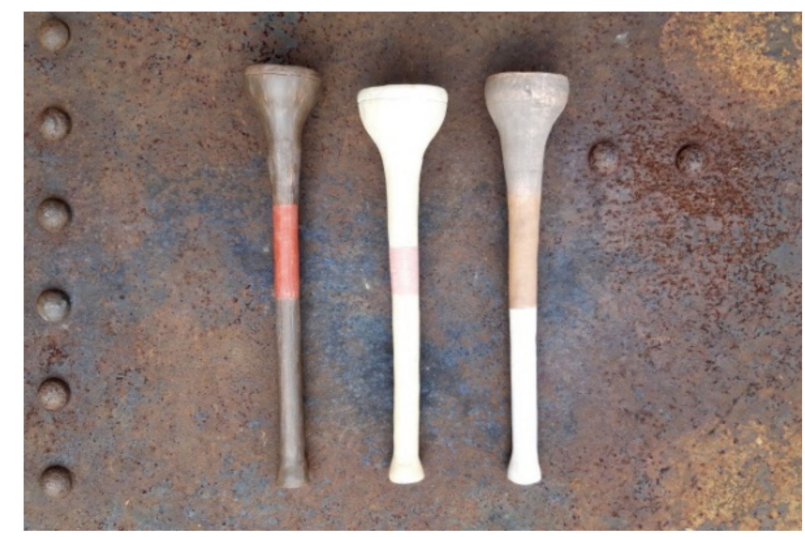

Figure 16. Ceramic trumpets. Experimental models by Friedemann Schmidt (2010) and Osvaldo Padrón (2019-2020), length: 26.0-30.5 cm.

As the original intact finds could not be sounded because of their fragile condition, a series of experimental models was produced with measurements in the range of the documented specimen (Figure 16). The models measure $26.0-30.5 \mathrm{~cm}$ in length and the bells have a diameter of $5.0-5.5 \mathrm{~cm}$. According to the application of both lower and intensified blowing pressures, the instruments produce fundamental frequencies between 294 and $320 \mathrm{~Hz}$ (equivalent to $\mathrm{D}_{4}{ }^{+2}$ to $\mathrm{DH}_{4}{ }^{+49}$ ) for the largest model in terms of length and $389-409 \mathrm{~Hz}$ (equivalent to $\mathrm{G}_{4}{ }^{-13}$ to $\mathrm{G}_{4}{ }^{-26}$ ) for the smallest model. As for the gradual increase in the length of the cylindrical bore, roughly $25 \mathrm{~Hz}$ per centimeter can be calculated, providing an estimated frequency of around $345-365 \mathrm{~Hz}\left(\mathrm{~F}_{4}{ }^{-21}\right.$ to $\left.\mathrm{F}_{4}{ }^{-24}\right)$ for the instrument stored in MNA and $320-340 \mathrm{~Hz}\left(\mathrm{DH}_{4}{ }^{+49}\right.$ to $\mathrm{F}_{4}{ }^{-46}$ ) for the instrument stored in the Met, respectively. These values were also confirmed by means of the experimental models produced according to the lengths of the sonic artefacts. By sounding the smallest trumpet of the sample, the levels of the first three harmonics are nearly equal to that of the fundamental frequency and gradually increase in amplitude from the lower to the 
higher harmonic (Figure 17, Table 3, Sample S7). In addition, the spectrum shows a rise in frequency at about $15 \mathrm{kHz}$, contributing to the very light and bright timbre of the trumpet.

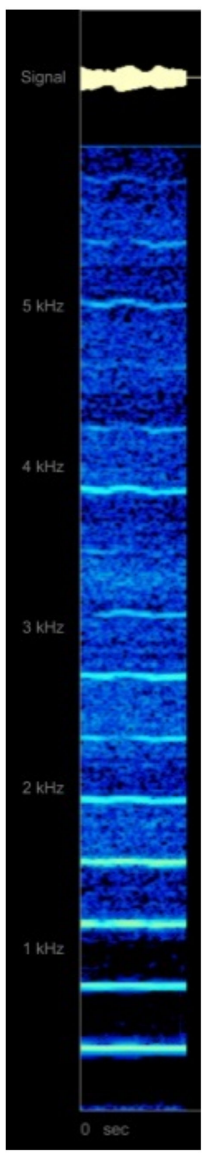

(a)

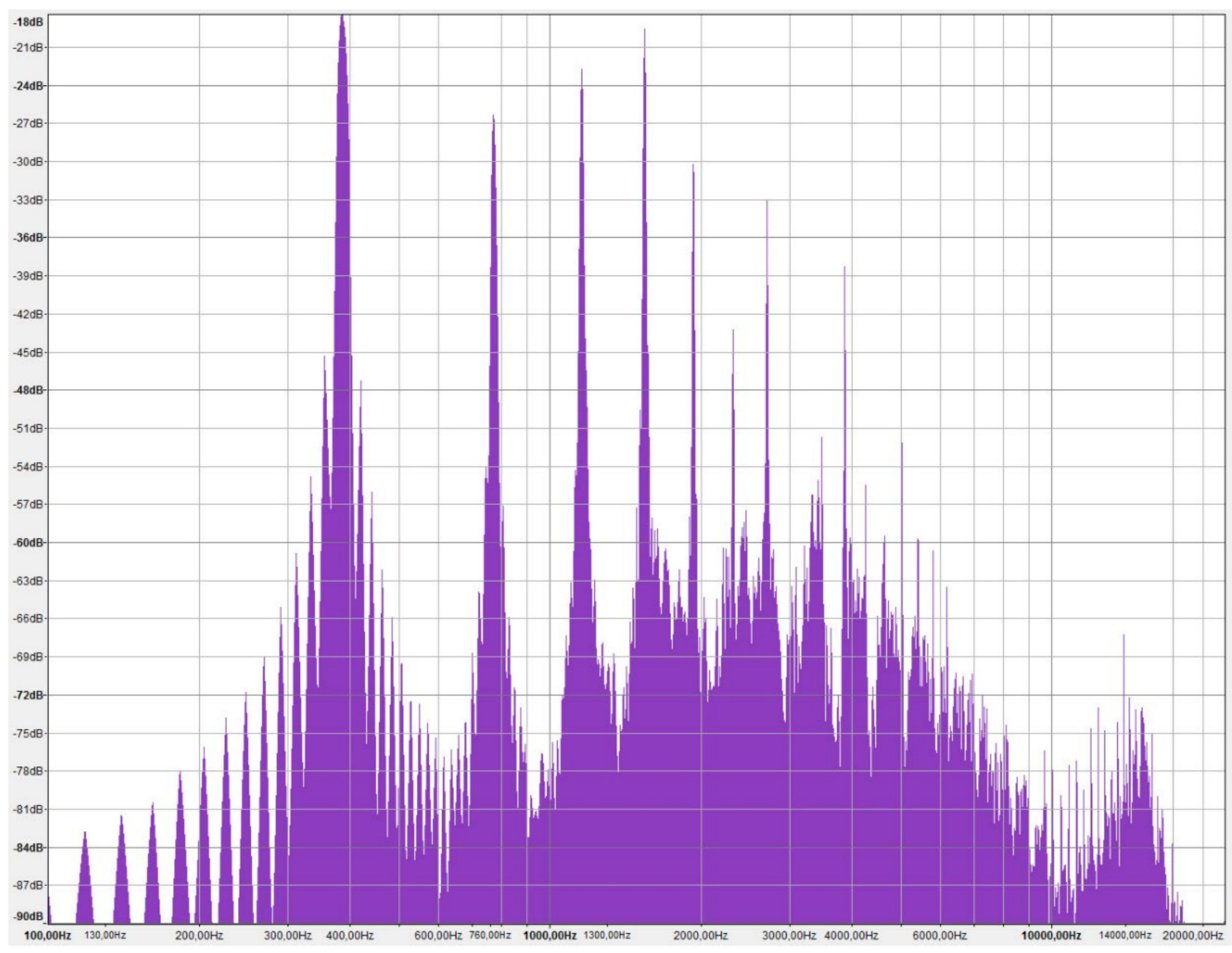

(b)

Figure 17. Spectral components of ceramic trumpet. Experimental model, low blowing pressure: (a) spectrogram; (b) spectrum (Sample S7).

Table 3. Acoustic data sheet of the analyzed ceramic trumpets (experimental models).

\begin{tabular}{|c|c|c|c|c|}
\hline $\begin{array}{l}\text { Teotihuacan Sound } \\
\text { Producing Instrument }\end{array}$ & Playing Technique & $\begin{array}{c}\text { Frequency Rates } \\
\text { (Fundamental Tones) }\end{array}$ & Tonal Deviation & $\begin{array}{l}\text { Sound Pressure Level } \\
\text { at } 1 \mathrm{~m} \text { (Max. Values) }\end{array}$ \\
\hline \multirow{2}{*}{$\begin{array}{l}\text { Ceramic trumpet, large } \\
\text { (experimental model, } \\
30.5 \mathrm{~cm} \text { ) }\end{array}$} & $\begin{array}{l}\text { lip-vibration, different } \\
\text { blowing pressure levels }\end{array}$ & $294-320 \mathrm{~Hz}$ & $\mathrm{D}_{4}+2$ to $\mathrm{D \#}_{4}+49$ & 100.5-105.1 dBA \\
\hline & $\begin{array}{l}\text { lip-vibration, low blowing } \\
\text { pressure, partially hand } \\
\text { stopping the bell }\end{array}$ & $285 \mathrm{~Hz}$ & $\mathrm{C \#}_{4}+48$ & 96.1-97.4 dBA \\
\hline \multirow{2}{*}{$\begin{array}{c}\text { Ceramic trumpet, small } \\
\text { (experimental model, } \\
26.0 \mathrm{~cm})\end{array}$} & $\begin{array}{l}\text { lip-vibration, different } \\
\text { blowing pressure levels }\end{array}$ & $389-409 \mathrm{~Hz}$ & $\mathrm{G}_{4}{ }^{-13}$ to $\mathrm{G \#}_{4}{ }^{-26}$ & 97.2-99.7 dBA \\
\hline & $\begin{array}{l}\text { lip-vibration, low blowing } \\
\text { pressure, partially hand } \\
\text { stopping the bell }\end{array}$ & $369 \mathrm{~Hz}$ & $\mathrm{~F}_{4}-5$ & 96.6-98.7 dBA \\
\hline
\end{tabular}

With 97.2-105.1 dBA at $1 \mathrm{~m}$, the instruments show comparable sound pressure levels than the values obtained for the shell horns, although the trumpets are not designed to reach the maximum level documented for the horns (see Tables 1 and 3). Nevertheless, the trumpets are powerful enough to propagate over a larger field and are, therefore, likely to 
be employed for long-distance communication within a radius of at least $1.0 \mathrm{~km}$ according to the environmental conditions. In this context, the vertical side walls of the cup-shaped bell facilitated projecting the sound in a particular direction.

Due to their particular construction, trumpets with wider and deeper cup-shaped mouthpieces are difficult to overblow as it is not possible to set up a higher vibration regime with the lips without the support of a smaller-diameter mouthpiece. This is also the case with the Teotihuacan ceramic trumpets. However, the characteristic sound of the instruments can be substantially modified by partially stopping the bell with the palm of the hand. Interestingly, the frequency range obtained is not significantly higher with the employment of this technique (only $10-20 \mathrm{~Hz}$, about a semi-tone or less) and with values of 96.1-99.7 dBA at $1 \mathrm{~m}$ the sound pressure levels are also not considerably inferior. In turn, the sound characteristics are considerably altered. The spectrogram and corresponding spectra show that the second harmonic is stronger than the fundamental and fewer high frequencies are generated than by the unstopped trumpet (Figure 18, Table 3 and Sample S8). Similar to the previously discussed horns, it cannot be ruled out that such a technique was employed. Extant ceramic figurines showing trumpet players (see [31], pp. 40-41, Figure 21) ([32], p. 376, Figure 106) indicate that the instruments were generally sounded in a standing position and supported by one hand. For the sheer number of fragmented finds all over Teotihuacan, single and simultaneous performances could have been carried out by small or larger groups of trumpeters for a range of different purposes, such as sounding signals for alert, calling or other announcements, including ritual activities.

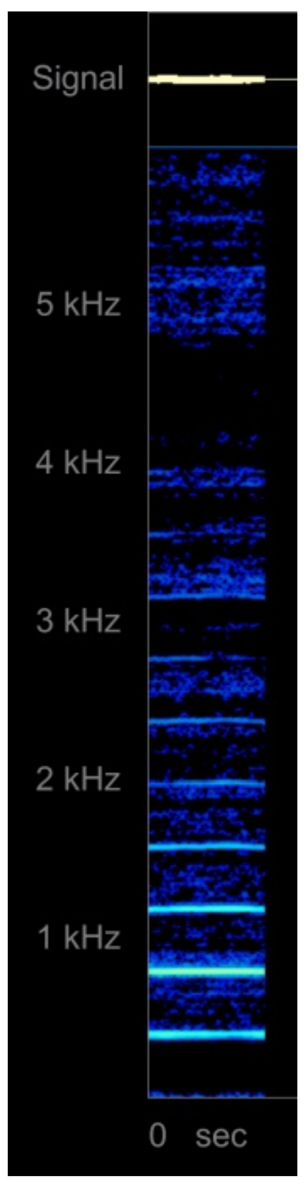

(a)

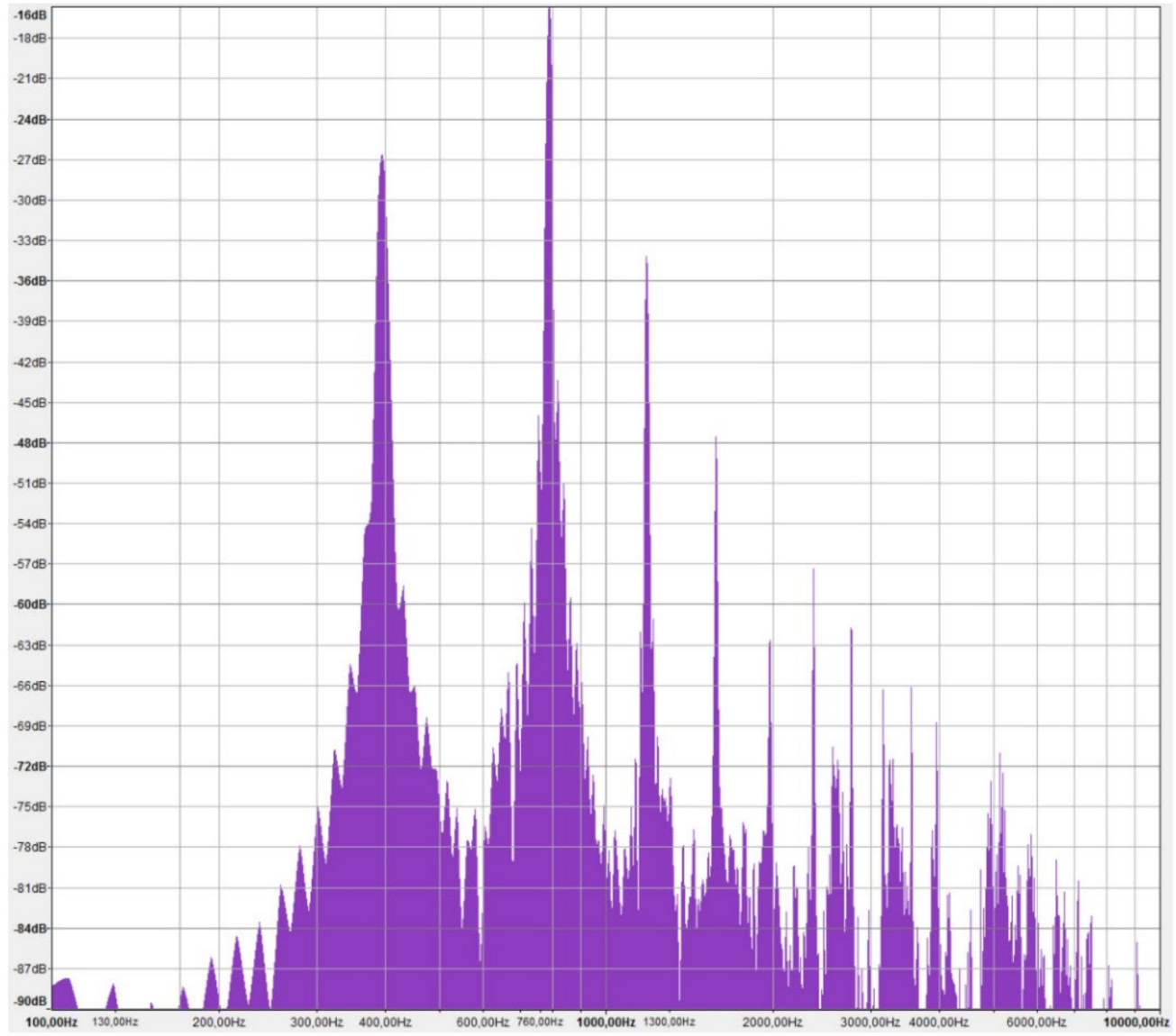

(b)

Figure 18. Spectral components of ceramic trumpet, experimental model, low blowing pressure, hand stopped: (a) spectrogram; (b) spectrum (Sample S8). 


\subsection{Ceramic Duct Flutes}

The largest and most diverse group in terms of morphology of Teotihuacan sound artefacts is composed of ceramic duct (or fipple) flutes, which are characterized by the employment of a mouthpiece in the form of a beak that is provided with an airduct and a window with a bladed edge. The group can be divided, according to the form of the resonators, into tubular flutes (or pipes) and globular flutes (or vessel flutes). For the pipes, Teotihuacan sub-types are characterized by the number of resonators (multiple flutes presenting more than one separated resonator) and the placement of a piston. As mentioned above, the Teotihuacan vessel flutes will be discussed in a complementary paper [14].

\subsubsection{Pipes}

The most prominent type of Teotihuacan pipes are the so-called quadruple flutes, which are instruments composed of four long tubular resonators equipped with a number of fingerholes and tone holes. Other multiple tubular flutes are far less frequently documented, but apparently existed according to mouthpiece fragments suggesting the employment of triple and double flutes. ${ }^{19}$ The shape of the latter instruments is unknown as the pipes did not survive. The same situation applies for mouthpiece fragments, which belong to Teotihuacan flutes with a single pipe. ${ }^{20}$ Without extant intact finds, the condition does not permit an understanding of the particular form of these instruments. For other finds of flutes with a single pipe, it is likely that such instruments were imported during Classic times from the Gulf Coast, while others certainly derive from Late Postclassic (Aztec) contexts. ${ }^{21}$ Further tubular flutes said to be from Teotihuacan are stored in museum collections but are late 19th/early 20th century inventions locally produced for the flourishing tourist market around Teotihuacan [33].22 The only indigenous Teotihuacan tubular flutes with a single pipe documented so far in terms of their organological and acoustical parameters are the so-called piston whistles; these are instruments without finger holes equipped with a movable cylinder inserted into the pipe. The acoustics of the latter instruments and the quadruple flutes are discussed in this paper.

\section{Quadruple Flutes}

The Teotihuacan quadruple flutes are among the most elaborate ceramic fipple flute instruments documented for Mesoamerica. According to the finds, the instruments were produced in at least two sizes, suggesting the employment of a family of alto and soprano instruments. They are characterized by a typical mouthpiece with four slit-shaped airducts converging in only two blow holes (Figure 19). The airducts are directed to the edge of four unusually formed apertures, which are in general much longer than wider and equipped with convex side walls. ${ }^{23}$ According to the extant finds (see below) and a series of quadruple flute miniatures excavated in Teotihuacan [34-37], ${ }^{24}$ the two rightmost or "melody" pipes (identified as A and B, for reference) are equipped with three more-or-less equidistant fingerholes placed in the central part and a tone hole placed in the lower part of the pipes. As a general principle, the fingerhole groups in the central part are not aligned in parallel but slightly shifted, with the fingerholes of pipe A placed three to five millimetres higher than those of pipe B (always measured from the centre of each fingerhole). The tone holes in pipes A and B are also not aligned in parallel, but shifted in the opposite direction, with the tone hole of pipe A placed a little bit lower than the one of pipe B (in acoustic terms, the frequency deviation as a result of the shifted fingerholes is thus counterbalanced). The two leftmost or "drone" pipes (C and D) are equipped with one or two fingerholes each that are placed in the lower part of the pipes and meant for adjusting the drone frequencies. According to the playing technique applied, the drone pipes can also be turned into melody pipes with a reduced tonal range. While pipes $\mathrm{A}$ to $\mathrm{C}$ are usually of the same length, pipe $\mathrm{D}$ is somewhat longer, thus producing tones in a lower frequency range compared to the other pipes. The pipes A-C are usually half-stopped by slightly dented walls or a disk with a central opening. Pipe D is most possibly half-stopped by a conical constriction at the distal end. Both these elements serve to ensure that the 
pitch of the instrument is lower than if the pipes were open. The instruments always create a colorful cluster of tones: according to the fingering positions, triads (chords composed of three tones) are frequently produced when the frequencies generated by two of the pipes overlap. Occasionally, also tetrads (chords composed of four tones) are produced. In exceptional cases dyads composed of two superimposed frequencies may be generated.

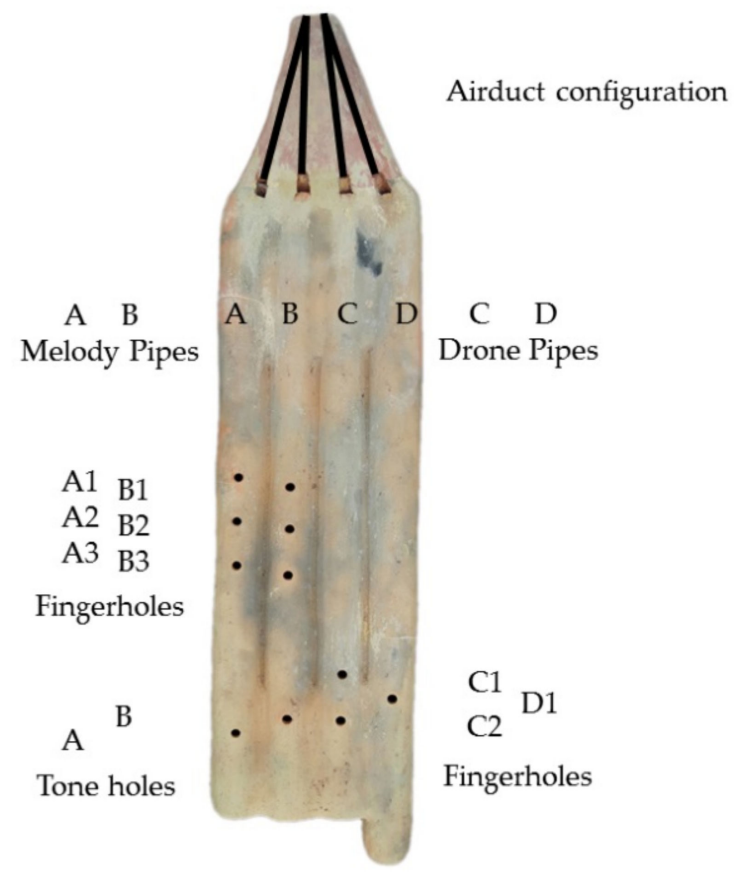

Figure 19. The organological components of a Teotihuacan quadruple flute (experimental model).

Within the urban setting of Teotihuacan, finds of quadruple flute fragments are predominantly but not exclusively related to the apartment compounds close to the civicreligious centre of the city $[5,7,26,38] \cdot{ }^{25}$ A selection of further fragments, in particular mouthpieces sometimes bearing upper sections of the pipes, is known from the Gulf Coast, Oaxaca and Guatemala $[5,31,37-43],{ }^{26}$ suggesting that the instruments were also exported. Sonic artefacts resembling Teotihuacan quadruple flutes but with distinct organological features are represented by other finds from West Mexico $[5,39]^{27}$ and from the Maya area [5], ${ }^{28}$ indicating that the Teotihuacan quadruple flute tradition spread during the peak of the city and for some time also lived on after its decline.

Only two finds from Teotihuacan are reported, which are preserved partly intact and restored with hypothetically reconstructed parts. The first is a larger instrument that had been excavated from Burial 30 of Zacuala Palace, forming part of the main temple of the compound (Figure 20a) $[5,26,27,31,44] .{ }^{29}$ The instrument was subject to at least three reconstruction attempts, which are not fully correct according to current research, especially in terms of the placement or omittance of some of the fingerholes and tone holes, the diameter of some of the fingerholes and the length of the pipes [1]. The reconstructions resulted in differing total lengths of the sonic artefact, ranging between $53.5 \mathrm{~cm}$ in the first, $64.5 \mathrm{~cm}$ in the second and $74.5 \mathrm{~cm}$ in the last reconstruction (the width of $13.2 \mathrm{~cm}$ and the height of $3.8 \mathrm{~cm}$ were always maintained and correspond to the original size; the height is equivalent to the maximum outer diameter of the pipes). The second is a smaller quadruple flute ("Anahuacalli 1") that has no archaeological background information except that it is from Teotihuacan. The instrument is from the Diego Rivera collection and has also been reconstructed (Figure 20b) $[39,45],{ }^{30}$ but likewise not fully satisfying in terms of the omitting of some of the fingerholes and the length of pipe D [1]. The actual measurements of this instrument are $43.0 \mathrm{~cm}$ in length, $10.4 \mathrm{~cm}$ in width and $2.7 \mathrm{~cm}$ in height. Its current 
condition is poor as some of the reconstructed sections came apart and further damages occurred to the preserved original parts. A fragmented quadruple flute ("Anahuacalli 2") with partly preserved pipes from the Diego Rivera collection, which has not been published so far (Figure 20c), is virtually identical to the previously-mentioned instrument in terms of morphology, organological details and wear marks. It is suggested that both finds stem from the same archaeological context.

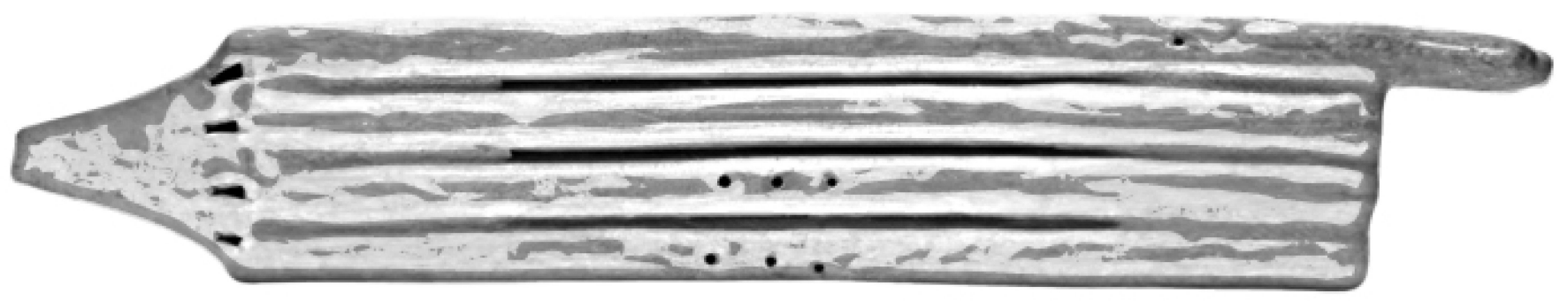

(a)

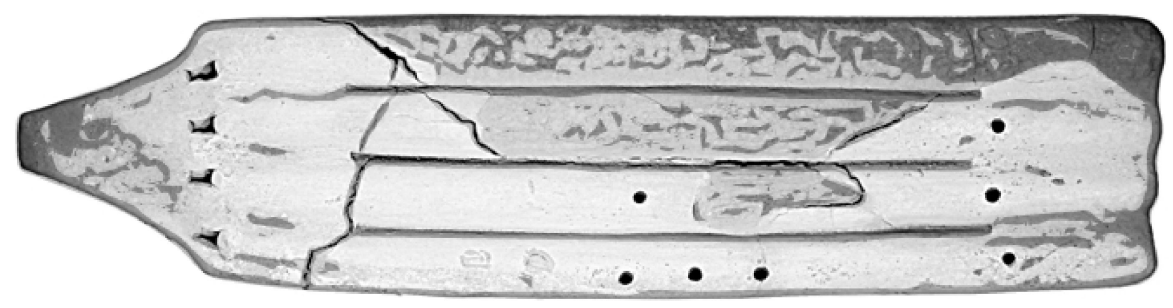

(b)

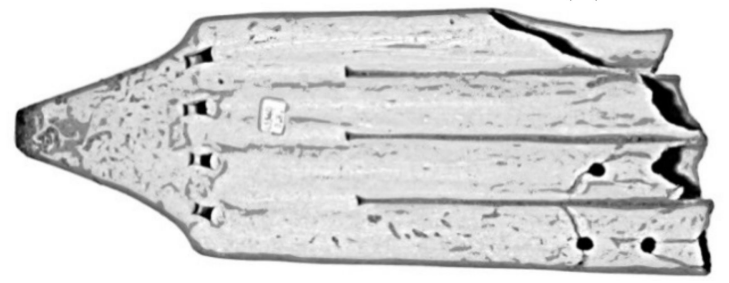

(c)

Figure 20. Quadruple flute finds from Teotihuacan: (a) Zacuala Palace (MNA, Inv. 10-223540), length: 74.5 cm; (b) Diego Rivera collection, "Anahuacalli 1" (MA, Inv. 51125), length: 43.0 cm; (c) fragment from the Diego Rivera collection, "Anahuacalli 2" (MA, Inv. 45540), length: $28 \mathrm{~cm}$.

Unfortunately, in both reconstructed sonic artefacts, only a selection of the pipes can be sounded. In the instrument from the Zacuala Palace, pipe D is mute. Pipes A-C were individually tested by blocking the windows of the remaining pipes. The playable parts of the instrument sounded in the range of fundamental frequencies between 227 and $399 \mathrm{~Hz}\left(\mathrm{A \#}_{3}{ }^{-46}\right.$ to $\left.\mathrm{G}_{4}{ }^{+31}\right)$ (Table 4$)$. As indicated above, it must be noted, however, that the current length of the pipes in the restored and reconstructed artefact is greater than actually believed to be appropriate and that the frequencies obtained are therefore located in a lower range than originally foreseen. In addition, the irregular size of the restored fingerholes creates sound deviations possibly not present in the original instrument. 
Table 4. Acoustic data sheet of the Zacuala Palace quadruple flute (MNA, Inv. 10-223540).

\begin{tabular}{|c|c|c|c|c|}
\hline $\begin{array}{l}\text { Teotihuacan Sound } \\
\text { Producing Instrument }\end{array}$ & Playing Technique & $\begin{array}{c}\text { Frequency Rates } \\
\text { (Fundamental Tones) }\end{array}$ & Tonal Deviation & $\begin{array}{c}\text { Sound Pressure } \\
\text { Level }\end{array}$ \\
\hline \multirow{12}{*}{$\begin{array}{c}\text { Quadruple flute, } \\
\text { large (MNA, } \\
\text { Inv. 10-223540, 74.5 cm) }\end{array}$} & $\begin{array}{l}\text { Pipe A, fingerholes 1-3 } \\
\text { stopped, low blowing } \\
\text { pressure fluctuation }\end{array}$ & $233-243 \mathrm{~Hz}$ & $\mathrm{A \#}_{3}{ }^{-1}$ to $\mathrm{B}_{3}{ }^{-28}$ & \multirow{12}{*}{ Not measured } \\
\hline & $\begin{array}{l}\text { Pipe A, fingerholes 1-2 } \\
\text { stopped, low blowing } \\
\text { pressure fluctuation }\end{array}$ & $296-312 \mathrm{~Hz}$ & $\mathrm{D}_{4}+14$ to $\mathrm{D \#}_{4}^{+5}$ & \\
\hline & $\begin{array}{l}\text { Pipe A, fingerhole } 1 \\
\text { stopped, low blowing } \\
\text { pressure fluctuation }\end{array}$ & $325-355 \mathrm{~Hz}$ & $\mathrm{E}_{4}-24$ to $\mathrm{F}_{4}^{+28}$ & \\
\hline & $\begin{array}{l}\text { Pipe A, all fingerholes } \\
\text { open, low blowing } \\
\text { pressure fluctuation }\end{array}$ & defect & & \\
\hline & $\begin{array}{l}\text { Pipe A, all fingerholes } \\
\text { open, overblown, different } \\
\text { blowing pressure levels } \\
\text { (4 regimes) }\end{array}$ & $\begin{array}{r}454-522 \mathrm{~Hz} \\
742-768 \mathrm{~Hz} \\
790-835 \mathrm{~Hz} \\
1037-1062 \mathrm{~Hz}\end{array}$ & $\begin{array}{l}\mathrm{A \#}_{4}{ }^{-46} \text { to } \mathrm{C}_{5}{ }^{-4} \\
\mathrm{FH}_{5}{ }^{+5} \text { to } \mathrm{G}_{5}{ }^{-36} \\
\mathrm{G}_{5}{ }^{+13} \text { to } \mathrm{GH}_{5}{ }^{+9} \\
\mathrm{C}_{6}{ }^{-16 /+25}\end{array}$ & \\
\hline & $\begin{array}{l}\text { Pipe B, fingerholes 1-3 } \\
\text { stopped, lower blowing } \\
\text { pressure fluctuation }\end{array}$ & $227-242 \mathrm{~Hz}$ & $\mathrm{A \#}_{3}{ }^{-46}$ to $\mathrm{B}_{3}-35$ & \\
\hline & $\begin{array}{l}\text { Pipe B, fingerholes 1-2 } \\
\text { stopped, low blowing } \\
\text { pressure fluctuation }\end{array}$ & $295-299 \mathrm{~Hz}$ & $\mathrm{D}_{4}^{+8 /+31}$ & \\
\hline & $\begin{array}{l}\text { Pipe B, fingerhole } 1 \\
\text { stopped, low blowing } \\
\text { pressure fluctuation }\end{array}$ & $348-355 \mathrm{~Hz}$ & $\mathrm{~F}_{4}^{-6 /+28}$ & \\
\hline & $\begin{array}{l}\text { Pipe B, all fingerholes } \\
\text { open, low blowing } \\
\text { pressure fluctuation }\end{array}$ & $377-399 \mathrm{~Hz}$ & $\mathrm{~F}_{4}{ }^{+32}$ to $\mathrm{G}_{4}{ }^{+31}$ & \\
\hline & $\begin{array}{l}\text { Pipe } B \text {, all fingerholes } \\
\text { open, overblown } \\
\text { ( } 2 \text { regimes) }\end{array}$ & $\begin{array}{c}482-485 \mathrm{~Hz} \\
1040-1042 \mathrm{~Hz}\end{array}$ & $\mathrm{~B}_{4}{ }^{-42 /-31} ; \mathrm{C}_{6}-11 /-7$ & \\
\hline & $\begin{array}{l}\text { Pipe C, low blowing } \\
\text { pressure fluctuation }\end{array}$ & $250-256 \mathrm{~Hz}$ & $\mathrm{~B}_{3}{ }^{+21}$ to $\mathrm{C}_{4}{ }^{-38}$ & \\
\hline & Pipe D & defect & & \\
\hline
\end{tabular}

For the timbre of the flute, much accompanying noise ('wind') is to be observed, especially from the third harmonic onwards, expanding over a range between $0.75-3.25 \mathrm{kHz}$ and higher (Figure 21, Table 4 and Sample S9a-c). This aspect and the half stopped voluminous resonators render the sound characteristics of the instrument comparable to a large vessel flute. Occasionally, tremolo and vibrato effects become visible in the spectrograms, especially in the overtone range observed for pipe A. The effect becomes stronger from one harmonic to a higher one and is result of small blowing pressure variations in combination with the particular organological condition of the pipes (this particular feature is also confirmed for certain finger combinations and playing postures of the experimental models; compare Figure 21a, finger combination 3, and the spectral components to the experimental flute models discussed below). 


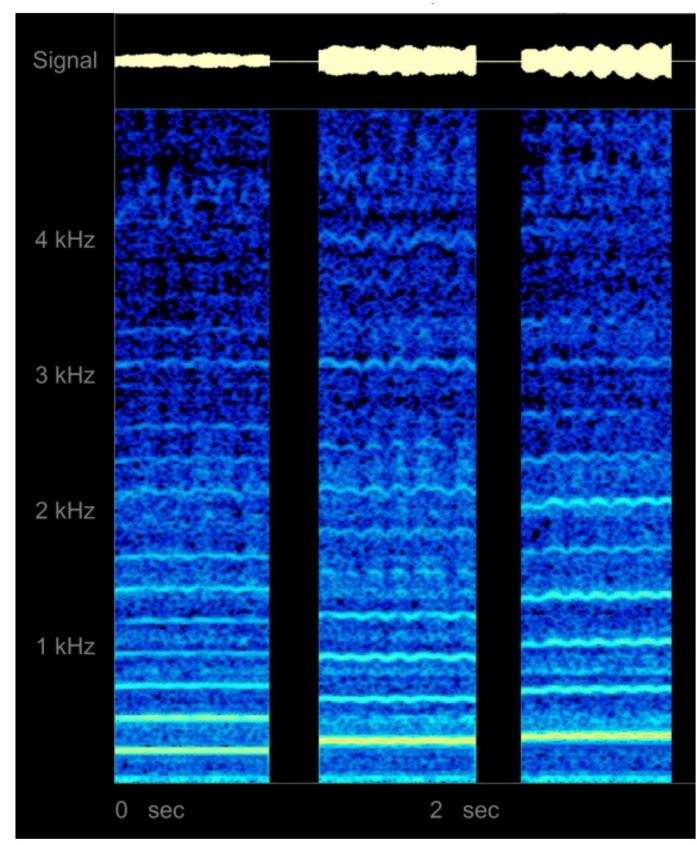

(a)

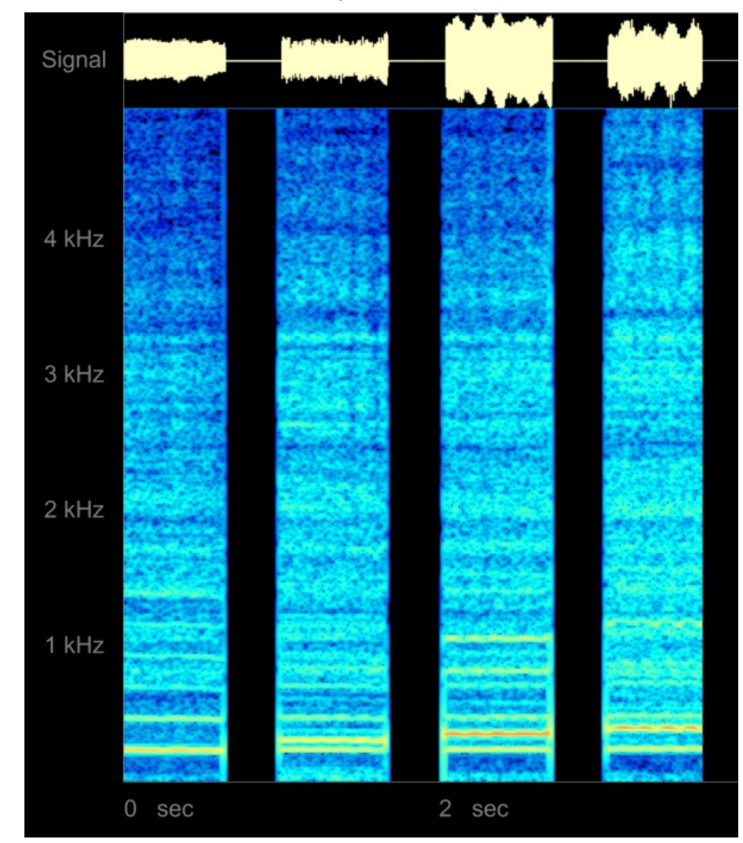

(b)

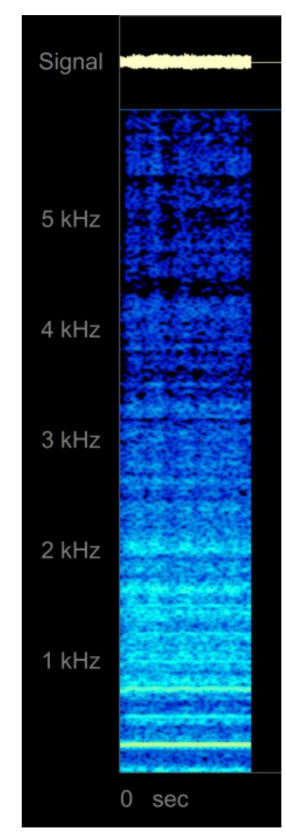

(c)

Figure 21. Spectrogram of quadruple flute, Zacuala Palace, Teotihuacan (MNA, Inv. 10-223540), low blowing pressure: (a) pipe A fingering combinations (left: A1-A3 stopped; centre: A1-A2 stopped; right: A1 stopped); (b) pipe B fingering combinations (from left to right: A1-A3 stopped; A1-A2 stopped; A1 stopped; A1-A3 open), pipe A has not been fully muted, as made visible by the lowest fundamental frequency in the combinations 2-4; (c) pipe C (Sample S9a-c).

Due to the air pressure sensitivity generally inherent in fipple flutes, which is increased by the particular quadruple flute organology, it has been noted that slightly altered blowing pressure levels produce variable fundamental frequencies for each of the fingering combinations tested (cross-fingering positions excluded) (Table 4). In the Zacuala Palace quadruple, the observed deviation is located within the range of a semi-tone, rendering it impossible to establish exact pitches for the instrument. However, the steps per each fingerhole combination, from the lowest frequency (all fingerholes stopped) to the highest (all fingerholes open), could be established, although still with uncertainty due to the irregular size of the fingerholes in the current instrument. They roughly correspond to intervals of four semi-tones, two semi-tones and unknown for pipe A and four semi-tones, three semi-tones and two semi-tones for pipe B. It also has been detected that the pitch ranges obtained on pipes A and B are virtually identical, although the pipes can scarcely be sounded in perfect unison due to the morphological differences inherent in their construction. Finally, the instrument can be overblown with slightly enforced blowing pressure and, with increasing blowing pressure, at least four regimes of oscillation are achieved. In comparison to the fundamental frequencies generated with lower blowing pressure, the frequencies obtained by overblowing are located in a greater band per regime (Table 4, especially in pipe A), rendering it difficult to control overblowing techniques.

When the three playable pipes of the Zacuala Palace quadruple are sounded simultaneously, the interaction of three fundamental frequencies with comparable intensity and clusters of stronger and less strong harmonics are to be observed (Figure 22, Table 4 and Sample S10). During excitation using low blowing pressure, the clusters show the highest density in the range of the first harmonics between 0.75 and $1.25 \mathrm{kHz}$. Furthermore, beats with a varying number of interruptions per second are generated. The only difference between the present sonic artefact in which pipe $\mathrm{D}$ is mute and a fully functional flute is that the fundamental frequency and related harmonics of the muted pipe are absent and that the original cluster of tones was even more colorful, especially since pipe D created lower frequencies than any other pipe due to its extended length. 


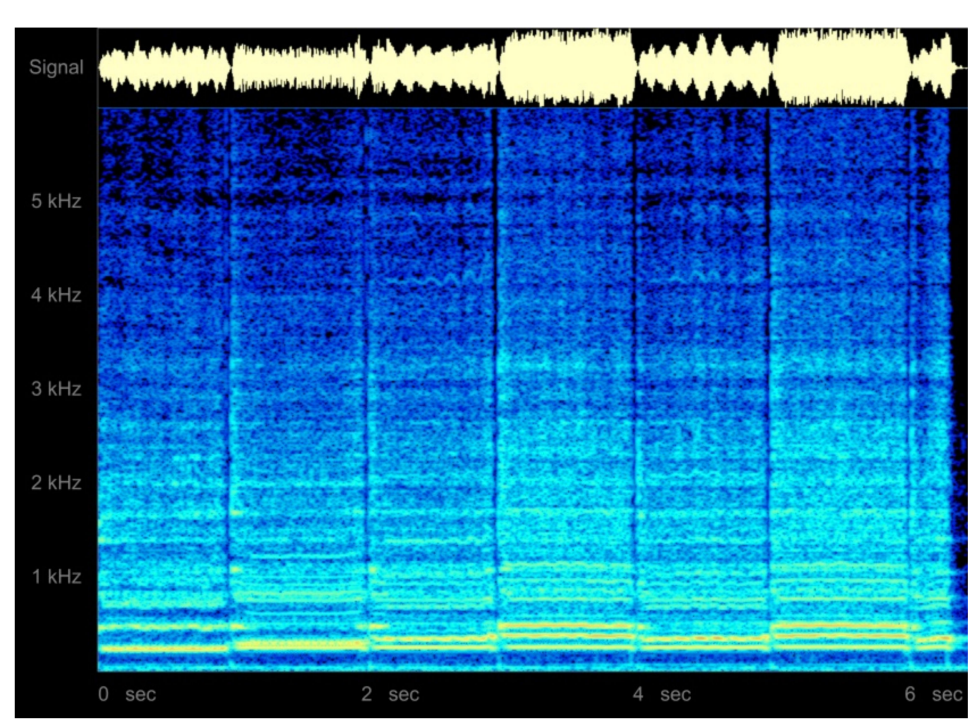

(a)

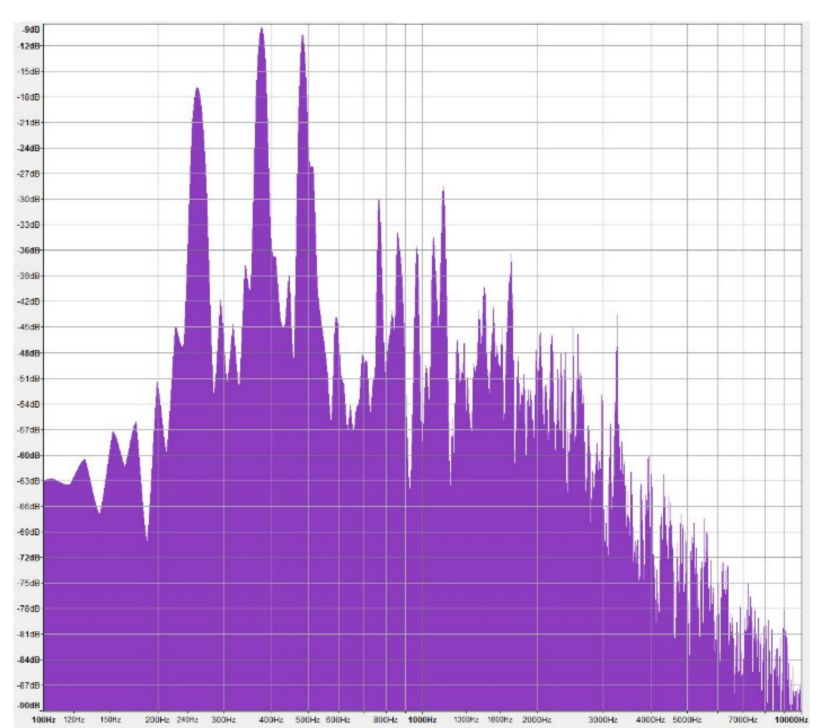

(b)

Figure 22. Spectral components of quadruple flute at the Zacuala Palace, Teotihuacan (MNA, Inv. 10-223540), low blowing pressure: (a) spectrogram, succession of different finger combinations on pipes A-B-C; (b) spectrum, excerpt of position 4 of the larger sample (Sample S10).

In the Anahuacalli 1 quadruple, only pipes $B$ and $C$ are playable. However, as both pipes are fractured at the upper part close to the window, only frequencies much higher than in the original intact flute may be produced and, therefore, the obtained values are not significant. The fragmented Anahuacalli 2 quadruple provides a slightly better idea of the original sound produced by a smaller Teotihuacan quadruple version as all four pipes of the instrument may be activated. However, as the lower part of this instrument is broken, the frequency values obtained are likewise irrelevant and the timbre is sharper and clearer than expected, especially as the pipes were originally half-stopped. It has been noted, however, that the pipes may be overblown easily.

As the original finds are not well reconstructed and partially damaged, a series of experimental models was produced, taking into account a revised reconstruction of the instruments in terms of the measurements, in particular the lengths of the individual pipes, the diameter of the fingerholes and tone holes and their respective placement [1]. The two instruments selected for acoustic testing (Figure 23) measure $66.0 \mathrm{~cm}$ in terms of length for the larger version ("Zacuala Palace experimental") and $46.0 \mathrm{~cm}$ in length for the smaller one ("Anahuacalli 1 experimental"). In sounding these instruments, effects comparable with the sonic artefacts may be observed. In addition, a more comprehensive picture of the original acoustics of the instruments can be obtained and, for the tonal ranges, the difference between a larger and a smaller model of the Teotihuacan quadruple flute family could be narrowed down. When applying lower blowing pressure, the larger model yields fundamental frequencies between $215-264 \mathrm{~Hz}$ (corresponding to $\mathrm{A}_{3}{ }^{-40}$ to $\mathrm{C}_{4}{ }^{+16}$ ) and the smaller model between $311-376 \mathrm{~Hz}$ (corresponding to $\mathrm{D \#}_{4}{ }^{-1}$ to $\mathrm{F}_{4}{ }^{+28}$ ).

In sounding all pipes of the experimental models simultaneously and according to the fingering positions applied, the tone clusters present four individual fundamental frequencies of which two or three are frequently superimposed or so close to one another that beats with a varying number of interruptions per second are produced (Figures 24-27, Samples S11 and S12). Furthermore, strong harmonics over a span of three regimes of oscillation are present. With slightly altered playing positions and blowing pressure levels, different amounts of air are inject into the airducts, thus activating the individual pipes in different manners. This has an impact on the range and the intensity of the fundamental frequencies and, thus, also the nature of the beats. In general, due to the wind noise 
(observed between 0.5 and $0.5 \mathrm{kHz}$ or higher) and the low frequency range of the pipes comparable to the timbre of a large ocarina, the beats are perceived as pleasant effects.

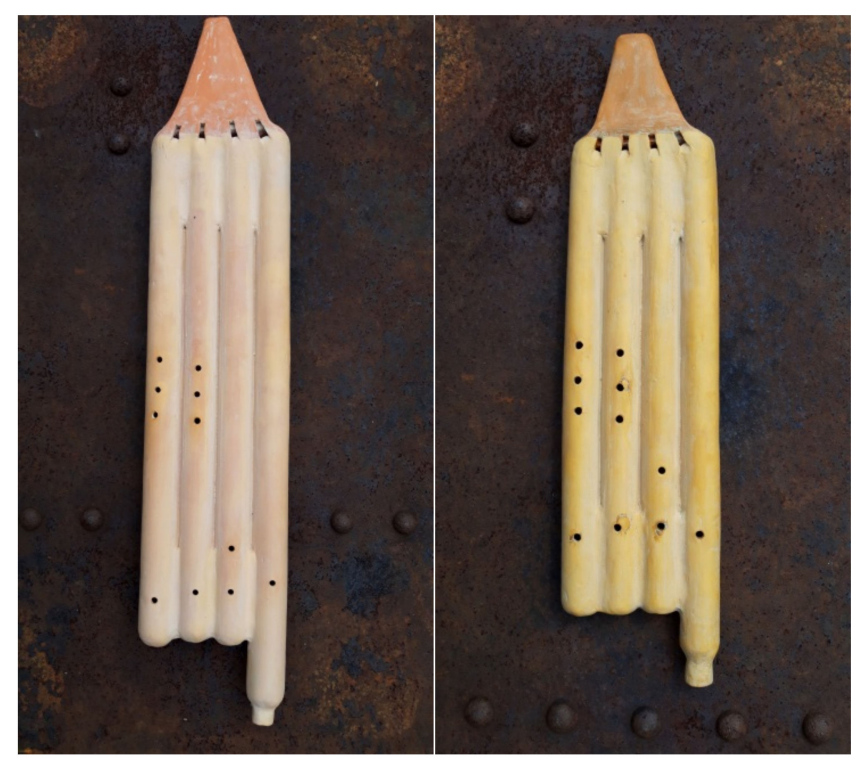

(a)

(b)

Figure 23. Experimental quadruple flute models made by Osvaldo Padrón (2020): (a) "Zacuala Palace", length: $66.0 \mathrm{~cm}$; (b) "Anahuacalli 1", length: $46.0 \mathrm{~cm}$.

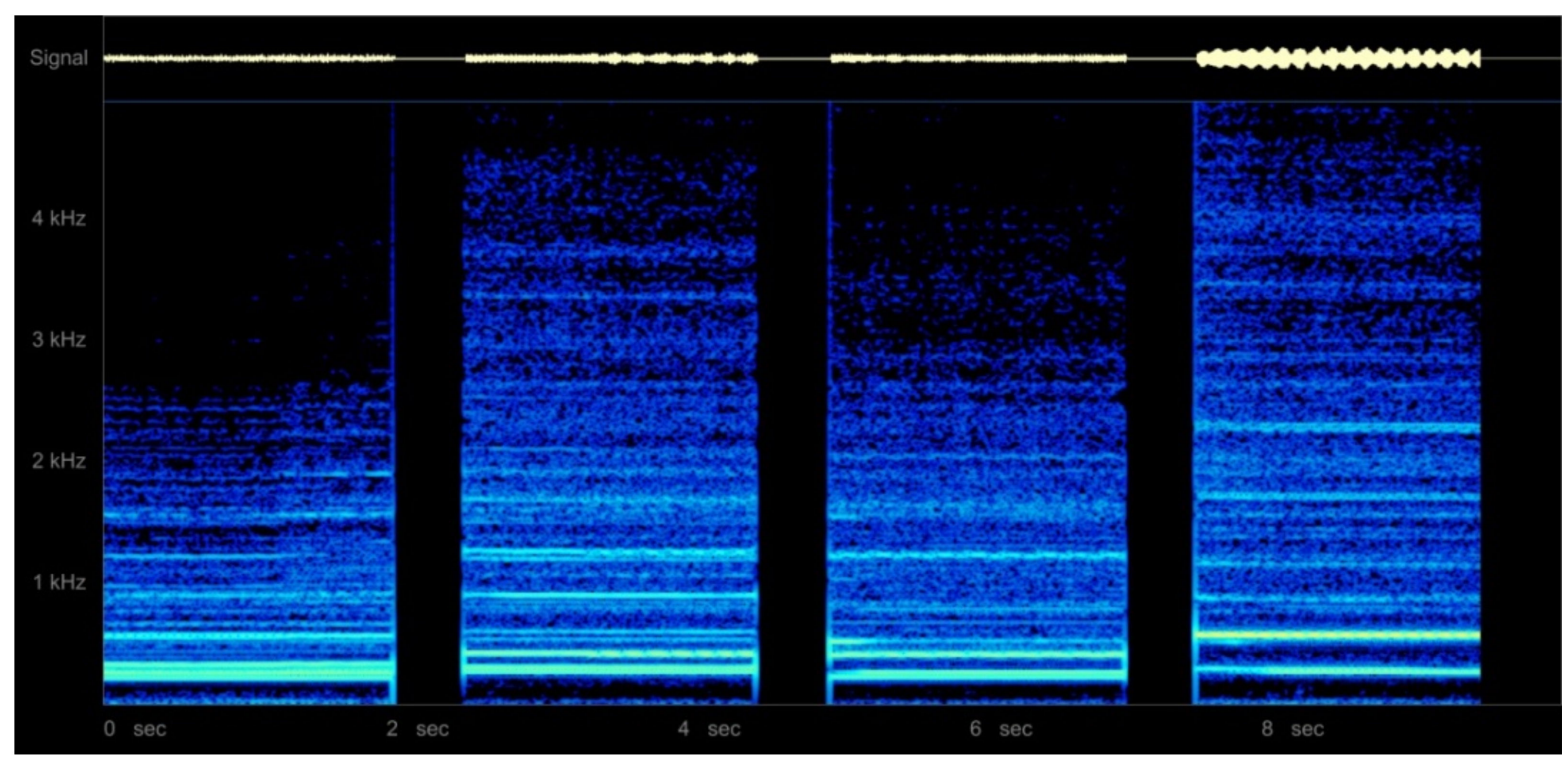

Figure 24. Spectrogram of quadruple flute experimental model from the "Zacuala Palace", low blowing pressure and fingering positions from left to right: all fingerholes stopped; all fingerholes open; fingerholes of pipes A-B open, pipes C-D stopped; fingerholes of pipes A-B stopped, pipes C-D open (Sample S11).

The experimental reconstruction process also offered the opportunity to investigate a range of different playing possibilities. This resulted in the discovery of particular acoustic effects, which would have been impossible to observe and document using the original restored and reconstructed sonic artefacts. It was discovered that the airduct configuration of the mouthpiece enables the player to sound the pipes with at least five different methods: (1) the four pipes of the flute simultaneously, (2) only the two rightmost pipes, if the left blow hole is stopped with the tip of the tongue, or (3) only the two leftmost pipes, if the right blow holes are stopped with the tip of the tongue. In these three combinations, the 
fullest and clearest tones of equal energy per pipe are generated when the instrument is held and played in a straight position. Further possibilities are, without stopping any of the blow holes, (4) holding and playing the instrument in a diagonal position to the right, resulting in reduced airstreams and less blowing pressure for the left blow hole (directed to pipes $C$ and $D$ ), and (5) holding and playing the instrument in a diagonal position to the left, resulting in reduced airstreams and less blowing pressure for the right blow hole (directed to pipes A and B). In applying the latter playing postures, according to the level of inclination and slightly altered blowing pressures, particular sound effects may be generated that differ from the above described quadruple flute acoustics (Figures 28 and 29, Samples S13 and S14). The reduced air streams and air pressure related to the two leftmost or rightmost pipes create a greater volume of wind noise in the range between 0.25 and $4 \mathrm{kHz}$ or higher and when overblowing a hiss results. The corresponding fundamental frequencies show less energy, can become weak or the pipes may not even be activated. Some of the effects are apparent with lower or even aspirated operation of the instrument while others appear to be stronger when overblowing. According to the applied playing position, the flutes can thus be sounded with greater variability than if they were held in a straight position.

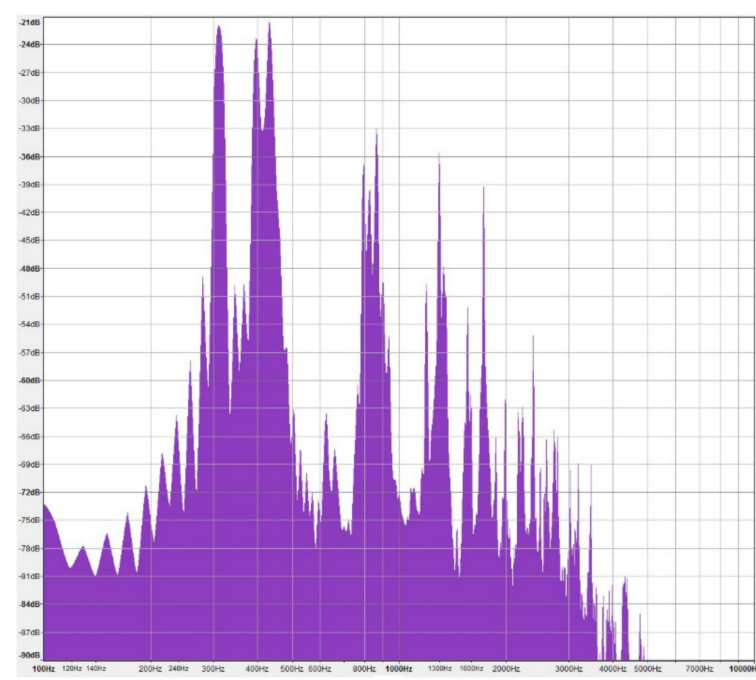

(a)

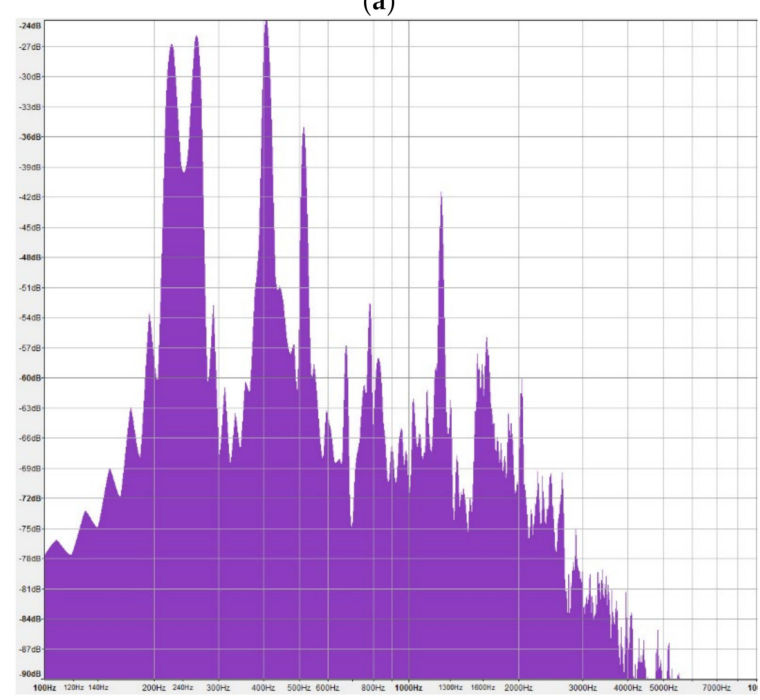

(c)

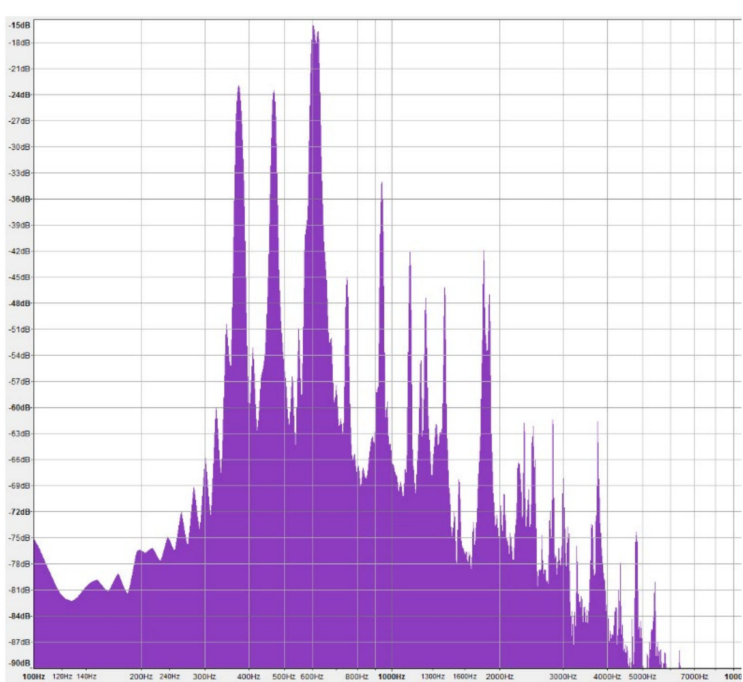

(b)

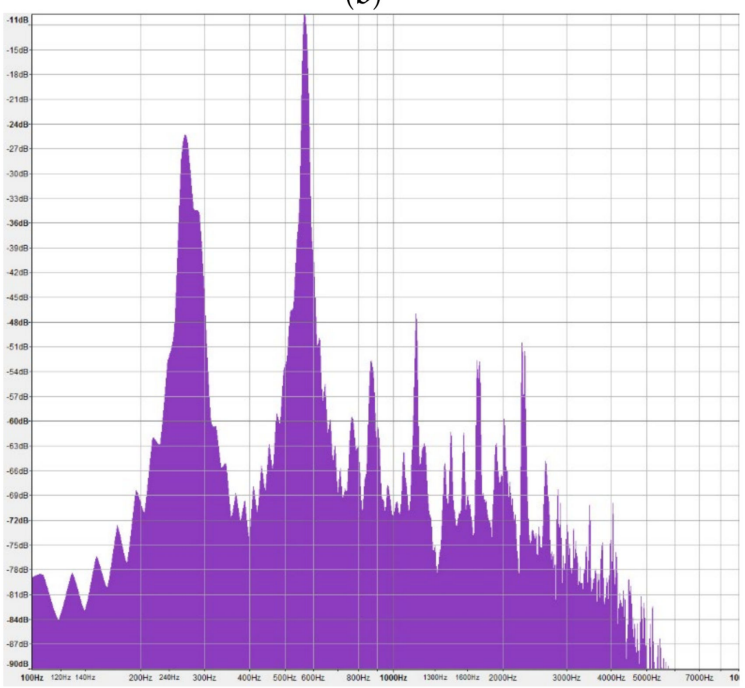

(d)

Figure 25. Spectra of quadruple flute experimental model from the "Zacuala Palace", low blowing pressure: (a) all fingerholes stopped; (b) all fingerholes open; (c) fingerholes of pipes A-B open, pipes C-D stopped; (d) fingerholes of pipes A-B stopped, pipes C-D open (Sample S11). 


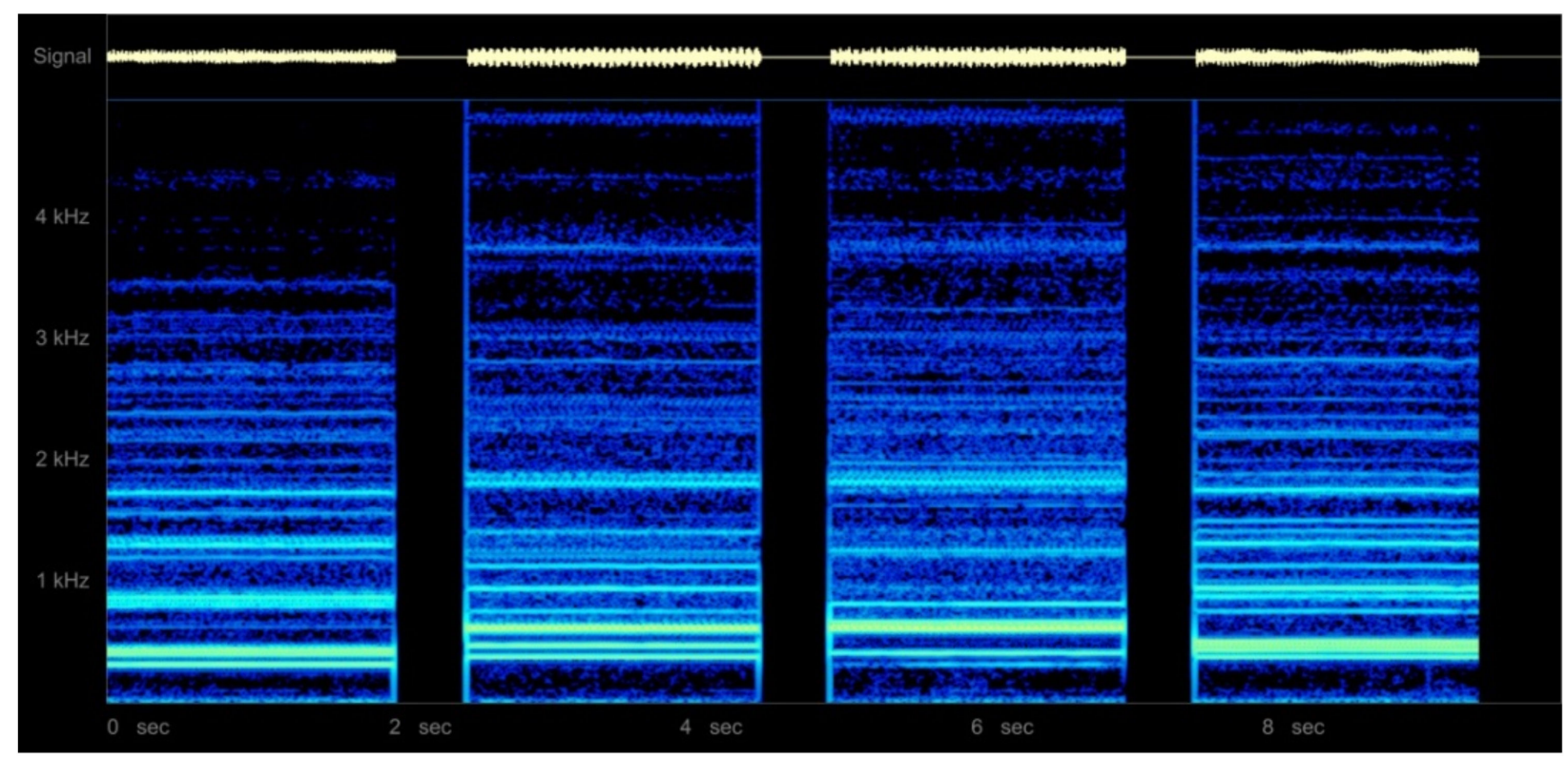

Figure 26. Spectrogram of quadruple flute experimental model "Anahuacalli 1", low blowing pressure, fingering positions from left to right: all fingerholes stopped; all fingerholes open; holes of pipes A-B open, pipes C-D stopped; holes of pipes A-B stopped, pipes C-D open (Sample S12).

While it is uncertain if the technique of stopping the left or the right blow hole with the tip of the tongue was employed, the two basic playing postures (straight and diagonal position of the instrument) are at least indicated by ceramic figurines and whistles showing quadruple flute players ([5], p. 88, Figure 12) ([38], pp. 106, Figure 83G) ([40] Figure 132). These finds also suggest that the instruments were played in a seated position. In this context, it is less likely that the technique of strongly overblowing the instruments for a longer duration of time was employed and that the first and second regimes were favored. In taking into account the archaeological context, it can be assumed that the instruments were performed in a ceremonial setting among smaller communities of people. According to the sound pressure level obtained on the experimental models, which are 69.8-78.0 dBA at $1 \mathrm{~m}$ for the larger and 69.1-77.6 dBA at $1 \mathrm{~m}$ for the smaller specimen (low blowing pressure applied, see Table 5), the instruments were likely to be sounded within the rooms of apartment compounds or temple structures and eventually also in selected open spaces, such as smaller patios and temple yards. In the outside environment, the quadruple flutes could not be heard over any significant distance, especially not if playing techniques with lower blowing pressures were applied and larger groups of people were present.

\section{Piston Whistles}

The Teotihuacan piston whistles (also called piston flutes) are composed of a mouthpiece in the form of a beak with a small airduct, a rectangular window and a half-stopped pipe equipped with a piston in form of a small cylinder that glides up and down (towards the window when the instrument is played in the upwards movement and towards the distal end of the pipe when it is played in the downwards movement). It is still uncertain if the instruments are derived from the single and double piston whistles employed in the Gulf Coast area or vice versa. Some of the Gulf Coast instruments, which frequently show elaborate figurative and symbolic attachments, are dated around 500 CE ([31], pp. 94-97, Figures 79-81) ([39], p. 155) ([28], p 81, Figures 1.3-117, 1.3-118), while others appear to be dated later than Teotihuacan in a period between 650 and 1300 CE ([28], pp. 81-83, Figures 1.3-115, 1.3-119, 1.3.220). 


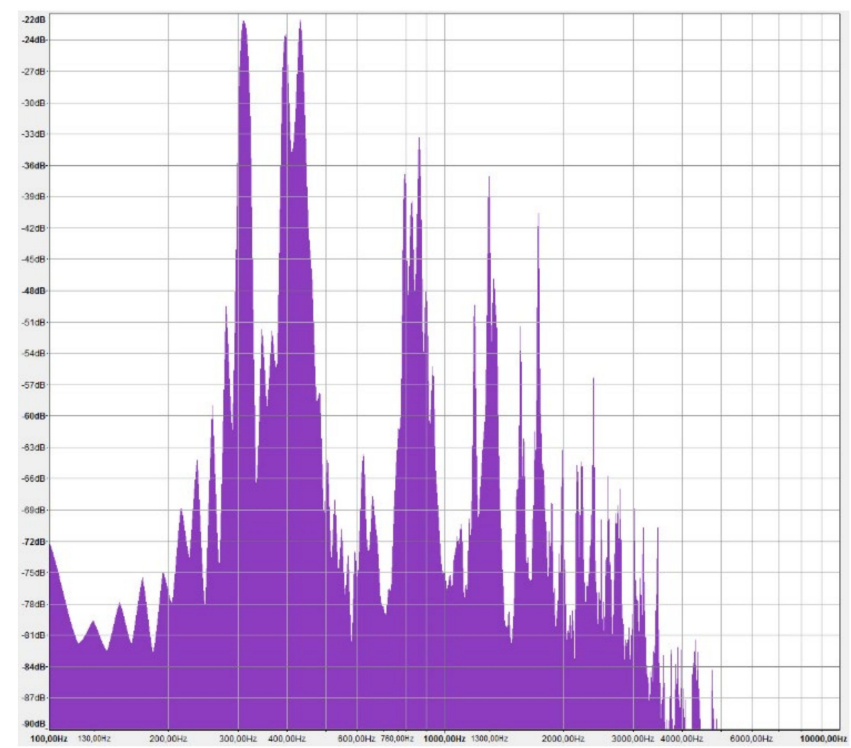

(a)

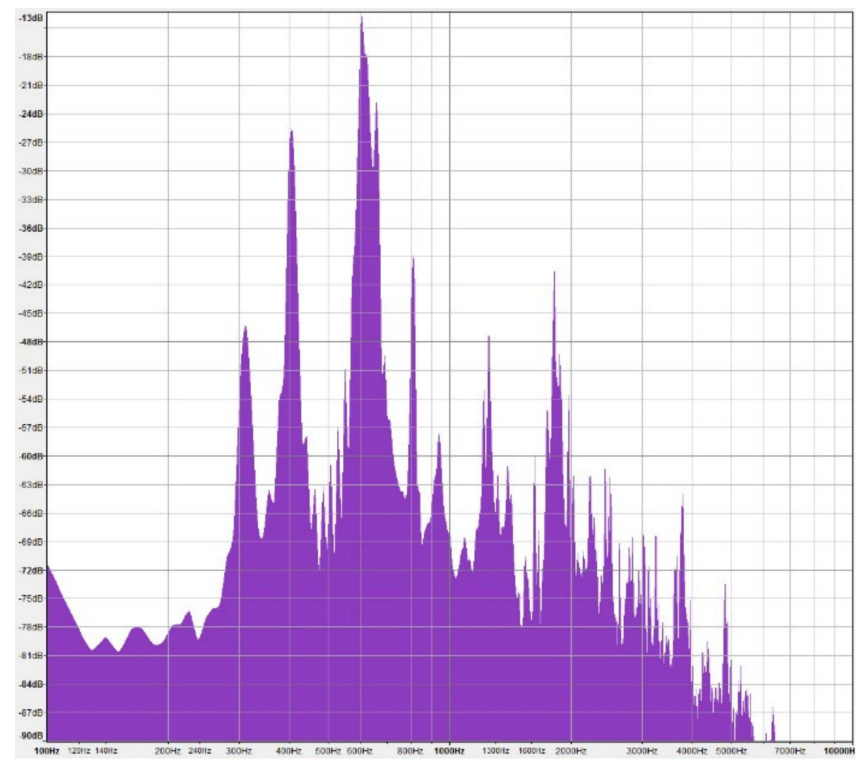

(c)

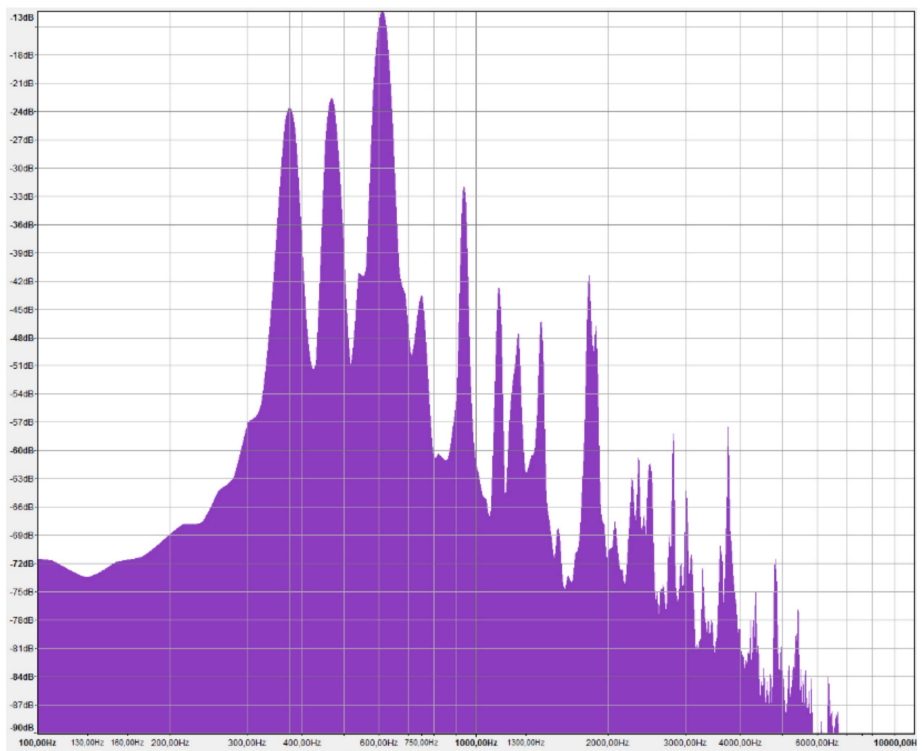

(b)

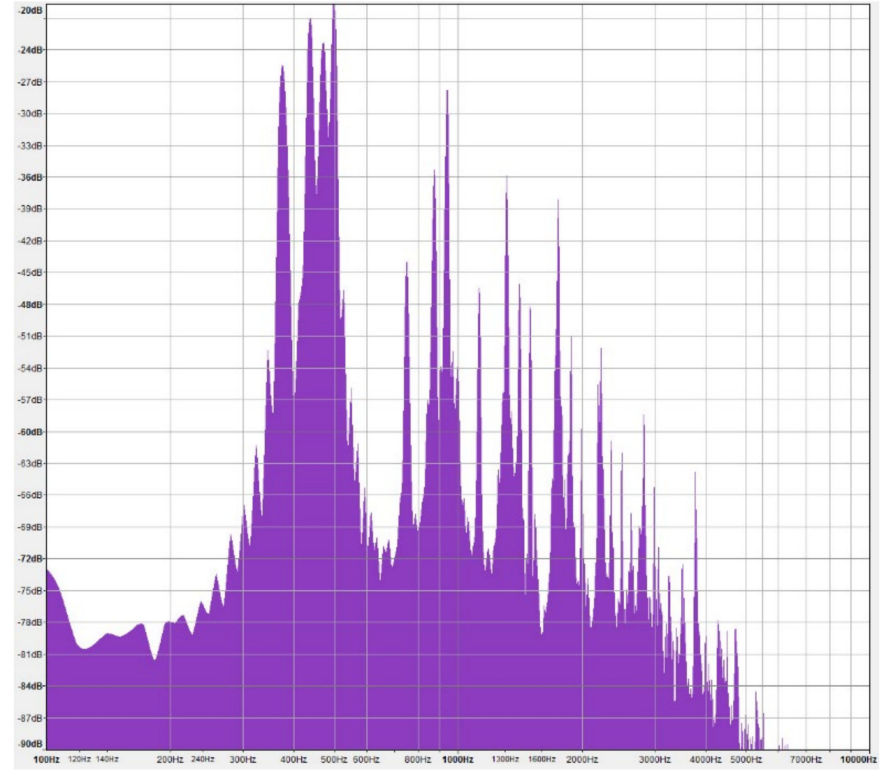

(d)

Figure 27. Spectra of quadruple flute experimental model "Anahuacalli 1", low blowing pressure: (a) all fingerholes stopped; (b) all fingerholes open; (c) fingerholes of pipes A-B open, pipes C-D stopped; (d) fingerholes of pipes A-B stopped, pipes C-D open (Sample S12).

For Teotihuacan, only two piston whistles have been documented, consisting of a single pipe without any decoration. One specimen preserved in the MNA is intact (Figure 30) (also see [27], p. 347, Cat. 166). The sound artefact measures $19.6 \mathrm{~cm}$ in length, $2.0 \mathrm{~cm}$ in width and $1.8 \mathrm{~cm}$ in height (the height corresponding to the outer diameter of the pipe). Its airduct (of $2.5 \mathrm{~cm}$ in length) is characterized by a circular blow hole (ranging from $0.5-0.6 \mathrm{~cm}$ in diameter) and a slit-shaped exit $(0.95 \mathrm{~cm}$ by $0.15 \mathrm{~cm})$. The rectangular window is very wide and short $(1.1 \mathrm{~cm}$ by $0.2 \mathrm{~cm})$, which is a configuration also observed in Teotihuacan vessel flutes types [14]. The pipe has a length of $17.1 \mathrm{~cm}$ with a bore of approximately $1.2 \mathrm{~cm}$ in diameter and a sound hole at the half-stopped distal end of 0.6 by $0.3 \mathrm{~cm}$. Due to the lack of radiographic or computed tomographies, the length of the cylindrical piston is unknown. Only its diameter could be measured $(0.7 \mathrm{~cm}$, in the position when the piston is moved close to the aperture). By means of the experimental models, it could be verified that the length of the piston must at least be $1.0-1.5 \mathrm{~cm}$, otherwise 
it would be too light for properly moving up and down inside the pipe. However, the piston could also be considerably larger (around 3.5-4.0 cm), such as in the piston whistles documented for the Gulf Coast [28] (p. 270, Figure 95). A fragment identified as part of a piston whistle has been excavated by Linné in Las Palmas, Teotihuacan (Figure 31). The preserved organological parts present slightly reduced dimensions (width $1.85 \mathrm{~cm}$ instead of $2.0 \mathrm{~cm}$; height $1.5 \mathrm{~cm}$ instead of $1.8 \mathrm{~cm}$; and the window's edge $0.75 \mathrm{~cm}$ instead of $1.1 \mathrm{~cm}$ ), suggesting a somewhat smaller instrument.

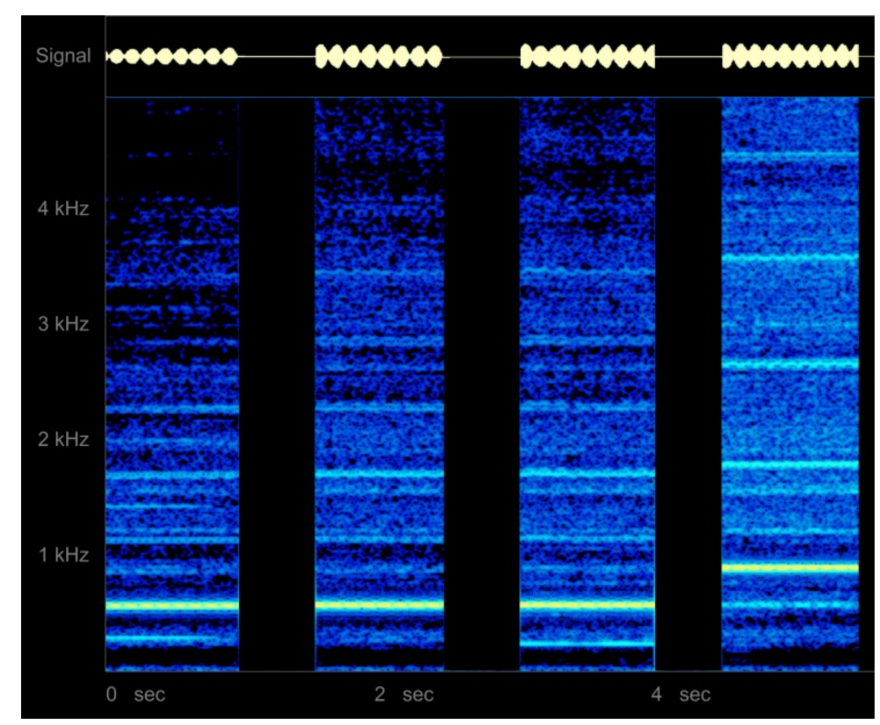

(a)

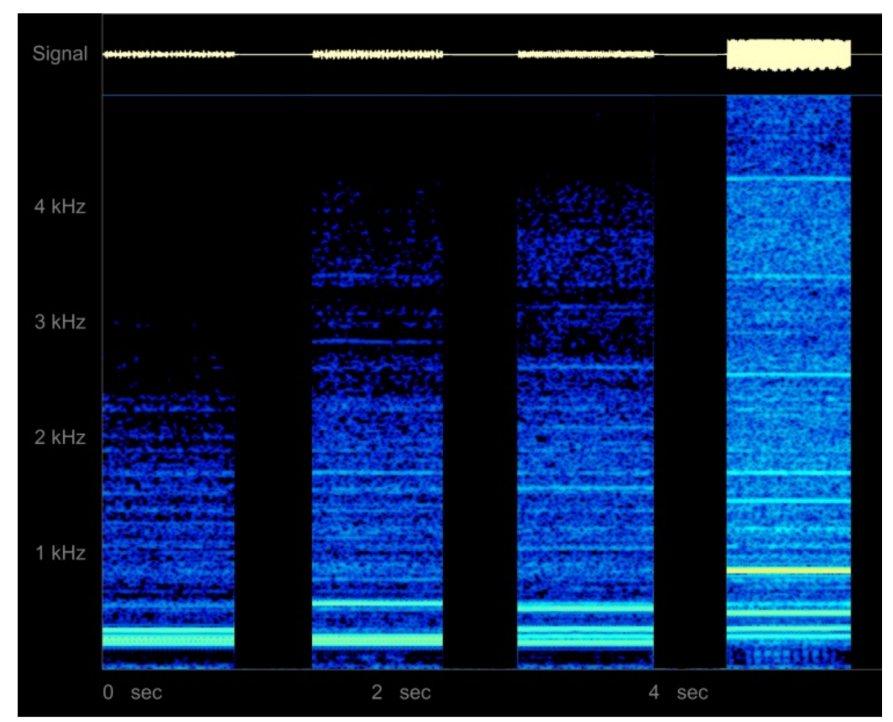

(b)

Figure 28. Spectrograms of quadruple flute experimental model "Zacuala Palace", all fingerholes stopped: (a) diagonal playing position to the right, different blowing pressures (1-3 gradually increasing, 4 overblown); (b) diagonal playing position to the left, different blowing pressures (1-3 gradually increasing, 4 overblown) (Sample S13).

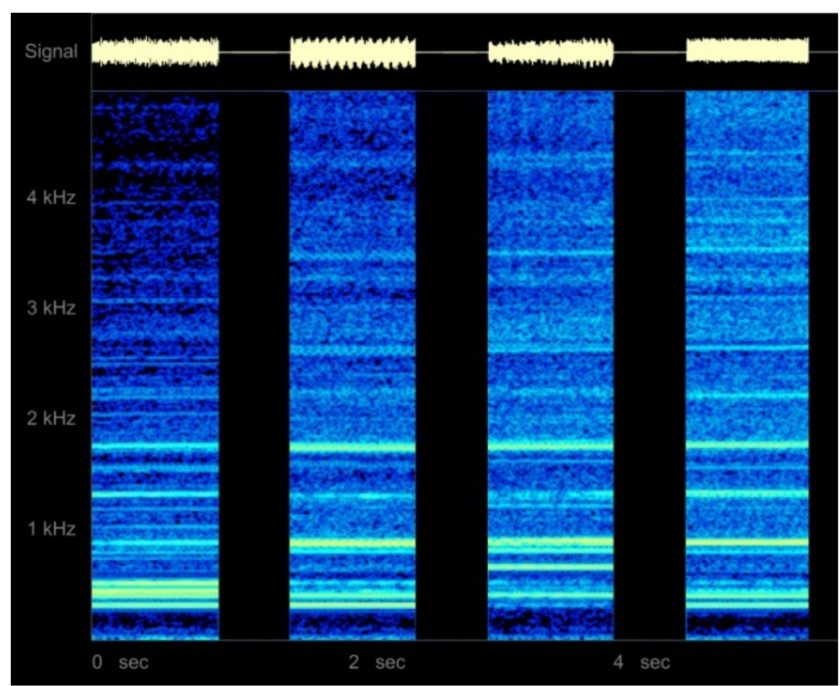

(a)

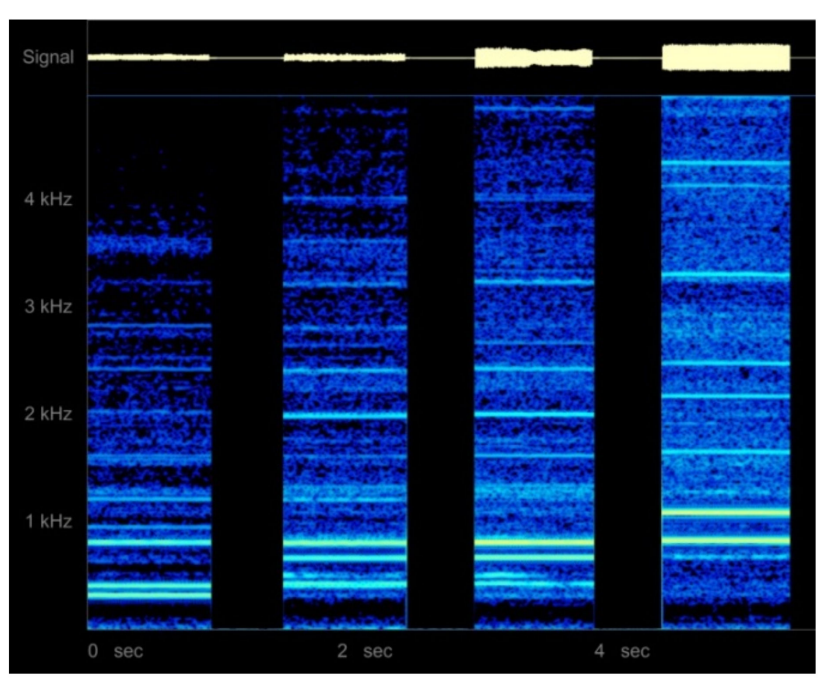

(b)

Figure 29. Spectrograms of quadruple flute experimental model "Anahuacalli 1", all fingerholes stopped: (a) diagonal playing position to the right, different blowing pressures (1-3 gradually increasing, 4 overblown); (b) diagonal playing position to the left, different blowing pressures (1-3 gradually increasing, 4 overblown) (Sample S14). 
Table 5. Acoustic data sheet of the quadruple flute experimental models.

\begin{tabular}{|c|c|c|c|c|}
\hline $\begin{array}{l}\text { Teotihuacan Sound } \\
\text { Producing Instrument }\end{array}$ & Playing Technique & $\begin{array}{c}\text { Frequency Rates } \\
\text { (Fundamental Tones) }\end{array}$ & Tonal Deviation & $\begin{array}{c}\text { Sound Pressure } \\
\text { Level at } 1 \mathrm{~m} \\
\text { (max. Values) }\end{array}$ \\
\hline \multirow{4}{*}{$\begin{array}{c}\text { Quadruple flute, large } \\
\text { "Zacuala Palace” } \\
\text { (experimental model, } 66.0 \mathrm{~cm} \text { ) }\end{array}$} & $\begin{array}{l}\text { Straight, all holes stopped } \\
\text { (except tone holes in pipes } \\
\text { A-B), lower blowing pressure }\end{array}$ & $215 / 255 / 329 \mathrm{~Hz}$ & $\mathrm{~A}_{3}-40 / \mathrm{C}_{4}-44 / \mathrm{E}_{4}-3$ & 69.8-74.1 dBA \\
\hline & $\begin{array}{l}\text { Straight, all holes stopped, } \\
\text { overblown (4 regimes) }\end{array}$ & $\begin{array}{c}220 / 264 / 555 \mathrm{~Hz} \\
474 / 569 \mathrm{~Hz} \\
474 / 535 / 880 \mathrm{~Hz} \\
474 / 535 / 880 / 1208 \mathrm{~Hz}\end{array}$ & $\begin{array}{c}\mathrm{A}_{3} / \mathrm{C}_{4}+16 / \mathrm{C}_{5}{ }^{+2} \text { (lowest); } \\
\mathrm{A}_{4}{ }^{+29} / \mathrm{C}_{5}{ }^{+38} / \mathrm{A}_{5} / \mathrm{D}_{6}{ }^{+48} \text { (highest) }\end{array}$ & 89.6-90.7 dBA \\
\hline & $\begin{array}{l}\text { Straight, all holes open, lower } \\
\text { blowing pressure }\end{array}$ & $264 / 303 / 407 \mathrm{~Hz}$ & $\mathrm{C}_{4}+16 / \mathrm{D} \#_{4}-46 / \mathrm{G}_{4}-35$ & $75.7-78.0 \mathrm{dBA}$ \\
\hline & $\begin{array}{l}\text { Straight, all holes open, } \\
\text { overblown ( } 4 \text { regimes) }\end{array}$ & $\begin{array}{l}\text { 424/516/593 Hz; } \\
\text { 522/605/955 Hz; } \\
\text { 614/757/974 Hz; } \\
772 / 908 / 958 \mathrm{~Hz}\end{array}$ & $\begin{array}{c}\mathrm{G}_{4}+36 / \mathrm{C}_{5}-24 / \mathrm{D}_{5}+17 \text { (lowest); } \\
\mathrm{G}_{5}-27 / \mathrm{A \#}_{5}-46 / \mathrm{A \#}_{5}+47 \text { (highest) }\end{array}$ & 92.9-97.0 dBA \\
\hline \multirow{4}{*}{$\begin{array}{c}\text { Quadruple flute, small } \\
\text { "Anahuacalli 1" } \\
\text { (experimental model, } 46.0 \mathrm{~cm} \text { ) }\end{array}$} & $\begin{array}{l}\text { Straight, all holes stopped, } \\
\text { lower blowing pressure }\end{array}$ & $311 / 393 / 436 \mathrm{~Hz}$ & $\mathrm{D \#}_{4}-1 / \mathrm{G}_{4}{ }^{+4} / \mathrm{A}_{4}{ }^{-16}$ & $69.1-71.8 \mathrm{dBA}$ \\
\hline & $\begin{array}{l}\text { Straight, all holes stopped, } \\
\text { overblown ( } 3 \text { regimes) }\end{array}$ & $\begin{array}{c}400 / 441 / 653 / 836 \mathrm{~Hz} \\
\text { 665/800/857 Hz; } \\
\text { 820/873/1081/1309 Hz }\end{array}$ & $\begin{array}{l}\mathrm{G}_{4}+35 / \mathrm{A}_{4}+4 / \mathrm{E}_{5}-17 / \mathrm{G}_{5}{ }^{+11} \text { (lowest); } \\
\mathrm{G}_{5}-22 / \mathrm{A}_{5}-14 / \mathrm{CH}_{6}-44 / \mathrm{E}_{6}{ }^{-13} \text { (highest) }\end{array}$ & 92.7-95.6 dBA \\
\hline & $\begin{array}{l}\text { Straight, all holes open, lower } \\
\text { blowing pressure }\end{array}$ & $376 / 470 / 617 \mathrm{~Hz}$ & $\mathrm{~F}_{4}+28 / \mathrm{A \#}_{4}+14 / \mathrm{D \#}_{5}-15$ & $71.2-77.6 \mathrm{dBA}$ \\
\hline & $\begin{array}{l}\text { Straight, all holes open, } \\
\text { overblown ( } 3 \text { regimes) }\end{array}$ & $\begin{array}{c}\text { 488/620/738 Hz; } \\
\text { 632/747/931 Hz; } \\
946 / 1099 / 1410 \mathrm{~Hz}\end{array}$ & $\begin{array}{l}\mathrm{B}_{4}{ }^{-21} / \mathrm{DH}_{5}-6 / \mathrm{F}_{5}-5 \\
\mathrm{~A}_{5}{ }^{+25} / \mathrm{CH}_{6}-15 / \mathrm{F}_{6}{ }^{+16} \text { (lowest); }\end{array}$ & 93.1-98.6 dBA \\
\hline
\end{tabular}

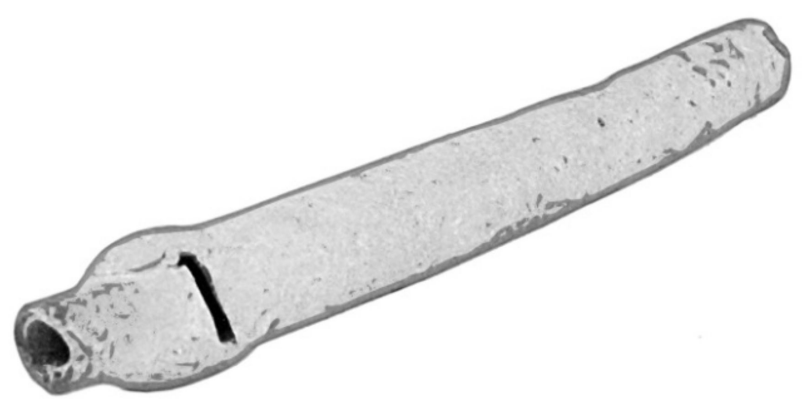

Figure 30. Piston whistle, Teotihuacan (MNA, Inv. 10-223558), length: $19.6 \mathrm{~cm}$.

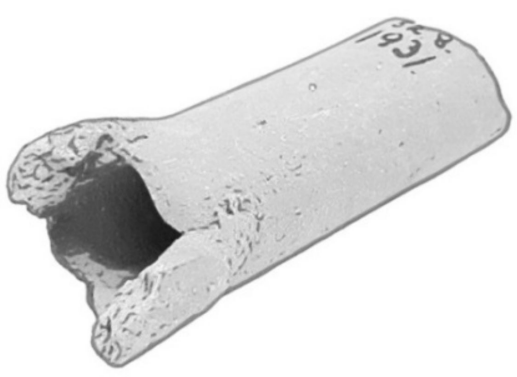

Figure 31. Piston whistle fragment, Las Palmas, Teotihuacan (EmS, Inv. 32.08.1931), length: $4.6 \mathrm{~cm}$.

The intact sonic artefact could be played and tested. It was observed that the instrument overblows easily and, in this condition, creates strong sound effects. The playing technique of overblowing is suggested by the observation that the pipe is fully muted if sounded softly and held upwards, which is when the piston is located right under the edge of the window, but that it sounds in this position when the instrument is overblown. The acoustic values generated when overblowing range between $3394 \mathrm{~Hz}\left(\mathrm{G}_{7}{ }^{+37}\right)$ for the lowest obtained frequency and $4441 \mathrm{~Hz}\left(\mathrm{C \#}_{8}{ }^{+2}\right)$ for the highest (Table 6). 
Table 6. Acoustic data sheet of the documented piston whistles.

\begin{tabular}{|c|c|c|c|c|}
\hline $\begin{array}{l}\text { Teotihuacan Sound } \\
\text { Producing Instrument }\end{array}$ & Playing Technique & $\begin{array}{c}\text { Frequency Rates } \\
\text { (Fundamental Tones) }\end{array}$ & Tonal Deviation & $\begin{array}{l}\text { Sound Pressure } \\
\text { Level at } 1 \mathrm{~m} \\
\text { (Max. Values) }\end{array}$ \\
\hline \multirow{4}{*}{$\begin{array}{l}\text { Piston whistle (MNA, } \\
\text { Inv. 10-223558, } 19.6 \mathrm{~cm} \text { ) }\end{array}$} & Low blowing pressure & Not measured & & \multirow{4}{*}{ Not measured } \\
\hline & Overblowing (8 steps) & $\begin{array}{c}3394 \mathrm{~Hz} ; 3403 \mathrm{~Hz} ; 3533 \mathrm{~Hz} ; \\
3567 \mathrm{~Hz} ; 3607 \mathrm{~Hz} ; 3637 \mathrm{~Hz} ; \\
3681 \mathrm{~Hz} ; 4441 \mathrm{~Hz}\end{array}$ & $\begin{array}{l}\mathrm{G \#}_{7}^{+37} \text { (lowest); } \\
\mathrm{C \#}{ }^{+2} \text { (highest) }\end{array}$ & \\
\hline & $\begin{array}{l}\text { Overblowing, descending } \\
\text { glissando movement } \\
\text { (3 alternating steps) }\end{array}$ & $\begin{array}{c}3753>3294 \mathrm{~Hz}<>2763>2245 \mathrm{~Hz} \\
<>1774>1575 \mathrm{~Hz}\end{array}$ & $\begin{array}{c}\mathrm{AH}_{7}+11>\mathrm{GH}_{7}-15<>\mathrm{F}_{7}-19 \\
\mathrm{CH}_{7}+21<>\mathrm{A}_{6}+14>\mathrm{G}_{6}{ }^{+8}\end{array}$ & \\
\hline & $\begin{array}{l}\text { Overblowing, ascending glissando } \\
\text { movement ( } 2 \text { alternating steps) }\end{array}$ & $\begin{array}{l}1611<1804 \mathrm{~Hz}<>2347<2589 \mathrm{~Hz} ; \\
2468<2776 \mathrm{~Hz}<>3415<3644 \mathrm{~Hz}\end{array}$ & $\begin{array}{c}\mathrm{G}_{6}{ }^{+47}<\mathrm{A}_{6}{ }^{+43}<>\mathrm{D}_{7}^{-2}<\mathrm{E}_{7}-32 \\
<>\mathrm{DH}_{7}^{-15}<\mathrm{F}_{7}^{-11}<>\mathrm{GH}_{7}+48 \\
<\mathrm{AH}_{7}-40\end{array}$ & \\
\hline \multirow{4}{*}{$\begin{array}{c}\text { Piston whistle, small } \\
\text { (experimental model, } 17.0 \mathrm{~cm} \text { ) }\end{array}$} & Low blowing pressure (key note) & $742-754 \mathrm{~Hz}$ & $\mathrm{FH}_{5}+5 /+32$ & $54.3-74.9 \mathrm{dBA}$ \\
\hline & Overblowing (6 steps) & $\begin{array}{l}1620 \mathrm{~Hz} ; 2378 \mathrm{~Hz} ; 2671 \mathrm{~Hz} ; \\
2795 \mathrm{~Hz} ; 4947 \mathrm{~Hz} ; 5961 \mathrm{~Hz}\end{array}$ & $\begin{array}{l}\mathrm{G}_{6}{ }^{-43} \text { (lowest); } \\
\mathrm{F}_{8}^{+12} \text { (highest) }\end{array}$ & \multirow{3}{*}{ 93.4-105.7 dBA } \\
\hline & $\begin{array}{l}\text { Overblowing, descending } \\
\text { glissando movement } \\
\text { (4 alternating steps) }\end{array}$ & $\begin{array}{c}5961>5268<>4848>4192<> \\
3586>3228<>2758>2325\end{array}$ & $\begin{array}{c}\mathrm{F \#}_{8}+12>\mathrm{E}_{8}^{-2}<>\mathrm{DH}_{8}-46>\mathrm{C}_{8}+2 \\
<\mathrm{A}_{7}^{+32}>\mathrm{G}_{7}^{+50}< \\
>\mathrm{F}_{7}-22>\mathrm{D}_{7}^{-18}\end{array}$ & \\
\hline & $\begin{array}{l}\text { Overblowing, ascending glissando } \\
\text { movement ( } 2 \text { alternating steps) }\end{array}$ & $2362<2754 \mathrm{~Hz}<>3433<3812 \mathrm{~Hz}$ & $\mathrm{D}_{7}^{+9}<\mathrm{F}_{7}^{-25}<>\mathrm{A}_{7}-43<\mathrm{A \#}_{7}+38$ & \\
\hline
\end{tabular}

When blowing and moving the pipe up and down, ascending and descending glissando effects are observed (Figure 32, Table 6 and Sample S15). The effects are caused by the movement of the piston within the pipe and are unusual in the way as overblowing is interrupted and the glissandos take three to eight alternating jumps within the scope of milliseconds. This particular condition produces the impression of a strong flutter effect within the glissandi and is probably due to the fact that the piston is not fully stopping the pipe. This creates a complex interaction of airflows and pressure levels within the resonator (if the piston would be fully stopping the pipe, the glissandi would be expected to show a more regular ascending or descending movement). The frequency ranges of the glissandi are characterized by alternating jumps in the range of the two lower regimes of oscillation between $1611<1804 \mathrm{~Hz}\left(\mathrm{G}_{6}{ }^{+47}<\mathrm{A}_{6}{ }^{+43}\right)$ and $2347<2589 \mathrm{~Hz}\left(\mathrm{D}_{7}{ }^{-2}<\mathrm{E}_{7}{ }^{-32}\right)$ for the ascending movement (Figure 32, Sample S15 and Position 1). With a slightly increased blowing pressure, a slightly higher regime of the overblowing frequency and alternating jumps in the lower regimes between $2468<2776 \mathrm{~Hz}\left(\mathrm{DH}_{7}{ }^{-15}<\mathrm{F}_{7}{ }^{-11}\right)$ and $3415<3644 \mathrm{~Hz}$ $\left(\mathrm{GH}_{7}+48<\mathrm{AH}_{7}{ }^{-40}\right)$ are observed. For the descending movement, two or even three alternating jumps in the range of $3753>3294 \mathrm{~Hz}\left(\mathrm{AH}_{7}{ }^{+11}>\mathrm{GH}_{7}{ }^{-15}\right), 2763>2245 \mathrm{~Hz}\left(\mathrm{~F}_{7}{ }^{-19}>\mathrm{CH}_{7}{ }^{+21}\right)$ and $1774>1575 \mathrm{~Hz}\left(\mathrm{~A}_{6}{ }^{+14}>\mathrm{G}_{6}{ }^{+8}\right)$ are generated (Figure 32, Sample S15 and Position 2). The glissandi are usually located in the range of the two or three regimes inferior to the frequency obtained by overblowing but, depending on blowing pressure variations, can also occasionally jump to higher regimes (as observed when blowing the experimental models).

For the physical effort of overblowing the whistle in the upward position, experimental playing suggests blowing of not more than one to two seconds until the downwards movement is initiated. The alternating glissando jumps are to be observed in less than half a second. If this is repeated in the upwards movement, a playing cycle with the duration of four to six seconds is likely to have been employed (breathing in, holding the pipe downwards, overblowing, upwards movement and ascending glissando jumps; breathing in, holding the pipe upwards, overblowing, downwards movement and descending glissando jumps). 


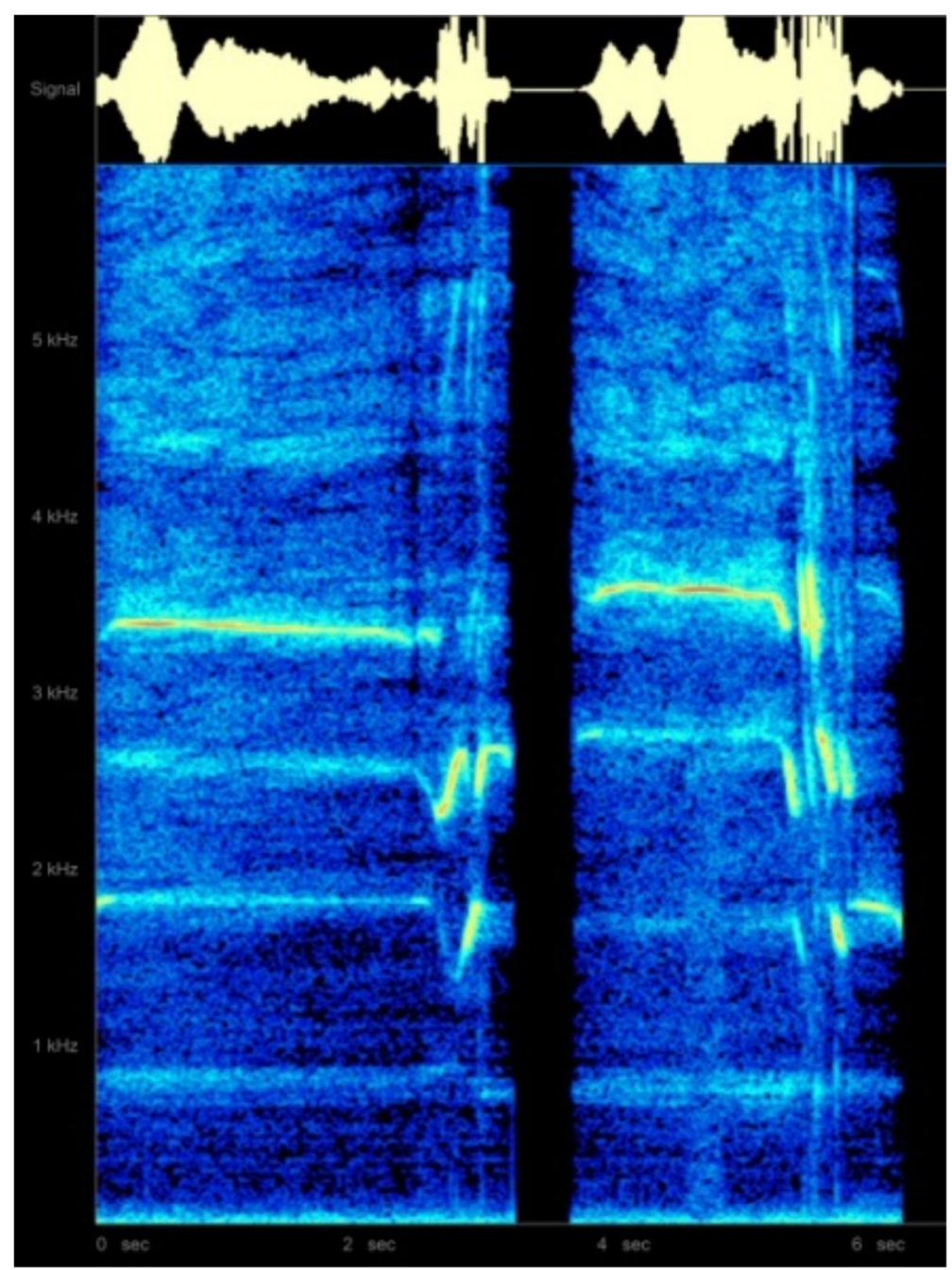

Figure 32. Spectrogram of piston whistle, Teotihuacan (MNA, Inv. 10-223558), overblown, two movements; left (Position 1): upwards, ascending alternating glissando effect; right (Position 2): downwards, descending glissando effect (Sample S15).

In the production of the experimental models (Figure 33), the documented size range of the sonic artefacts has been adopted. The models measure $17.0-19.0 \mathrm{~cm}$ in length, $2.0-2.4 \mathrm{~cm}$ in width and $1.8-1.9 \mathrm{~cm}$ in height. The smallest instrument of the sample has been selected for acoustic tests as it possibly corresponds to the size of the fragmented sonic artefact from Las Palmas, Teotihuacan. The frequencies generated by overblowing range between $1620 \mathrm{~Hz}\left(\mathrm{G \#}_{6}{ }^{-43}\right)$ for the lowest frequency and $5961 \mathrm{~Hz}$ $\left(\mathrm{F}_{8}{ }^{+12}\right)$ for the highest (Table 6). The frequency ranges of the glissandi are two alternating jumps of $2362<2754 \mathrm{~Hz}\left(\mathrm{D}_{7}^{+9}<\mathrm{F}_{7-25}\right)$ and $3433<3812 \mathrm{~Hz}\left(\mathrm{~A}_{7}{ }^{-43}<\mathrm{A \#}_{7}{ }^{+38}\right)$ for the ascending movement (Figure 34, position 1, Table 6 and Sample S16); and four alternating jumps of $5961>5268 \mathrm{~Hz}\left(\mathrm{F \#}_{8}{ }^{+12}>\mathrm{E}_{8}{ }^{-2}\right), 4848>4192 \mathrm{~Hz}\left(\mathrm{D \#}_{8}{ }^{-46}>\mathrm{C}_{8}{ }^{+2}\right)$, $3586>3228 \mathrm{~Hz}\left(\mathrm{~A}_{7}{ }^{+32}>\mathrm{G}_{7}{ }^{+50}\right)$ and $2758>2325 \mathrm{~Hz}\left(\mathrm{~F}_{7}{ }^{-22}>\mathrm{D}_{7}{ }^{-18}\right)$ for the descending movement (Figure 34, position 2, Table 6 and Sample S16). The maximum sound pressure level obtained by overblowing is quite high (105.7 dBA at $1 \mathrm{~m})$. 


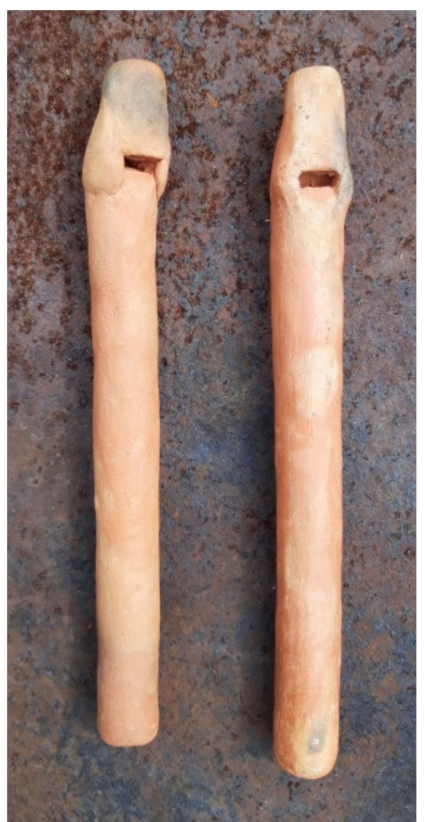

(a)

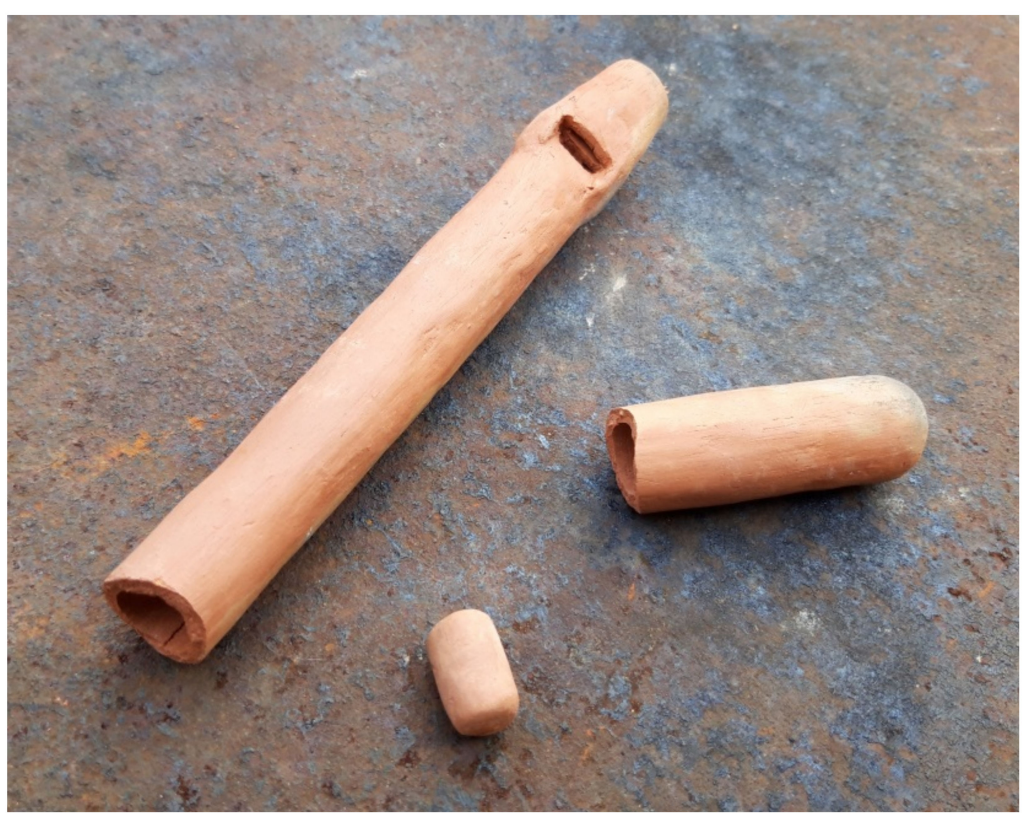

(b)

Figure 33. Piston whistles. Experimental models by Osvaldo Padrón (2020): (a) versions of slightly different dimensions, (b) broken model showing the piston.

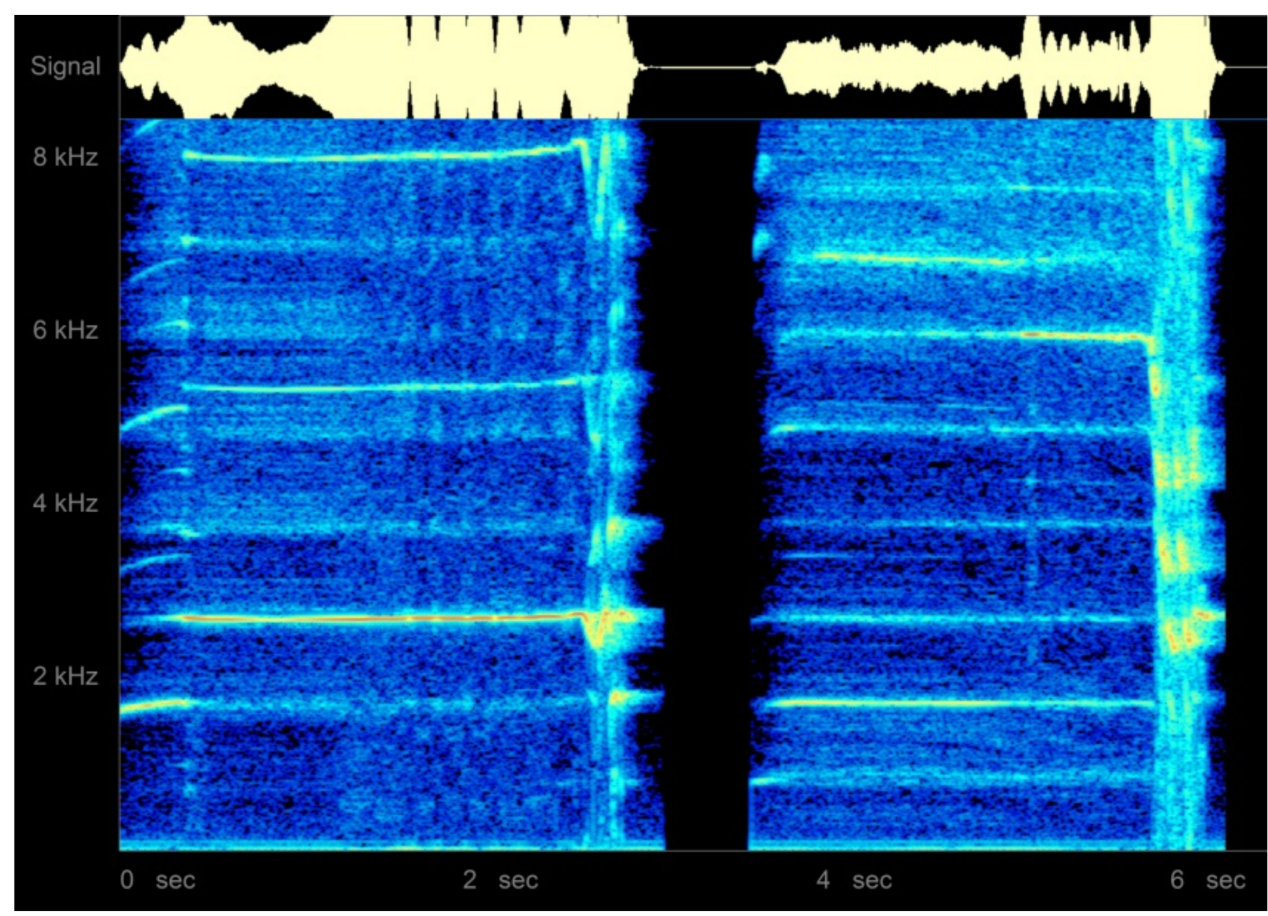

Figure 34. Spectrogram of piston whistle, experimental model, overblown, two movements, left (position 1): upwards, ascending alternating glissando effect; right (position 2): downwards, descending glissando effect (Sample S16).

Further tests were carried out with two pipes sounded at the same time, which is a technique possibly employed in Teotihuacan if the double piston whistles from the Gulf Coast are to be taken into account. With two pipes sounded simultaneously, not only is a shrill timbre produced when overblowing but also a range of additional strong frequencies close to the fundamental frequencies, located in the range between 2.25 and 
$3.0 \mathrm{kHz}$ (Figure 35, Sample S17). These frequencies are both higher and lower than the fundamental notes and known as collateral frequencies [46] (p. 121) (not related to the harmonics of the overtone or the undertone series). As the high frequencies are very strong in terms of the sound pressure levels and located in the most sensitive human hearing range, two or more pipes would obviously create strong combination tones. The acoustic and psychoacoustic effects, including the effects on the human brain and circulatory system in the upwards and downwards movement while overblowing, and the cyclic nature of the physical and acoustic movements, suggest the employment of the piston whistles in ritual or ceremonial activities.

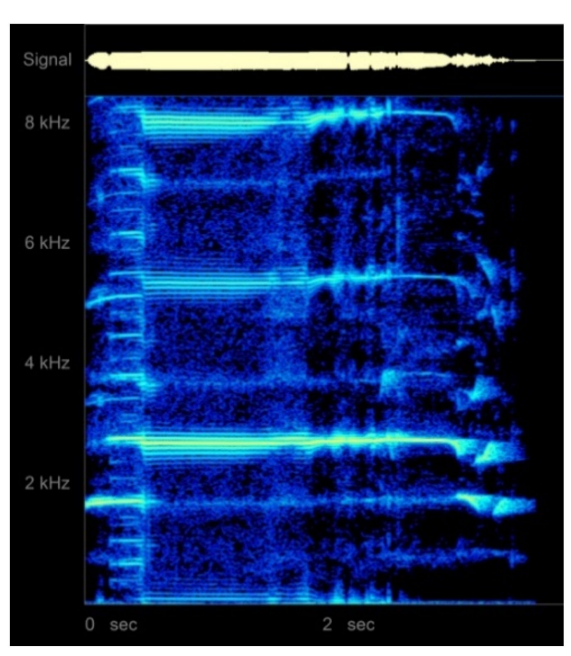

(a)

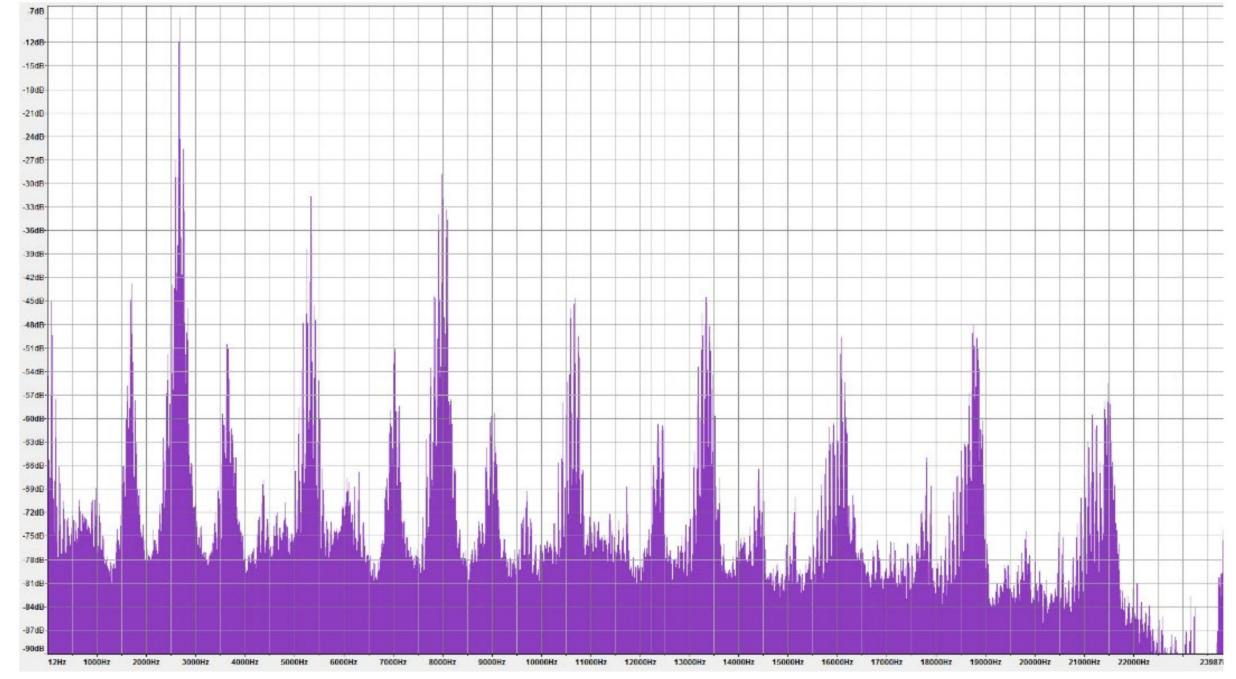

(b)

Figure 35. Spectral content of two piston whistles played simultaneously. Experimental models, overblown: (a) spectrogram; (b) spectrum taken from middle part of the sample, 250 milliseconds (Sample S17).

\section{Results}

While the exploration of the acoustics of an ancient culture is a difficult task, as a range of different parameters is to be taken into account, it is by no means impossible. For Teotihuacan, the fragmented condition of most of the sonic artefacts often require manufacturing accurate reconstructions in order to obtain a clear picture of the original acoustic effects that once formed part of the musical and non-musical soundscape of the site. This process of reconstruction enabled us to investigate the ancient instrument manufacturing technologies along with the corresponding acoustic designs developed in Teotihuacan, thus considerably enhancing the knowledge of pre-Columbian organology and acoustics. When subsequently sounding the sonic artefacts and the experimental models, anthropological factors are involved as most of the instruments discussed can be sounded with multiple methods (described by Jean-François Brohée as the "gestural interface" [47]) and the applied playing techniques require particular knowledge and musical practice. In this paper, it has been demonstrated that the possibilities inherent in the experimental playing of ancient sound-producing instruments can be narrowed down to a certain extent when all available information is to be taken into account (for Teotihuacan, including archaeological contextual information and iconographic data). In this manner, the basic acoustic parameters of the instruments investigated could be obtained in terms of the tonal ranges, sound pressure levels and sound spectra. It can be assumed that the described parameters once formed part of the acoustic ecology characteristic of Teotihuacan.

For the Teotihuacan horns and trumpets, different types and variants have been described in terms of their individual organology and acoustics. In supposing that the instrument design reflected certain societal roles and related acoustic requirements, but 
also taking into account the available context-related information, it is likely that the Teotihuacan shell horns were exclusively sounded by members of an elite, possibly a group of high-ranking officials and priests taking part in ceremonial gatherings and events related to the principal pyramids and temples of the site. The horns were also by far the loudest sound-producing devices employed in Teotihuacan. These instruments were probably heard all over the site when sounded in processions and especially from the top of the pyramids. In turn, according to the archaeological record, the ceramic trumpets were used all over the city, commonly in the realm of apartment compounds. Most possibly, these instruments were available to a larger group of people than the shell horns. Possessing inferior sound pressure levels than the latter instruments, it is likely that the trumpets could not be perceived over a greater distance than the adjacent compounds. It can be assumed that these instruments were employed for a variety of purposes in intra-urban communication.

As for the pipes, the experimentation yielded further insights into sound output and performance characteristics. Experimental playing of the quadruple flutes revealed different playing possibilities, producing in musical terms an infinite range of triads and tetrads with beats and accompanying wind noise perceived to be pleasant. As the sound pressure levels of these instruments are not very high, it is likely that they were sounded exclusively among smaller groups of people in interior environments or smaller patios and courtyards. According to the iconographic information, the instruments were sounded in a seated position and might have been employed in some form of chamber music, among other possible uses. As one of the finds was made in a temple, the instruments could also have been played by priests or temple musicians. The sound pressure levels of the piston whistles, in turn, are comparable to the ceramic trumpets and the instruments could thus have been employed in ceremonial gatherings in which larger groups of people were present. The shrill timbre, beats and combination tones produced when more than one pipe are played together, in addition to the observed cyclic physical and acoustic movements, suggest a specific ritual context in which these instruments were sounded. Acoustical testing carried out with the experimental models within the architectural setting of Teotihuacan will help verify the functional hypotheses developed through the application of musical acoustics research.

Supplementary Materials: The corresponding sound files are available online at https:/ /www.md pi.com/article/10.3390/acoustics3030034/s1, Sample S1: Shell horn orig MNA, Sample S2: Shell horn exp Pleuroploca large, Sample S3: Shell horn exp mouthpiece, Sample S4: Shell horn exp mouthpiece overblown, Sample S5: Shell horn exp Strombus small, Sample S6: Ceramic horn orig MNA, Sample S7: Ceramic trumpet exp, Sample S8: Ceramic trumpet exp stopped, Sample S9a: Zacuala orig MNA, pipe A 1-3, 1-2, 1, Sample S9b: Zacuala orig MNA, pipe B 1-3, 1-2, 1, 0, Sample S9c: Zacuala orig MNA, pipe C, Sample S10: Zacuala orig MNA, A-B-C, Sample S11: Zacuala exp AB CD stop, op, AB op CD stop, AB stop CD op, Sample S12: Anahuacalli exp AB CD stop, op, AB op CD stop, $A B$ stop CD op, Sample S13a: Zacuala exp right ABCD stopped, Sample S13b: Zacuala exp left ABCD stopped, Sample S14a: Anahuacalli exp right ABCD stopped, Sample S14b: Anahuacalli exp left ABCD stopped, Sample S15: piston whistle orig MNA, Sample S16: piston whistle exp, Sample S17: two piston whistles exp.

Funding: This research was funded by the European Commission, H2020-MSCA Individual Fellowship, Grant agreeement ID: 846012. For more information, please consult https:/ / cordis.europa.eu/p roject/id/846012 (accessed on 21 March 2021).

Acknowledgments: Rubén Cabrera, George Cowgillt, Edgar Rosales, Martin Schultz, Felipe Solíst and Karla Torres for their valuable support in museographical research. Doro Arndt, Francisco García, Sergio Ortiz and Jean-Loup Ringot for their assistance in museographical research. Osvaldo Padrón for the production of the experimental models and related research. Hendrik Mokry for recording the experimental models. Rupert Till and Markus Ziegler for providing recording equipment and support in the analysis of the acoustic data. Jean-François Brohée, Peter Holmes and Olga Sutkowska for providing support in the analysis of the organological and acoustic data. Rupert Till and Peter Holmes for the English corrections. Mia Broné, Miriam Kolar, Gonzalo Sánchez, Matthias Stöckli 
and Adrián Velázquez for providing context-related information. Miriam Kolar, Susan Rawcliffe and Rupert Till for the reviews.

Conflicts of Interest: The author declares no conflict of interest.

\section{Appendix A. List of the Institutions in Which the Discussed Sonic Artefacts Are Preserved}

C-ZMAT (Ceramoteca of the Zona de Monumentos Arqueológicos de Teotihuacán, San Martín Teotihuacán; finds from various excavations, among others by Rubén Cabrera in La Ventilla)

EmG (Etnografiska museet, Göteborg; find from a private collection)

EmS (Etnografiska museet, Stockholm; finds made by Sigvald Linné from various excavations)

IIA-UNAM (Instituto de Investigaciones Antropológicas, Universidad Autónoma de México, Mexico City; finds by Linda Manzanilla from various excavations, among others from Teopancazco, Tunels CP and CV and Xalla)

ITESM (Instituto Tecnológico y de Estudios Superiores de Monterrey; Monterrey, two finds from the Joseph Hellmer collection)

MA (Museo Anahuacalli, Mexico City; finds from the Diego Rivera collection)

MCT (Museo de la Cultura Teotihuacana, San Juan Teotihuacán; finds from various excavations)

Met (Metropolitan Museum of Art, New York, one find from a private collection)

MNA (Museo Nacional de Antropología, Mexico City; finds originating from various collections and various excavations)

MqB (Museé du quai Branly, Paris; one find from the Eugène Boban collection)

RL-ASU (Research Laboratory of the Arizona State University, San Juan Teotihuacán; finds from the TMP and made by Saburo Sugiyama from various excavations, among others from the Moon Pyramid Project)

TMP (Teotihuacan Mapping Project, see RL-ASU)

\section{Notes}

1 Research carried out at the Research Laboratory of the Arizona State University and the Ceramoteca of the Zona de Monumentos Arqueológicos de Teotihuacán (2008); TVSM (Teotihuacan Virtual Sound Map), University of Huddersfield, UK (2019-2022). For more information, see Funding. All institutions mentioned in this paper are identified with acronyms listed in the Appendix A.

3 The musical notes given here are calculated according to the Frequency to Musical Note Converter by Andrew Botros, Acoustics Lab of the School of Physics, University New South Wales, Sydney [8]. In the note name convention used, middle C is C4 and the note below it is B3.

4 The recordings of the sonic artefacts were made with KM184 Neumann microphones on a 4 channel digital recording device ( $1 \mathrm{~m}$ of recording distance in an isolated cabin in museum environment). The recordings of the experimental models were made with DPA MMC4006 microphones on a digital recorder (1m of recording distance in studio environment). Excerpts of $250 \mathrm{~ms}$ taken from the middle part of each take were analyzed with the programs Audacity [9], Praat by Paul Boersma and David Weenink [10], and Spectrogram by Richard Horne [11]. For analysis of the sound pressure levels (1m of recording distance in studio environment), a calibrated measurement system consisting of a miniDSP UMIK-1 microphone and the freeware program Schallpegelmesser Pro by Markus Ziegler was used [12]. The sound propagation levels were estimated with the inverse square law, according to the online calculator by R. Nave [13].

5 The partially fragmented bone trumpet has been excavated in the Teotihuacan-related site of Aljojuca, Puebla (EmS, Inv. 35.100017.A/B), see [16] (p. 33, 35, Figure 27). The identification of the bone as a human femur has been carried out by Mia Broné in 2019. In size and shape, particularly the length, form of the mouthpiece and the bore, the instrument presents a comparable morphology than the ceramic trumpets described below and therefore also comparable acoustic parameters.

6 For the instruments from Burials 3 and 5 of the Moon Pyramid (RL-ASU, Ent. 3 Elem. 508; Ent. 5 Elem. 1130), see [4] (pp. 190-192, Figures 17-23). From the recent finds from the Tlalolcan project so far only an iconographic study of a selection of the horns has been published [17].

7 For the specimen preserved in the MNA, see [4] (pp. 188-189, Figures 11-15); a further specimen said to be from Teotihuacan belongs to the Diego Rivera collection (MA). 
The find is currently exhibited in the MCT and has been briefly mentioned by Velázquez Castro et al. [18] (p. 248), see also [19]. MNA (Inv. 10-0009260), see [20].

10 It cannot be excluded, however, that some Teotihuacan shell horns were adorned with a row of quetzal bird feathers around the lip of the shell [4] (p. 194, Figure 25); [21] (p. 272, Figure 5).

11 Finds from the TMP (RL-ASU); Las Palmas and Xolalpan (EmS, Inv. 32.08.0268; 32.08.1962; 32.08.2363; 32.08.6598, the latter two specimens presenting rests of Maya blue pigmentation and are possibly imported from the Maya area).

The effect is a form of sideband distortion or intermodulation distortion (IMD), which is the result of two interacting signals generated by the shell horn and the mouthpiece, functioning as two separate acoustic entities [25].

The self-sounding condition is repeatedly shown in a series of depictions and possibly reflects the belief in a sort of animisation or deification of the instruments, which is also supported by the employment of tassel headdresses composed of the plumes of the quetzal bird and the occasional depiction of a numinous being emerging out of the bell, possibly representing the Teotihuacan God of Music [4,21].

See [26] (p. 231, Figure 121, Lám. CVII), for a drawing and a photo of the specimen before restoration, [27] (p. 349, Cat. 170).

More than 600 finds of trumpets in fragmented condition are preserved in the following institutions: from the TMP (RL-ASU) and excavations in La Ventilla, among others (C-ZMAT); Xalla and the Tunnels CV and CP (IIA-UNAM); Las Palmas and Xolalpan (EmS). For find distribution maps of the mouthpieces and tube fragments, established on the basis of the data from the RL-ASU and C-ZMAT, see [6] (pp. 132-134, Figures 2.58-2.60).

16 The particular form of cup-shaped bells can be compared to the Greek salpinges, for ancient brass instruments. In acoustic terms, the flared section of the bell assists in giving a range of wave impedances, which are more-closely in line with a natural harmonic series. The cup shape of the bell end, in turn, increases the end impedance discontinuity (giving a greater impedance change than if the flare had continued to the end of the bell yard), which means that more of the standing wave in the tube is reflected. On the other hand, less of the standing wave energy escapes into the environment, making the instrument quieter. The cup-shaped bell also changes the timbre of the instrument, making it less strident [30].

17 The forms possibly refer to comparable instruments made from reed or comparable plant material, which did not survive in the archaeological record.

18 See [26] (p. 230, Figure 120, Lám. CVI), for a drawing of the specimen and a photo of the find in situ, [27] (p. 350, Cat. 171), [30] (pp. 48-49, Figure 27).

Finds from the TMP (RL-ASU), see [6] (pp. 44-46, Figures 2.10-2.12); one fragment preserved in the MNA (Inv. 9-22259). Finds from the TMP (RL-ASU); two finds from Las Palmas and Xolalpan (EmS, Inv. 32.08.6914; 32.08.6911).

21 For the flutes possibly originating from the Gulf Coast, one has been published by Séjourné [26] (p. 235, Figure 125) and one fragment is known from a private collection (EmG, Inv. 2013.04.0338); for unpublished fragments of Aztec flutes: finds from the TMP (RL-ASU), see [6] (pp. 30-31, 40, 49, Abb. 2.6, Table 2.2); from Las Palmas and Tlamimilolpan (EmS, Inv. 32.08.2994; 35.08.0194; 35.08.0595); from the Tunnels CP and CV (IIA-UNAM); and further finds stored in the MNA (Inv. 10-150381; 9-4576). An early publication of these "Aztec flutes" was made by Wilson [33] (pp. 606-607, Figures 252-253). Comparable unpublished finds are stored, for example, in the Met.

23 This particular configuration is unusual if compared to other aperture forms applied in the ceramic fipple flutes from Mesoamerica, conventionally presenting rectangular or quadratic and less frequently oval, circular or semicircular shapes.

The miniatures are produced in the form of small ceramic plaques with a flat inferior side and the superior side simulating the instrument in relief, frequently simulating the fingerholes, apertures, and decoration [5] (pp. 76-81: Figures 6-8), [26] (pp. 237-238, 240, Figures 127-129), [34] (p. 379, Figure 268), [35] (p. 13, Table 4), [36] (p. 46, Photo 129), [36] (p. 3, Photo 130). A series of finds is stored in the RL-ASU and the C-ZMAT; one further find in the MNA (the latter without inventory number).

Documented for the project are 40 fragmented finds from the TMP (RL-ASU), for a selection see [5] (pp. 74-76, Figure 5); finds from Atetelco, La Ventilla and other excavation sites (C-ZMAT; Inv. 10-600289; 10-599898; Elem. 19897; 57888; further finds without inventory no., for a selection see [5] (p. 71, 74-76, Figure 2); one find in the MA (Inv. 45540); finds from Zacuala, Yayahuala and Tetitla, see [26] (p. 236, Figure 126), [38] (p. 106, Figure 83D,E); two finds from Teopancazco [7] (p. 202, 205, Figures 4.47-4.48). A distribution map, based on the finds stored in the RL-ASU and the C-ZMAT, has been compiled by Arndt [5] (p. 83, Figure 9).

26 Several fragmented specimen: one semicomplete instrument (MNA), see [5] (pp. 85-86, Figure 10), [38] (p. 194), and a mouthpiece from the Joseph Hellmer collection, see [5] (p. 86, Figure 11), [31] (p. 48), [39] (p. 191), these finds ascribed to the Gulf Coast, but according to organological and iconographical features certainly originating from Teotihuacan; whistle showing a quadruple flute player of uncertain provenance, possibly from the Gulf Coast, see [5] (p. 88, Figure 12), [40] (Figure 132); fragmented mouthpieces from Monte Albán, Oaxaca, see [5] (pp. 86-90, Figure 11), [41] (pp. 631-632, Figure 3), [42] (p. 170, Figure 5.60); mouthpiece fragment from Río Seco, Escuintla, Guatemala [42] (p. 261, 270, Figure 10).

Finds from the ITESM collection (No. 3648 1/2 and 2/2), see [5] (pp. 93-94, Figure 15). According to Martí [39] (p. 195), the sonic artefacts are from Colima. The West Mexican origin is also supported by organological features, such as the quadratic form of the windows and the attachment of side frames. 
Two finds from Jaina, Campeche; further finds from Baking Pot, Belize [5] (pp. 90-93. Figures 13-14).

29 The Zacuala Palace quadruple has been published in several occasions, see [5] (pp. 70-73, Figure 3), [26] (p. 207, Lám. CVIII), [27] (p. 347, Cat. 165), [31] (pp. 48-49, Figure 28), [44] (p. 131, Figure 10).

30 So far, the Anahuacalli 1 quadruple has been published in only two occasions, see [39] (p. 209), [45] (p. 140).

\section{References}

1. Both, A.A.; Padrón, O. The Quadruple Flutes of Teotihuacan, Mexico. Heritage Special Issue "Sonic Heritage: Sound and Multisensory Interactions in Immersive Virtual Reality and Cultural Heritage". Eva, P., Angela, B., Eds.; in preparation.

2. Both, A.A. Teotihuacan Whistling Vessels. J. Anthropol. Archaeol. Special Issue. Scullin, D., Herrera, A., Eds.; submitted, peer-reviewed.

3. Both, A.A. Los artefactos sonoros de Teotihuacan, México (Percusión). Rev. De Arqueol. Am. 2021, 39, in preparation.

4. Both, A.A. Las trompetas de caracol marino de Teotihuacan. In Ecos Del Pasado: Los Moluscos Arqueológicos de México; Colección Científica, 572; Diez, L.S., Castro, A.V., Eds.; INAH: Mexico City, Mexico, 2010; pp. 183-196.

5. Arndt, D.J. The Quadruple Flutes of Teotihuacan Resurfaced. In Flower World—Music Archaeology of the Americas; Stöckli, M., Howell, M., Eds.; Ekho Verlag: Berlin, Germany, 2014; Volume 3, pp. 67-100.

6. Arndt, D.J. Klangartefakte Im Archäologischen Befund Teotihuacans. Unpublished Master's Thesis, Philosophische Fakultät, Rheinische Friedrich-Wilhelms-Universität Bonn, Bonn, Germany, 2015.

7. Zalaquett, F.; Espino, D.S.; Vázquez, V. Instrumentos sonoros procedentes de las excavaciones de Teopancazco. In Teopancazco Como Centro de Barrio Multiétnico de Teotihuacan: Los Sectores Funcionales Y El Intercambio a Larga Distancia; Linda, R.M., Ed.; UNAM: Mexico City, Mexico, 2018; pp. 181-212.

8. Frequency to Musical Note Converter. Available online: https://newt.phys.unsw.edu.au/music/note/ (accessed on 21 March 2021).

9. Audacity. Available online: http://audacityteam.org/ (accessed on 21 March 2021).

10. Praat. Available online: www.praat.org (accessed on 21 March 2021).

11. Spectrogram. Available online: http://db0fhn.efi.fh-nuernberg.de/ \{\}dg8ygz/voicetools/ (accessed on 21 March 2021).

12. Schallpegelmesser Pro. Available online: https://spaichinger-schallpegelmesser.de/index.html (accessed on 21 March 2021).

13. Estimating Sound Levels with the Inverse Square Law. Available online: http:/ /hyperphysics.phy-astr.gsu.edu/hbase/ Acoustic /isprob2.html (accessed on 21 March 2021).

14. Both, A.A. Sonic Artefacts of Teotihuacan, Mexico (Vessel Flutes). Acoustics Special Issue "Acoustics, Soundscapes and Sounds as Intangible Heritage". Álvarez-Morales, L., Díaz-Andreu, M., Eds.; in preparation.

15. Both, A.A. Music Archaeology: Some Methodological and Theoretical Considerations. Yearb. Tradit. Music 2009, 41, 1-11.

16. Linné, S. Mexican Highland Cultures: Archaeological Researches at Teotihuacan, Culpulalpan and Chalchicomula in 1934/35; New Series, No. 7; Hakan Ohlssons Boktryckeri: Lund, Sweden; The Ethnographical Museum of Sweden (Statens Etnografiska Museum): Stockholm, Sweden, 1942.

17. Grube, N.; Gómez, C.S. Preliminary Iconographic Study of the Shell Trumpets from the Tlalocan Project. In Teotihuacan: City of Water, City of Fire, 248. Exhibition Catalogue; De Young Museum: San Francisco, CA, USA; Los Angeles County Museum of Art: Los Angeles, CA, USA; University of California Press: Berkeley, CA, USA, 2017.

18. Castro, A.V.; Bautista, C.P.; Roldán, G.P. Bearbeitete Muscheln und Knochen in Teotihuacan. In Teotihuacan: Geheimsnisvolle Pyramidenstadt; Exhibition Catalogue, Museé du Quai Branly, Eds.; Somogy Éditions D’art/Museé Du Quai Branly: Paris, France, 2009; pp. 147-151.

19. Caracol. Available online: https://www.mediateca.inah.gob.mx/islandora_74/islandora/object/objetoprehispanico\%3A24277 (accessed on 21 March 2021).

20. Caracol. Available online: https://www.mediateca.inah.gob.mx/islandora_74/islandora/object/objetoprehispanico\%3A18573 (accessed on 21 March 2021).

21. Both, A.A. Shell Trumpets in Mesoamerica: Music-Archaeological Evidence and Living Tradition. In Studien zur Musikarchäologie; Hickmann, E., Eichmann, R., Eds.; VLM: Rahden, Germany, 2004; Volume 4, pp. 261-278.

22. Herrera, A.; Hurtado, E.; Pablo, J.; Moncada, G.; Gregorio, J.; Morris, A. Arqueomusicología de las trompetas de caracol andinas de concha y cerámica. In Flower World—Music Archaeology of the Americas; Stöckli, M., Howell, M., Eds.; Ekho Verlag: Berlin, Germany, 2014; Volume 3, pp. 141-168.

23. Kolar, M.; Rick, J.W.; Cook, P.R.; Abel, J.S. Ancient Putus Contextualized: Integrative Archaeoacoustics at Chavín de Huántar, Peru. In Flower World—Music Archaeology of the Americas; Stöckli, M., Both, A.A., Eds.; Ekho Verlag: Berlin, Germany, 2012; Volume 1, pp. 23-54.

24. Both, A.A. Nuevos datos acerca de los cuernos de caracol de Teotihuacan, México. In Avances Y Perspectivas en la Investigación de Los Materiales Arqueológicos de Concha; Castro, A.V., Ed.; in preparation.

25. Till, R.; Department of Music and Drama, University of Huddersfield, Huddersfield HD1 3DH, UK. Personal communication.

26. Séjourné, L. Arqueología de Teotihuacan: La Cerámica; Fondo de Cutura Económico: Mexico City, Mexico; Buenos Aires, Argentina, 1966.

27. MqB (Museé du quai Branly) (Ed.) Teotihuacan: Geheimsnisvolle Pyramidenstadt; Exhibition Catalogue; Somogy Éditions D’art/Museé du Quai Branly: Paris, France, 2009.

28. Hickmann, E. Klänge Altamerikas: Musikinstrumente in Kunst und Kult; Publikationen der Reiss-Engelhorn-Museen; Wissenschaftliche Buchgesellschaft: Darmstadt, Germany, 2007; Volume 25. 
29. Gudemos, M. Trompetas Andinas Prehispánicas: Tradiciones Constructivas Y Relaciones de Poder. Anales Del Museo de América. 2009, Volume XVII, pp. 184-224. Available online: file:/ / C:/Users/Intel/Downloads/Dialnet-TrompetasAndinasPrehispanicas TradicionesConstructi-3661098.pdf (accessed on 21 March 2021).

30. Holmes, P.; Senior Acoustics and AV Consultant at Inhabit Group Shanghai. Personal communication.

31. Martí, S. Alt-Amerika; Musikgeschichte in Bildern, Musik des Altertums, Lieferung 7; VEB Deutscher Verlag für Musik: Leipzig, Germany, 1970; Volume 2.

32. Pasztory, E. The Murals of Tepantitla, Teotihuacan; Garland: New York, NY, USA, 1976.

33. Wilson, T. Prehistoric Art; or the Origin of Art as Manifested in the Works of Prehistoric Man; Government Printing Office: Washington, DC, USA, 1898.

34. Manzanilla, L. Anatomía De Un Conjunto Residencial Teotihuacano en Oztayahualco, Vol 1: Las Excavaciones; UNAM: Mexico City, Mexico, 1993.

35. Sugiyama, S. Censer Symbolism and the State Polity in Teotihuacán. 2002. Available online: http://www.famsi.org/reports/97 050/97050Sugiyama01Text.pdf (accessed on 21 March 2021).

36. Sugiyama, S. Censer Symbolism and the State Polity in Teotihuacán, III. Anthropomorphic Attributes of Deities and Characters. 2002. Available online: http://www.famsi.org/reports/97050/97050Sugiyama01Images3.pdf (accessed on 21 March 2021).

37. Sugiyama, S. Censer Symbolism and the State Polity in Teotihuacán, IV. Other Motifs: Different Representations and Symbols. 2002. Available online: http://www.famsi.org/reports/97050/97050Sugiyama01Images4.pdf (accessed on 21 March 2021).

38. Séjourné, L. Un Palacio en la Ciudad de los Dioses [Teotihuacán]; INAH: Mexico City, Mexico, 1959.

39. Martí, S. Instrumentos Musicales Precortesianos; INAH: Mexico City, Mexico, 1968.

40. Goldstein, M.M. Ceremonial Sculpture of Ancient Veracruz; Hillwood Art Gallery, Long Island University: New York, NY, USA, 1987.

41. Winter, M.; López, C.M.; Torres, A.H.M. Monte Albán y Teotihuacan: Política e ideología. In Ideología Y Política a Través de Materiales, Imágenes Y Símbolos; Memoria de la Primera Mesa Redonda de Teotihuacan; Ruíz Gallut, M.E., Ed.; UNAM/INAH: Mexico City, Mexico, 2002; pp. 627-644.

42. Santiago, G.S. Las Culturas Musicales del Oaxaca Prehispánico: Una Perspectiva Desde la Etapa de las Aldeas Hasta las CiudadesEstado (1400 c.C.-1521 d.C.). Unpublished Ph.D. Thesis, Facultad de Filosofía y Letras, Instituto de Investigaciones Estéticas, UNAM, Mexico City, Mexico, 2016.

43. De Monterroso, M.I.; Matthias, S. Tierra, viento y fuego: Las figurillas y objetos sonoros de Río Seco (La Gomera, Escuintla). In XXVIII Simposio de Investigaciones Arqueológicas en Guatemala; Arroyo, B., Salinas, L.M., Paiz, L., Eds.; Museo Nacional de Arqueología y Etnología: Guatemala City, Guatemala, 2015; pp. 255-270.

44. Castellanos, P. Horizontes de la Música Precortesiana; Fondo de Cultura Económica: Mexico City, Mexico, 1970.

45. Martí, S. Instrumentos Musicales Precortesianos; INA: Mexico City, Mexico, 1955.

46. Castellengo, M. Écoute Musicale et Acoustique; Avec 420 Sons et Leurs Sonagrammes Décryptés; Eyrolles: Paris, France, 2015.

47. Brohée, J.-F. Pre-Columbian Music(s) of Mesoamerica and Central America: Interdisciplinary Approach through in-Depth Investigation of the Sonorous Artifacts from the MAH and MIM Collections (Brussels). Ph.D. Thesis, Université Libre de Bruxelles, Brussels, Belgium. in preparation. 